\title{
Satellite passive microwave sea-ice concentration data set intercomparison: closed ice and ship-based observations
}

\author{
Stefan Kern ${ }^{1}$, Thomas Lavergne ${ }^{2}$, Dirk Notz ${ }^{3}$, Leif Toudal Pedersen ${ }^{4}$, Rasmus Tage Tonboe ${ }^{5}$, Roberto Saldo ${ }^{4}$, and \\ Atle MacDonald Sørensen ${ }^{2}$ \\ ${ }^{1}$ Integrated Climate Data Center (ICDC), Center for Earth System Research and Sustainability (CEN), \\ University of Hamburg, Hamburg, Germany \\ ${ }^{2}$ Research and Development Department, Norwegian Meteorological Institute, Oslo, Norway \\ ${ }^{3}$ Institute for Marine Research, University of Hamburg and Max Planck Institute for Meteorology, Hamburg, Germany \\ ${ }^{4}$ Danish Technical University, Lyngby, Denmark \\ ${ }^{5}$ Danish Meteorological Institute, Copenhagen, Denmark
}

Correspondence: Stefan Kern (stefan.kern@uni-hamburg.de)

Received: 24 May 2019 - Discussion started: 17 June 2019

Revised: 28 October 2019 - Accepted: 30 October 2019 - Published: 10 December 2019

\begin{abstract}
We report on results of a systematic intercomparison of 10 global sea-ice concentration (SIC) data products at 12.5 to $50.0 \mathrm{~km}$ grid resolution for both the Arctic and the Antarctic. The products are compared with each other with respect to differences in SIC, sea-ice area (SIA), and sea-ice extent (SIE), and they are compared against a global wintertime near- $100 \%$ reference SIC data set for closed pack ice conditions and against global year-round ship-based visual observations of the sea-ice cover. We can group the products based on the concept of their SIC retrieval algorithms. Group I consists of data sets using the selfoptimizing EUMETSAT OSI SAF and ESA CCI algorithms. Group II includes data using the Comiso bootstrap algorithm and the NOAA NSIDC sea-ice concentration climate data record (CDR). The standard NASA Team and the ARTIST Sea Ice (ASI) algorithms are put into group III, and NASA Team 2 is the only element of group IV. The three CDRs of group I (SICCI-25km, SICCI-50km, and OSI-450) are biased low compared to a $100 \%$ reference SIC data set with biases of $-0.4 \%$ to $-1.0 \%$ (Arctic) and $-0.3 \%$ to $-1.1 \%$ (Antarctic). Products of group II appear to be mostly biased high in the Arctic by between $+1.0 \%$ and $+3.5 \%$, while their biases in the Antarctic range from $-0.2 \%$ to $+0.9 \%$. Group III product biases are different for the Arctic, $+0.9 \%$ (NASA Team) and $-3.7 \%$ (ASI), but similar for the Antarctic, $-5.4 \%$ and $-5.6 \%$, respectively. The standard deviation is smaller in the Arctic for the quoted group I products
\end{abstract}

(1.9\% to $2.9 \%$ ) and Antarctic (2.5\% to $3.1 \%$ ) than for group II and III products: $3.6 \%$ to $5.0 \%$ for the Arctic and $4.0 \%$ to $6.5 \%$ for the Antarctic. We refer to the paper to understand why we could not give values for group IV here. We discuss the impact of truncating the SIC distribution, as naturally retrieved by the algorithms around the $100 \%$ sea-ice concentration end. We show that evaluation studies of such truncated SIC products can result in misleading statistics and favour data sets that systematically overestimate SIC. We describe a method to reconstruct the non-truncated distribution of SIC before the evaluation is performed. On the basis of this evaluation, we open a discussion about the overestimation of SIC in data products, with far-reaching consequences for surface heat flux estimations in winter. We also document inconsistencies in the behaviour of the weather filters used in products of group II, and we suggest advancing studies about the influence of these weather filters on SIA and SIE time series and their trends.

\section{Introduction}

For more than 40 years, the fraction of the polar oceans covered by sea ice, or sea-ice concentration, has been monitored by means of satellite microwave radiometry. This enabled a better understanding of ocean-sea-ice-atmosphere interactions for the polar regions where observations with means 
Table 1. Overview of relevant multichannel satellite microwave sensors.

\begin{tabular}{lrr}
\hline Sensor & Relevant frequencies (GHz) & Operation periods \\
\hline Scanning Multichannel Microwave Radiometer (SMMR) & $6.6,10.7,18.0,21.0,37.0$ & 25 Oct 1978-20 Aug 1987 \\
Special Sensor Microwave/Imager (SSM/I) & $19.4,22.2,37.0,85.5$ & 9 Jul 1987-today \\
Special Sensor Microwave Imager/Sounder (SSMIS) & $19.4,22.2,37.0,91.7$ & 18 Oct 2003-today \\
Advanced Microwave Scanning Radiometer for EOS (AMSR-E) & $6.9,10.7,18.7,23.8,36.5,89.0$ & 5 May 2002-4 Oct 2011 \\
Advanced Microwave Scanning Radiometer 2 (AMSR2) & $6.9,7.3,10.7,18.7,23.8,36.5,89.0$ & 18 May 2012-today \\
\hline
\end{tabular}

other than satellites are challenging due to remoteness, harsh environment, and limited daylight. Based on the long-term satellite record, a substantial negative trend in the Arctic seaice area and extent has been found (e.g. Meier et al., 2014; Comiso, 2012; Comiso et al., 2017a). In the Antarctic, seaice area and extent are highly variable, with a period of positive trends (Turner et al., 2013; Comiso et al., 2017b) and sea-ice extent maxima (Reid et al., 2015) being followed recently by record minima (Schlosser et al., 2018; Turner et al., 2017; Stuecker et al., 2017).

In this contribution, we evaluate a number of satellite estimates of the sea-ice concentration from which sea-ice area and extent are derived. Such detailed evaluation allows one to better estimate the uncertainties of these products, knowledge of which is required for all their applications. These applications range from estimates of the future evolution of the Arctic sea-ice cover, whose confidence is directly affected by observational uncertainty of sea-ice concentration (e.g. Niederdrenk and Notz, 2018), and short-term forecasts for ship routing (e.g. Wayand et al., 2019; Melia et al., 2017 ) to detailed climate-model evaluation (e.g. Ivanova et al., 2017).

The sea-ice concentration is computed from satellite observations of the microwave brightness temperature (TB), which is a measure of the Earth-leaving thermal microwave radiation received by the satellite sensor. A number of different satellite sensors have been in place for sea-ice monitoring, summarized in Table 1 (see also Lavergne et al., 2019, Table 2). With these sensors the polar regions have been covered almost completely daily since October 1978 (every other day with Scanning Multichannel Microwave Radiometer (SMMR) before July 1987).

A considerable number of different algorithms to compute the sea-ice concentration from microwave satellite TB measurements have been developed during the past decades. All exploit the fact that under typical viewing angles $\left(50-55^{\circ}\right)$ the difference in microwave brightness temperature, measured at horizontal $(\mathrm{h})$ and vertical (v) polarization, between open water and sea ice is sufficiently large to estimate sea-ice concentration. Whether or not a given algorithm is accepted by the scientific community as a candidate for computing a climate data record (CDR) depends among other things on the length of the available satellite raw data record, spatial and temporal resolution, quantification of uncertainties, and sensitivity to noise, which might introduce artificial trends (e.g. Tonboe et al., 2016; Lavergne et al., 2019).

Several inter-comparison studies were carried out to assess the quality of the sea-ice concentration obtained with different algorithms (e.g. Andersen et al., 2007; Ivanova et al., 2014, 2015; Beitsch et al., 2015; Comiso et al., 2017a). Two different kinds of such inter-comparisons exist. One kind deals with an inter-comparison of sea-ice cover products of a certain number of algorithms without incorporating independent information of the sea-ice cover. Such intercomparisons provide very valuable information about interproduct consistencies in the overall sea-ice concentration distribution and in sea-ice area and extent time series and trends. They also reveal differences, for instance, with respect to the representation of the seasonal cycle or with respect to regional differences between sea-ice concentration estimates. Inter-comparisons of this kind are Ivanova et al. (2014) and Comiso et al. (2017a). These studies, however, do not provide information about how accurate a sea-ice concentration product is. The other kind of algorithm inter-comparison study deals with the comparison of the satellite sea-ice concentration with independent data. These can be ship-based observations, or sea-ice concentration estimates derived from independent satellite observations, for instance, in the optical frequency range or with active microwave sensors such as synthetic aperture radar (SAR). Inter-comparisons of this second kind seldom involve more than one to two algorithms (e.g. Wiebe et al., 2009; Meier, 2005; Comiso et al., 1997; Comiso and Steffen, 2001; Markus and Dokken, 2002; Kern et al., 2003; Cavalieri et al., 2010; Spreen et al., 2008). Exceptions to this are Andersen et al. (2007), who compared seven different algorithms with ship-based sea-ice cover observations and SAR imagery for the high Arctic, and Beitsch et al. (2015), who compared six different algorithms with ship-based sea-ice cover observations in the Antarctic. Both these studies each focused on one hemisphere only. The work of Andersen et al. (2007) is based on comparably old versions of the algorithms and products. In the present paper, we inter-compare the newest available versions of the sea-ice concentration algorithm and products used in both studies, including three CDRs. We perform our evaluation for both hemispheres. Additionally, we take advantage of a recently published new calibration-validation data package (see Sect. 2.2). 
Table 2. Overview of the investigated sea-ice concentration products. The column "ID (algorithm)" holds the identifier we use henceforth to refer to the data record and which algorithm it uses. Group is an identifier for the retrieval concept used. The column "Input data" refers to the input satellite data for the data set. The column "Open water filter" refers to whether weather-related spurious sea-ice concentrations in open water and low-concentration areas are filtered. Weather filters do not remove weather-related noise over areas with near-100\% sea-ice concentrations. The column "Atmospheric correction" refers to correcting the input TBs for a potential inherent weather influence using additional independent weather information. The column "Error" refers to the provision of sea-ice concentration uncertainties, and "Period" is the time period for which we use the data set, given as StartYearStartMonth-EndYearEndMonth.

\begin{tabular}{|c|c|c|c|c|c|c|c|}
\hline $\begin{array}{l}\text { ID } \\
\text { (algorithm) }\end{array}$ & Group & $\begin{array}{l}\text { Input data \& } \\
\text { frequencies }\end{array}$ & $\begin{array}{l}\text { Grid resolution \& } \\
\text { type }\end{array}$ & $\begin{array}{l}\text { Open } \\
\text { water } \\
\text { filter }\end{array}$ & $\begin{array}{l}\text { Atmospheric } \\
\text { correction }\end{array}$ & Error & Period \\
\hline OSI-450 (SICCI2) & I & $\begin{array}{l}\text { SMMR, SSM/I, SSMIS } \\
19.35 \& 37.0 \mathrm{GHz}\end{array}$ & $\begin{array}{l}25 \mathrm{~km} \times 25 \mathrm{~km} \\
\text { EASE-Grid } 2.0\end{array}$ & Yes & Yes & Yes & 197901-201512 \\
\hline SICCI-12km (SICCI2) & I & $\begin{array}{l}\text { AMSR-E, AMSR2 } \\
18.7 \& 89.0 \mathrm{GHz}\end{array}$ & $\begin{array}{l}12.5 \mathrm{~km} \times 12.5 \mathrm{~km} \\
\text { EASE-Grid } 2.0\end{array}$ & Yes & Yes & Yes & 200205-201705 \\
\hline SICCI-25km (SICCI2) & I & $\begin{array}{l}\text { AMSR-E, AMSR2 } \\
18.7 \& 36.5 \mathrm{GHz}\end{array}$ & $\begin{array}{l}25 \mathrm{~km} \times 25 \mathrm{~km} \\
\text { EASE-Grid } 2.0\end{array}$ & Yes & Yes & Yes & 200205-201705 \\
\hline SICCI-50km (SICCI2) & I & $\begin{array}{l}\text { AMSR-E, AMSR2 } \\
6.9 \& 36.5 \mathrm{GHz}\end{array}$ & $\begin{array}{l}50 \mathrm{~km} \times 50 \mathrm{~km} \\
\text { EASE-Grid } 2.0\end{array}$ & Yes & Yes & Yes & 200205-201705 \\
\hline CBT-SSMI (Comiso bootstrap) & II & $\begin{array}{l}\text { SMMR, SSM/I, SSMIS } \\
19.35 \& 37.0 \mathrm{GHz}\end{array}$ & $\begin{array}{l}25 \mathrm{~km} \times 25 \mathrm{~km} \\
\text { PolarStereo }\end{array}$ & Yes & No & No & 197810-201712 \\
\hline $\begin{array}{l}\text { NOAA CDR (Comiso bootstrap \& } \\
\text { NASA Team) }\end{array}$ & II & $\begin{array}{l}\text { SSM/I, SSMIS } 19.35 \& \\
37.0 \mathrm{GHz}\end{array}$ & $\begin{array}{l}25 \mathrm{~km} \times 25 \mathrm{~km} \\
\text { PolarStereo }\end{array}$ & Yes & No & Yes & 198708-201712 \\
\hline CBT-AMSR-E (Comiso bootstrap) & II & $\begin{array}{l}\text { AMSR-E } \\
18.7 \& 36.5 \mathrm{GHz}\end{array}$ & $\begin{array}{l}25 \mathrm{~km} \times 25 \mathrm{~km} \\
\text { PolarStereo }\end{array}$ & Yes & No & No & 200205-201109 \\
\hline ASI-SSMI (ASI) & III & SSM/I, SSMIS $85.5 \mathrm{GHz}$ & $\begin{array}{l}12.5 \mathrm{~km} \times 12.5 \mathrm{~km} \\
\text { PolarStereo }\end{array}$ & Yes & No & No & 199201-201812 \\
\hline NT1-SSMI (NASA Team) & III & $\begin{array}{l}\text { SMMR, SSM/I, SSMIS } \\
19.35 \& 37.0 \mathrm{GHz}\end{array}$ & $\begin{array}{l}25 \mathrm{~km} \times 25 \mathrm{~km} \\
\text { PolarStereo }\end{array}$ & No & No & No & 197810-201712 \\
\hline NT2-AMSR-E (NASA Team-2) & IV & $\begin{array}{l}\text { AMSR-E } 18.7,36.5 \& \\
89.0 \mathrm{GHz}\end{array}$ & $\begin{array}{l}25 \mathrm{~km} \times 25 \mathrm{~km} \\
\text { PolarStereo }\end{array}$ & Yes & Yes & No & 200205-201109 \\
\hline
\end{tabular}

This paper is the first of a series of papers in which we are going to present and discuss results of a systematic evaluation of 10 sea-ice concentration products (see Sect. 2). We want to provide users and algorithm developers with new information about the accuracy and precision of this suite of products, some of which are widely used in the climate research community. In this paper, we present the sea-ice concentration products used. We focus on differences in sea-ice concentration, area, and extent and on intercomparisons with near- $100 \%$ reference sea-ice concentrations and with a large suite of ship-based manual visual observations of the sea-ice conditions. The second paper is going to focus on an inter-comparison with sea-ice parameters derived from Moderate Resolution Imaging Spectroradiometer (MODIS) satellite observations in the Arctic. The third paper is going to focus on presenting and discussing results of an inter-comparison with sea-ice concentrations computed from Landsat satellite visible imagery.

In the following Sect. 2, we introduce the sea-ice concentration data sets and ancillary data used as input. This section further describes the preparation of the ancillary data and inter-comparison steps. Section 3 illustrates how the sea-ice concentration products compare with each other in terms of multi-annual monthly average sea-ice concentration as well as sea-ice area and extent. In Sects. 4 and 5, we show the results of the inter-comparison against a near- $100 \%$ reference data set and against ship-based sea-ice observations, respectively. Section 6 covers a discussion, an outlook, and conclusions.

\section{Data and methodologies}

\subsection{Sea-ice concentration data sets}

For this study, we consider 10 different sea-ice concentration products (Table 2, with more details in Appendices AF). There are many more algorithms and products available than we are using here; see e.g. Ivanova et al. (2015). The main criteria for our choice of algorithms and products are (1) length of the product time series, (2) grid resolution, and (3) accessibility and sustained production. We exclude products with less than 10-year coverage and/or with a finer grid resolution than $12.5 \mathrm{~km}$. Following Table 2 we comment on several specific issues that are important for 
the correct interpretation of sea-ice concentration products, namely the grid resolution, the land spillover correction, the weather/open water filter, and the sea-ice concentration distributions around $0 \%$ and $100 \%$.

We group the products according to their concept for sea-ice concentration retrieval (Table 2, column "Group"). Group I contains the four European Organisation for the Exploitation of Meteorological Satellites-Ocean and Sea Ice Satellite Application Facility - European Space AgencyClimate Change Initiative (EUMETSAT OSI SAF and ESA CCI) products. Group II contains the Comiso bootstrap (CBT) algorithms, which are CBT-SSMI (Special Sensor Microwave/Imager), CBT-AMSR-E (Advanced Microwave Scanning Radiometer aboard Earth Observation Satellite), and National Oceanic and Atmospheric Administration (NOAA) CDR (the third is a combination of CBTSSMI and NASA Team (NT1)-SSMI but is clearly dominated by CBT-SSMI). NT1-SSMI and Artist Sea Ice (ASI)SSMI are assigned to group III. These algorithms follow a different concept to retrieve the sea-ice concentration where the sea-ice concentration is mainly based on a brightness temperature polarization difference. Finally, the enhanced NASA Team (NT2)-AMSR-E is assigned to group IV; its concept to derive sea-ice concentrations via a lookup table and modelled atmospheric profiles is fundamentally different from the other nine algorithms.

\subsubsection{Grid resolution}

Given grid resolutions apply to every grid cell for group I products since their EASE-Grid has equal area of all grid cells (Appendix A). For all other products which are provided on a polar-stereographic grid (Appendices B-F), the grid resolution is true at $70^{\circ}$ latitude (see also Peng et al., 2013). For the computation of sea-ice area and extent (Sect. 3), we take this difference in grid cell area into account and use the respective files of the grid cell areas provided by NSIDC (ftp://sidads.colorado.edu/pub/DATASETS/ brightness-temperatures/polar-stereo/tools/geo-coord/grid, last access date: 26 September 2018).

\subsubsection{Land spillover correction}

The difference in brightness temperatures observed over open water (low) and land (high) combined with the size of the field of view of several kilometres to a few tens of kilometres can cause spurious sea-ice concentrations to appear along coasts (e.g. Lavergne et al., 2019). Various methods to reduce this so-called land spillover effect are applied in all products (Cavalieri et al., 1999; Cho et al., 1996; Maass and Kaleschke, 2010). For ASI-SSMI (Appendix B), reduction of land spillover effects is carried out for both the ASI algorithm and the NASA Team algorithm product used over open water. For NOAA CDR (Appendix F), the reduction of land spillover effects is applied separately to both input data sets before merging (Meier and Windnagel, 2018). In this paper, we do not further correct potential differences between the 10 products caused by this effect.

\subsubsection{Weather/open water filter}

The two standard weather filters based on brightness temperature gradient ratios at 19,22 , and $37 \mathrm{GHz}$, which mitigate noise due to atmospheric moisture and wind-induced roughening of the ocean surface (Cavalieri et al., 1995, 1999), are applied in the products NT1-SSMI and NT2-AMSR-E. In the products CBT-SSMI and CBT-AMSR-E, spurious seaice concentrations caused by weather effects are filtered using the same frequencies as mentioned above but applying a bootstrap technique (Comiso and Nishio, 2008). For NOAA CDR (Appendix F), the above-mentioned weather filters are applied before the merge (Meier and Windnagel, 2018). In the two National Aeronautics and Space Administration Goddard Space Flight Center (NASA GSFC) (Appendices C, D) sea-ice concentration products, i.e. NT1-SSMI version 1 and CBT-SSMI version 3, weather effects are reduced by screening of input brightness temperatures, application of the above-mentioned weather filters, and some additional manual correction (Meier and Windnagel, 2018; Peng et al., 2013, https://nsidc.org/data/g02202/versions/3, last access: 7 February 2019, https://nsidc.org/data/nsidc-0051, last access: 7 February 2019, and https://nsidc.org/data/nsidc-0079, last access: 7 February 2019). In the ASI-SSMI product no specific weather filter is applied to the ASI algorithm itself. However, ASI algorithm sea-ice concentrations are set to $0 \%$ where NASA Team algorithm sea-ice concentration values are $<30 \%$ (see Appendix B). Because the abovementioned two weather filters are applied to the NASA Team sea-ice concentration, the ASI-SSMI product implicitly contains a weather filter as well (Ezraty et al., 2007). Note that the $5 \mathrm{~d}$ median filter used for the ASI-SSMI product used here (Kern et al., 2010) not only removes remaining spurious sea ice over open ocean but also reduces weather-induced elevated sea-ice concentrations along the ice edge. In the group I products a dynamic open water filter is applied. It is based on the quoted standard weather filters but takes into account changes in filter efficiency due to changes in the frequencies between the different sensors, for instance between SMMR and SSM/I. Also, it does not use the channels close to $22 \mathrm{GHz}$. All weather filters may in addition to the spurious ice also remove real ice along the ice edge. All 10 products apply a monthly varying climatological sea-ice cover mask to erase spurious sea ice at low latitudes.

We investigate the temporal consistency of the weather filters. For this we focus on the sea-ice concentration interval $] 0.0 \%, 30.0 \%$ ]; i.e. we exclude grid cells set to exactly $0.0 \%$ by the weather filter. Then, for each day of the month, we identify the 5th percentile of all gridded sea-ice concentrations falling into the above-mentioned interval. Subsequently, we average over the month. We look at two aspects. 
First, it is desirable that these time series are mostly stable across the time period covered by a given data record, indicating that the weather filter cuts the sea-ice edge evenly across inter-annual variability and changes of frequencies. Second, it is also desirable that the weather filter cuts "well below" the $15 \%$ SIC threshold that is commonly used in the computation of the sea-ice extent (SIE) (e.g. Gloersen et al., 1992; Meier et al., 2014; Comiso et al., 2017a). We choose the 5th percentile (and not a minimum value) to obtain less noisy time series. We plot examples of these time series for all 10 products in Figs. 1 and 2 for the Arctic and Antarctic, respectively. For the Arctic we use March (Fig. 1a) and September (Fig. 1g); for the Antarctic we use September (Fig. 2a) and February (Fig. 2g). In addition to the time series, we also plot the cumulative distribution of the daily sea-ice concentrations of the range $] 0.0 \%$ to $30.0 \%$ ] for the respective month for the year 2004 as an example for CBTSSMI, OSI-450, NT1-SSMI, ASI-SSMI, and NT2-AMSRE.

We find little inter-annual variation in the monthly mean percentile sea-ice concentration over time, particularly for OSI-450 and SICCI-25km (see also Lavergne et al., 2019). Changes as caused due to a switch in sensor remain below $1 \%$. On average, the 5 th percentile sea-ice concentration is $<12 \%$, which ensures that the enhanced open water filter applied in these two products barely influences computation of SIA and SIE. For group II products, these monthly mean 5th percentile sea-ice concentrations are considerably larger and sometimes exceed $15 \%$. Additionally, the time series for CBT-SSMI and NOAA CDR reveal larger inter-annual variations than OSI-450, inter-sensor transitions (e.g. in 19871988 changing from SMMR to SSM/I, Fig. 1g); and in 20072008 changing from SSM/I to SSMIS, Fig. 1a) leading to trends in the percentile time series. Compared to OSI-450 and SICCI-25km, for NOAA CDR we find the following. (1) The sea-ice concentration at which the weather filter applies varies seasonally. For instance, in the year 1996, the mean 5 th percentile of sea-ice concentrations within the interval ] $0 \%, 30 \%$ ] is $14 \%$ for the Arctic in March but $17 \%$ in September, and for the Antarctic it is $16 \%$ in September but $18 \%$ in February. OSI-450 cuts at $10 \%$ and SICCI$25 \mathrm{~km}$ cuts at $11 \%$ in these months, and for both hemispheres. (2) The inter-annual variation in the sea-ice concentration at which the filter applies is larger for NOAA CDR than for OSI-450 and SICCI-25km. The time series for NT1-SSMI, ASI-SSMI, and NT2-AMSR-E, in contrast, have very low $(\sim 1 \%)$ monthly mean 5 th percentile sea-ice concentration values with little or no inter-annual variation.

In the plots showing the daily cumulative fraction for the year 2004, which exemplifies the typical cumulative fraction, we find a cumulative distribution with a first increasing, later merely constant slope with no sea-ice concentrations below $\sim 10 \%$ and $\sim 8 \%$ for CBT-SSMI and OSI-450, respectively (panels b, c, h and $\mathrm{i}$ in Figs. 1 and 2). This agrees with the application of the open water filter presented in Lavergne et al. (2019). For NT1-SSMI and NT2-AMSR-E, in contrast, we find a substantial amount of near- $0 \%$ sea-ice concentrations (panels d, f, j and 1 in Figs. 1 and 2). This suggests that while a weather filter is applied (according to the documentations) there are still concentrations near $0 \%$ left. We checked this by looking at the respective daily sea-ice concentration maps. Both products reveal a considerable number of grid cells with $<5 \%$ sea-ice concentration along the ice edge. All but the group I products (see Table 2) only provide integer sea-ice concentration values. At the near- $0 \%$ end of the sea-ice concentration distribution these products have sea-ice concentrations of $0 \%, 1 \%, 2 \%$, and so forth. The number of NT2-AMSR-E sea-ice concentration values of $1 \%$ exceeds the 5th percentile most of the time, which is the explanation for why most NT2-AMSR-E values are missing in the time series in plots (a) and (g) of Figs. 1 and 2. We take the results shown in these two figures into account when discussing the results presented in Sect. 3.

\subsubsection{Distribution around $100 \%$}

A considerable fraction of this paper focuses on the evaluation near $100 \%$ sea-ice concentration. Sea-ice concentrations are retrieved from satellite microwave brightness temperatures using a geophysical algorithm, usually involving tie points. Tie points are typical signatures, e.g. brightness temperatures, or parameters derived from these, of ice (SIC: $100 \%$ ) and open water (SIC: 0\%). Because of the natural variability of the surface properties of $100 \%$ sea ice relevant for its microwave remote sensing, one fixed tie point value for $100 \%$ sea ice, even if retrieved daily, can only be an average representation of these properties. In other words, 10 different kinds of $100 \%$ sea ice can cause 10 different brightness temperatures. As a result, a retrieved sea-ice concentration naturally varies around $100 \%$. This means even though the actual sea-ice concentration is exactly $100 \%$ the retrieved one could be, for example, $97 \%$ or $100 \%$ or $103 \%$. While the group I products retain the naturally retrieved sea-ice concentration, the others do not; in all group II to group IV products (see Table 2) sea-ice concentrations are truncated at $0 \%$ and $100 \%$; i.e. values $<0 \%$ are set to $0 \%$ and values $>100 \%$ are set to $100 \%$. Figure 3 illustrates the sea-ice concentration distribution at the locations of the near-100\% sea-ice concentration reference data set (see Sect. 2.2) for SICCI-25km, SICCI-50km, and NOAA CDR for the Arctic (panels a-c) and the Antarctic (panels d-f).

We use a Gaussian fit to reconstruct the true distribution of the sea-ice concentration retrieval around $100 \%$ for group II and III products. The methodology is tested on the group I products. This is done by finding that Gaussian curve which provides the lowest root-mean-squared difference (RMSD) to the sea-ice concentration distribution for values $\leq 99 \%$, i.e. basically the left-hand side of the histograms shown in Fig. 3. For the fitting process, we also take into account the fraction of sea-ice concentrations $\leq 99 \%$ relative to the en- 

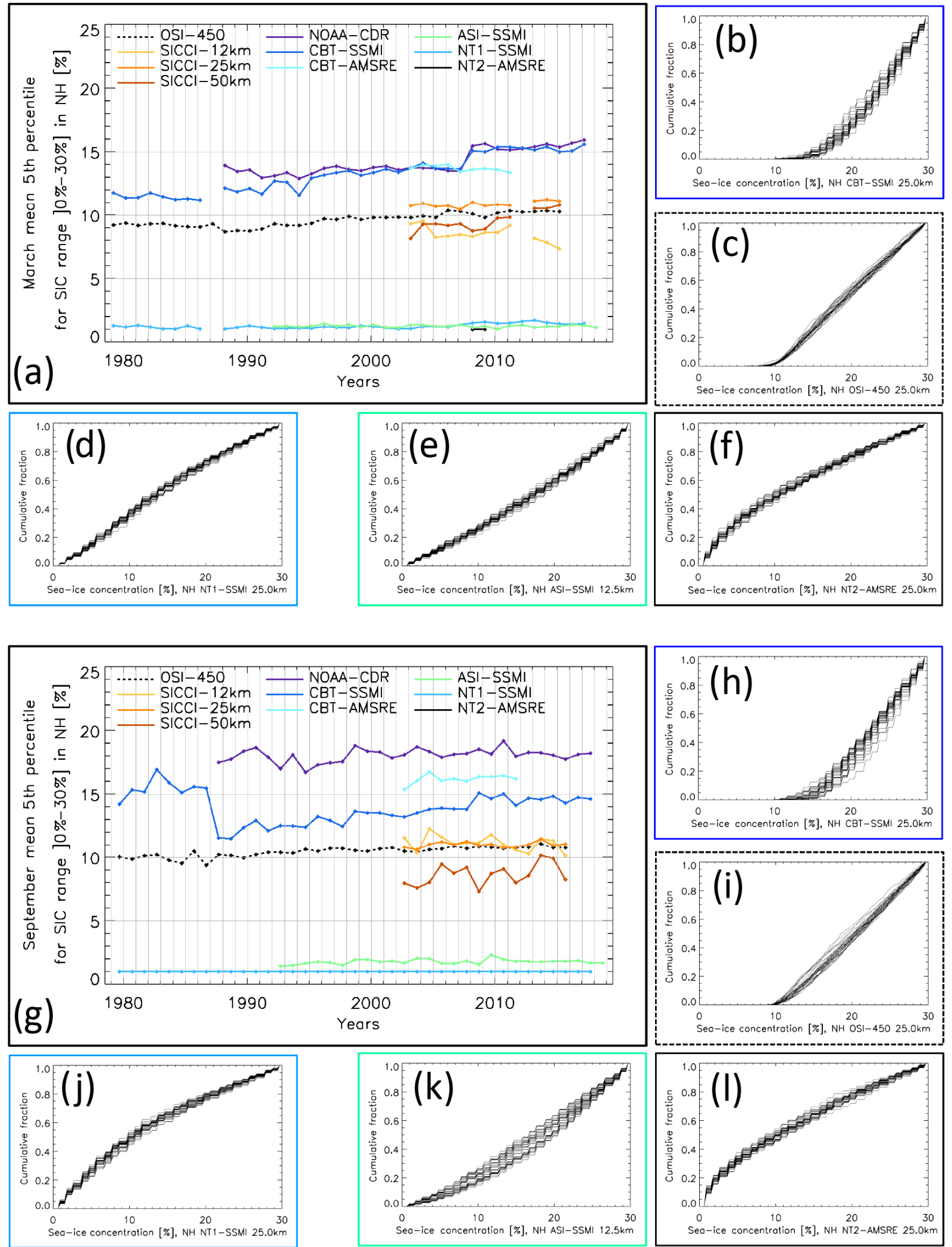

Figure 1. Time series of the monthly mean 5th percentile sea-ice concentration of the range ]0.0\% to 30.0\%] for the Arctic in (a) March and (g) September for all 10 products. Panels (b-f) and (h-l) show daily cumulative sea-ice concentration distributions of five selected products in these two months, respectively, in a sample year: 2004. See Table 2 for the time periods with data from the respective products. 

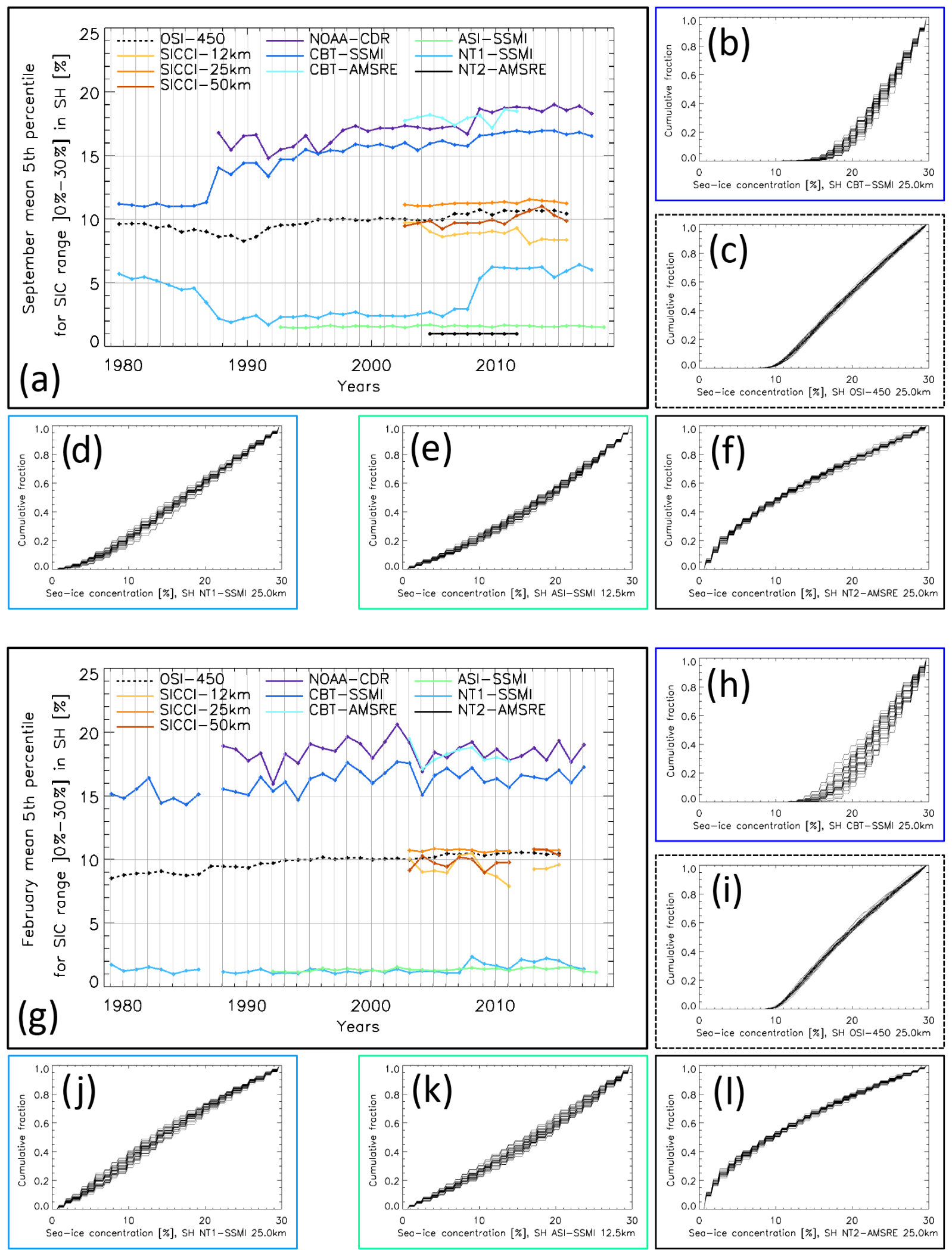

Figure 2. Time series of the monthly mean 5th percentile sea-ice concentration of the range $] 0.0 \%$ to $30.0 \%$ ] for the Antarctic in (a) September and (g) February for all 10 products. Panels (b-f) and (h-l) show daily cumulative sea-ice concentration distributions of five selected products in these two months, respectively, in a sample year: 2004. See Table 2 for the time periods with data from the respective products. 

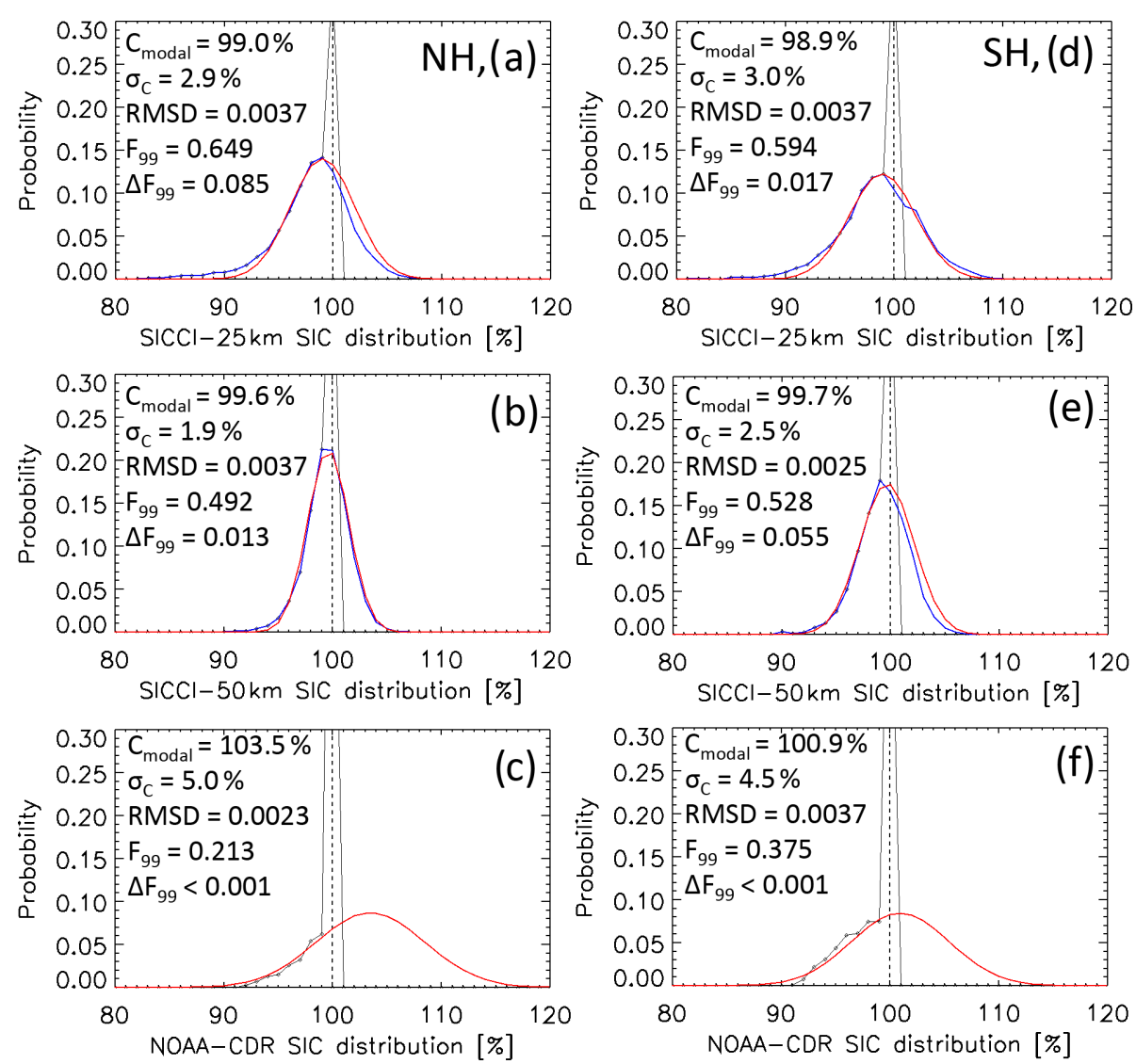

Figure 3. Examples of the sea-ice concentration distribution at near-100\% reference sea-ice concentration locations. Black symbols and lines show values cut off at $100 \%$; blue lines denote the original distribution (for SICCI-25km and SICCI-50km only); red lines denote the distribution resulting from the Gaussian fit to values of the distribution $\leq 99 \%$. In each panel, the modal sea-ice concentration (centre of the Gaussian fit: $C_{\text {modal }}$ ), the standard deviation of the fit $\sigma_{\mathrm{C}}$ and fit parameters with respect to the fraction of the distribution $\leq 99 \%$ ( $F_{99}, \Delta F_{99}$; see text for more explanation), and the root-mean-squared difference (RMSD) between original and fitted probability are given. (a-c) Arctic; (d-f) Antarctic. See Appendix H for Figs. H1 and H2 containing plots of this kind for all 10 products.

tire count of valid sea-ice concentrations: $F_{99}$. The difference between original $F_{99}$ and $F_{99}$ resulting from the Gaussian fit, $\Delta F_{99}$, has to be $<0.1$. We allow a maximum RMSD value of 0.0125 . We first binned SICCI-25km and SICCI-50km seaice concentration values to integer values to be consistent with the other products. Figure $3 \mathrm{a}, \mathrm{b}$ and d, e illustrate that the fits (red) agree well with the originally retrieved SICCI$25 \mathrm{~km}$ and SICCI-50km sea-ice concentrations (blue) with modal values slightly below $100 \%$. Figure $3 \mathrm{c}$, f illustrate how well the Gaussian fit matches the original sea-ice concentration distribution for sea-ice concentrations $\leq 99 \%$ for NOAA CDR as an example. Here the modal sea-ice concentrations of the Gaussian fit are larger than $100 \%: 103.5 \%$ for Northern Hemisphere (NH, Fig. 3c) and $100.9 \%$ for Southern Hemisphere (SH, Fig. 3f). In addition, the Gaussian curve is broader than for SICCI-25km and SICCI-50km, resulting in larger values for the standard deviation. We also note that $F_{99}$ is $\sim 0.6$ and $\sim 0.5$ for SICCI- $25 \mathrm{~km}$ and SICCI-50km, respectively, but only $\sim 0.2$ and $\sim 0.4$ for NOAA CDR. We take the information from Fig. 3 into account when interpret- ing the results presented in Sects. 4 and 5. We refer to Appendix $\mathrm{H}$ for the full set of sea-ice concentrations and Gaussian fits obtained for all 10 products in both hemispheres.

\subsection{The near-100 \% sea-ice concentration reference data set}

For the evaluation of the 10 products at $100 \%$ sea-ice concentration (see Sect. 4), we use the Round Robin Data Package version 2 (RRDP2) near-100\% reference sea-ice concentration data set developed within the ESA Sea_Ice_cci and European Union "Spaceborne observations for detecting and forecasting sea ice cover extremes" (EU-SPICES) projects (Pedersen et al., 2019). In short, for this reference data set, areas of $\sim 100 \%$ sea-ice concentration are found by identifying areas of interest (AOIs) of approximately $100 \mathrm{~km} \times 100 \mathrm{~km}$ with net convergence in the ice drift pattern on two consecutive $1 \mathrm{~d}$ periods. Information about convergence is derived from the PolarView/MyOcean/CMEMS ice drift data set derived from Envisat ASAR, RADARSAT-2 


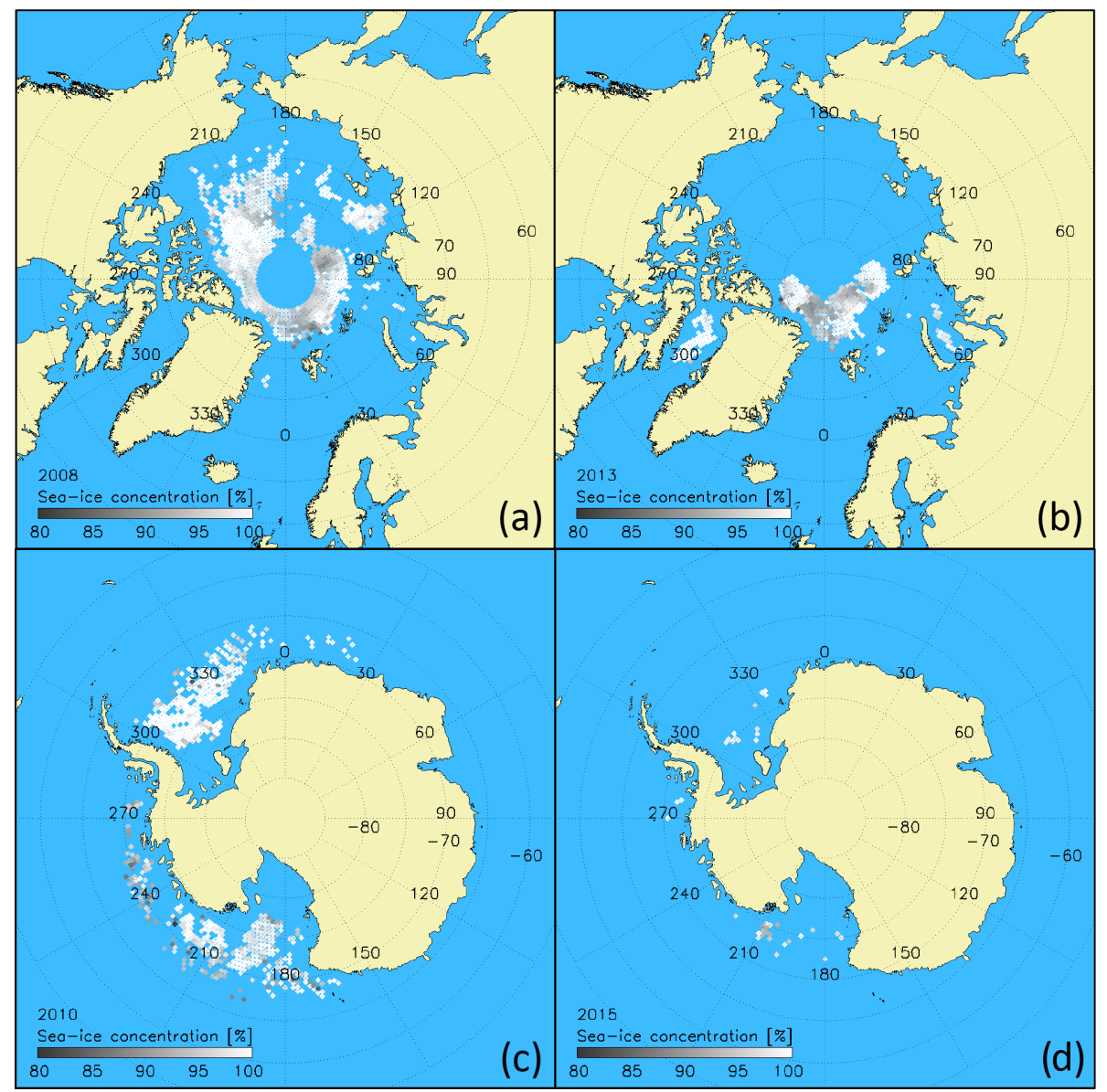

Figure 4. Illustration of the typical distribution of near-100\% SIC reference data by means of the co-located OSI-450 sea-ice concentration for $(\mathbf{a}, \mathbf{b})$ the Arctic and $(\mathbf{c}, \mathbf{d})$ the Antarctic in a year with good $(\mathbf{a}, \mathbf{c})$ and poor $(\mathbf{b}, \mathbf{d})$ data coverage.

SAR, and Sentinel-1 SAR imagery. By choosing AOIs for regions with high concentrations, near- $100 \%$ sea-ice concentration can be assured (e.g. Kwok, 2002; Andersen et al., 2007) in winter. Each AOI contains up to a hundred $10 \mathrm{~km} \times 10 \mathrm{~km}$ cells for which the SAR ice drift is computed. The number of cells depends on SAR image coverage. Convergence in the ice drift pattern results in a decrease in the total area of these cells. A cell is included in the data set of $\sim 100 \%$ sea-ice concentration if the area reduction between day 1 and day 2 is between $0.4 \%$ and $1.5 \%$ and if more than $40 \%$ of the AOI contains cells with such an area reduction. The RRDP2 near- $100 \%$ sea-ice concentration reference data set contains the AOI centre geographic latitude and longitude, time, total sea-ice concentration $(100 \%)$, and AOI average area reduction due to net ice convergence. It is available for the years 2007 through 2015 for both hemispheres.

We cannot provide a definite uncertainty for this reference data set but for its production. We combine a suite of measures to ensure high precision and close-to-zero bias (high accuracy). The drift-convergence selection is based on convergence on two consecutive days of $1 \mathrm{~d}$ drift. During win- ter, i.e. November through March (Arctic) and May through September (Antarctic), this is assumed to ensure that all openings existing on day 0 (prior to the two convergence days) are closed by convergence or refrozen. The refreezing assumption is the reason for the product quality to be higher during winter when openings rapidly refreeze than during summer when openings may not freeze up. There is no prior assumption of the initial ice concentration (on day 0 ), but the ice drift product requires quite high concentrations for the 2D cross correlation to work. Andersen et al. (2007) reported a sea-ice concentration standard deviation of $\sim 1 \%$ for coldseason high-resolution high-quality SAR image classification and an accuracy of $2 \%$ for ice-water SAR image classification from ice analysts without additional drift-convergence information. Based on our above-mentioned measures and the results of Andersen et al. (2007), we can state estimated values for precision $(\sim 1 \%)$ and accuracy $(<0.5 \%)$ for our reference data set.

We co-locate the sea-ice concentrations of the 10 products with the selected AOI grid cells by computing the minimum distance between AOI grid cell centre and grid cell centre of 
the respective sea-ice concentration product. For this step, we convert the geographic coordinates of all data sets into Cartesian coordinates taking into account the different projections. Figure 4 illustrates the spatial distribution of selected AOIs for both hemispheres for two different years by showing the co-located OSI-450 sea-ice concentration. We give an example of a typical "good distribution" (Fig. 4a, c) and of a typical "poor distribution" (Fig. 4b, d). The RRDP2 near-100\% sea-ice concentration reference data set contains basically no AOIs in the eastern Antarctic because of the lack of SAR image coverage required for the ice drift product used to generate this RRDP2 data set.

We evaluate the products at their native grid resolution without applying any spatial averaging. For each product, we compute the mean difference "product minus $100 \%$ " and its standard deviation as well as the cumulative distribution function of the differences.

\subsection{Ship-based visual sea-ice cover observations}

According to the Antarctic Sea Ice Processes \& Climate (AS$\mathrm{PeCt}$ ) protocol (http://www.aspect.aq, last access: 18 February 2019; Worby and Allison, 1999; Worby and Dirita, 1999; see also Worby et al., 2008) and the Ice Watch/ASSIST (Arctic Ship-based Sea-Ice Standardization) protocol (http: //icewatch.gina.alaska.edu, last access: 5 March 2019), shipbased observations of the sea-ice conditions shall be carried out every hour, at least every second hour, during daylight conditions while the ship is traversing the sea ice. Observations shall be carried out from the ship's bridge for an area of about $1 \mathrm{~km}$ around the ship and shall report ice conditions as follows: total ice concentration, type of openings, concentration, thickness, ridge fraction and height, and snow depth and type for up to three ice types. All ship-based visual observations used here result from manual, non-automated observations.

For our evaluation of the 10 products with respect to ship-based visual observations of the sea-ice conditions (see Sect. 5), we use about 15000 individual observations. About $\sim 7000$ of these were carried out in the Antarctic (ASPeCt) and $\sim 8000$ in the Arctic (Ice Watch/ASSIST). A substantial fraction of the Antarctic observations (until 2005) is available via http://www.aspect.aq (last access: 18 February 2019, Worby et al., 2008). The more recent observations were collected from various sources (e.g. PANGAEA, ACECRC, AWI; see also Beitsch et al., 2015) and merged with the existing ASPeCt data. The majority of the ASSIST data are taken from the data portal http://icewatch.gina.alaska.edu (last access: 5 March 2019). Additional sources for ASSIST data are PANGAEA (for Polarstern cruises before Ice Watch/ASSIST), the Arctic Data Center of the NSF (https: //arcticdata.io/catalog/\#data, last access: 5 March 2019), and the data archive of the Bering Sea Ecosystem Study (BEST): https://www.eol.ucar.edu/projects/best/ice.shtml (last access: 5 March 2019). All data are standardized; i.e. the ASCII for- mat data files containing the observations use similar formats for all variables and missing data. The data are also manually quality checked for outliers. For the comparison presented in this paper, we use all ASPeCt and Ice Watch/ASSIST observations from the period June 2002 through December 2015 (Kern, 2019).

Figure 5 summarizes the locations of the ship-based observations used in this paper, separately for the Arctic (Fig. 5a, b) and the Antarctic (Fig. 5c, d). For both hemispheres, just comparably small regions contain such observations. Figure 5a, c illustrate that some regions were visited during several years, while others were visited just once or twice during the 13-year period considered. The seasonal distribution (Fig. 5b, d) illustrates that the more central (Arctic) or southern (Antarctic) regions were only visited during summer months due to harsh winter conditions and missing daylight for these regions.

We co-locate the sea-ice concentrations of the 10 products with the selected ship-based observations by computing the minimum distance between geographic location of the shipbased observation and the grid cell centre of the respective sea-ice concentration product. For this step, we convert the geographic coordinates of all data sets into Cartesian coordinates taking into account the different projections of the seaice concentration products. Following the co-location, we average over all ship-based and all satellite-based sea-ice concentration values, including reports of open water, i.e. $0 \%$ concentration, of $1 \mathrm{~d}$ following the approach of Beitsch et al. (2015). This results in a comparison of along-ship-track daily average sea-ice conditions. Data pairs with fewer than three ship-based observations per day are discarded. The results of the comparison between ship-based and satellitebased sea-ice concentration are solely based on these daily average sea-ice concentrations. Note that all satellite-based data are used at their native grid resolution.

The ship-based and satellite-based sea-ice concentration data sets are inter-compared (Sect. 5) by means of scatterplots and linear regression analysis and statistics separately for summer data, winter data, and data of the entire year. Summer comprises the months May through September for the Arctic and the months November through March for the Antarctic; winter comprises the remaining months. In the scatterplots, we compare the daily average sea-ice concentrations and additionally compute averages of the satellitebased sea-ice concentration after binning the ship-based data into $5 \%$ wide bins ( $0 \%$ to $5 \%$ and $95 \%$ to $100 \%$ ) and $10 \%$ wide bins (sea-ice concentrations between $5 \%$ and $95 \%$ ) and vice versa. We compute the overall average sea-ice concentration difference and its standard deviation and perform a linear regression analysis based on the daily average and the binned data. 


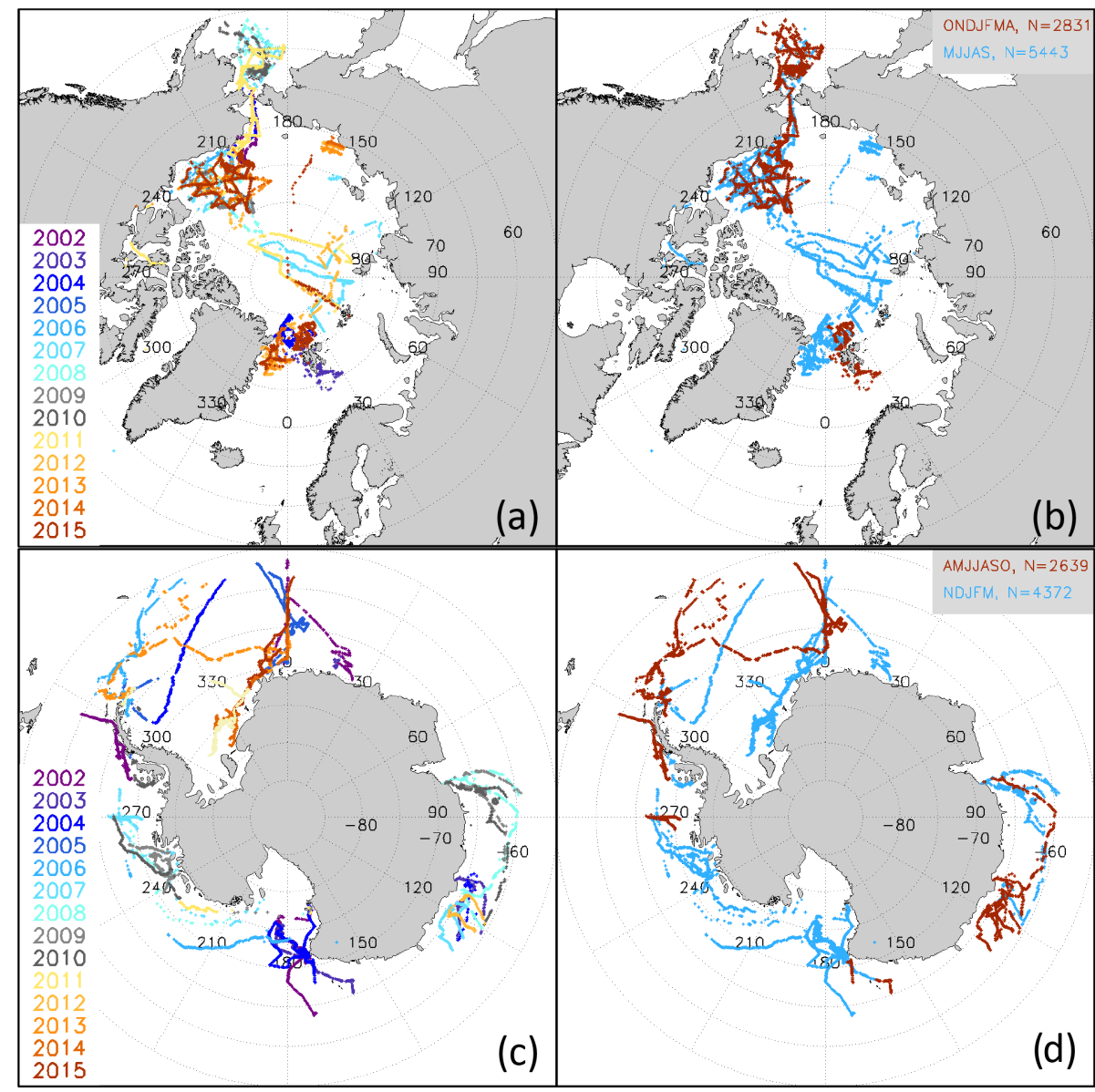

Figure 5. Spatio-temporal distribution of the ship tracks for $(\mathbf{a}, \mathbf{b})$ the Arctic and (c, d) the Antarctic from which ship-based visual observations of the sea-ice cover were used. Panels $(\mathbf{a}, \mathbf{c})$ illustrate the years, and panels $(\mathbf{b}, \mathbf{d})$ distinguish between winter (red) and summer (cyan) months.

\section{Inter-comparison of sea-ice area, extent, and distribution}

We follow Ivanova et al. (2014) and begin our intercomparison with time series of the sea-ice area (SIA) and sea-ice extent (SIE) (Sect. 3.1 and 3.2) derived from monthly mean sea-ice concentration. The monthly mean sea-ice concentration is derived for every product at the native grid and grid resolution using data of all days of a month of the entire sea-ice concentration range including $0 \%$. SIE is computed by summing over the grid cell area with $>15 \%$ sea-ice concentration. SIA is computed by summing over the ice-covered portion of the grid cell area with $>15 \%$ sea-ice concentration. By using this threshold, we follow Gloersen et al. (1992) and numerous SIA and SIE inter-comparison studies. We compare SIA and SIE time series for the entire period for which we have data from the respective products at the time of the analysis. We exclude sea-ice concentrations estimated for lakes and other inland waters. We fill the circular area with missing data around the pole caused by the satellite orbit inclination and swath width with a constant sea-ice concentration value of $98 \%$. Andersen et al. (2007) found a mean sea-ice concentration of $\sim 98 \%$ from a comparison of cold-season passive microwave and synthetic aperture radar observations in the high Arctic. They noted a smaller value of $\sim 95 \%$ in summer. Both values are confirmed by Kern (2018, http://icdc.cen.uni-hamburg. de/fileadmin/user_upload/ESA_Sea-Ice-ECV_Phase2/

SICCI_Phase2_SIV-Retrieval_Report_v02.pdf, last access: 6 September 2019). Using $98 \%$ instead of $95 \%$ during summer results in an overestimation of the SIA of about $10000 \mathrm{~km}^{2}$, a small value compared to other sources of biases for the SIA during summer. This filling is applied to the Arctic and only to the products at polar-stereographic projection. This area is already interpolated spatially in the four group I products. As described in Lavergne et al. (2019), these products contain a fully filtered and truncated (to the range $\left[\begin{array}{llll}0.0 \% & \ldots & 100.0 \%\end{array}\right]$ ) version and a non-filtered, non-truncated version of the sea-ice concentration. The latter contains the naturally retrieved sea-ice concentrations, i.e. also values $<0 \%$ and $>100 \%$ (see Sect. 2.1.3), and no weather filters are applied (see Sect. 2.1.3). We use the fully 


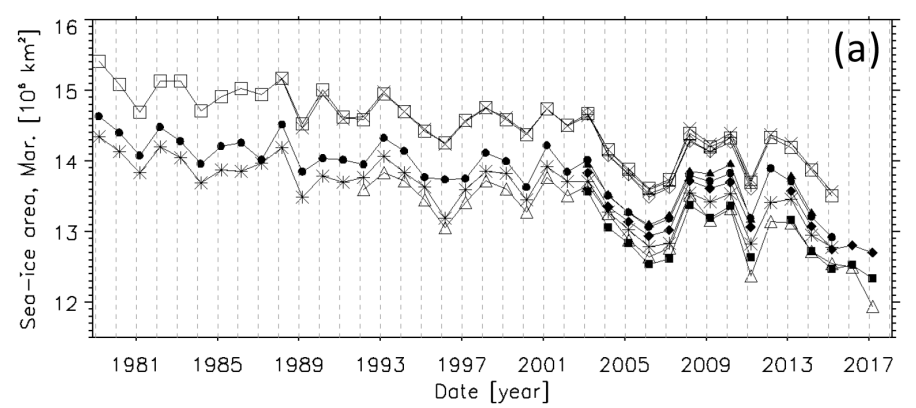

SIA winter $\mathrm{NH}$

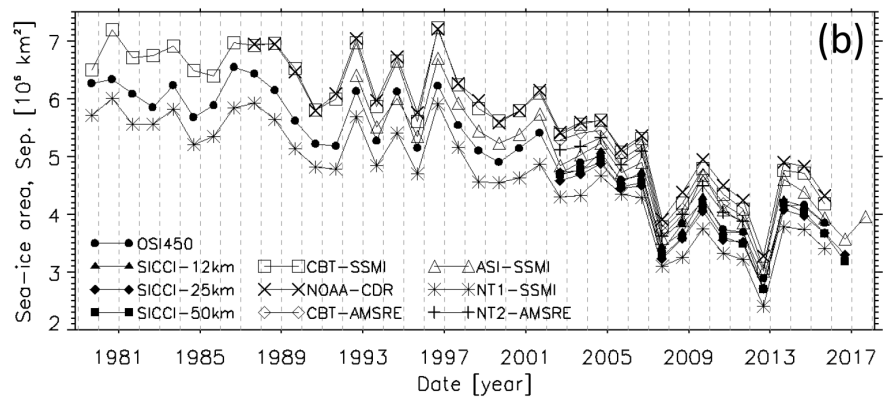

SIA summer $\mathrm{NH}$

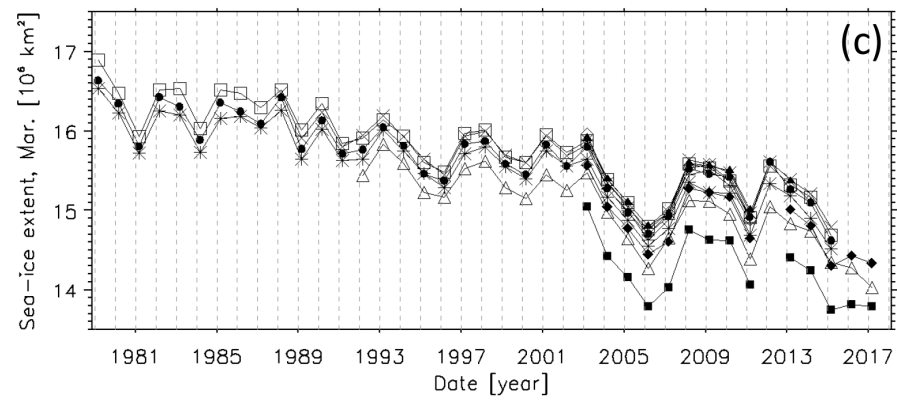

SIE winter $\mathrm{NH}$

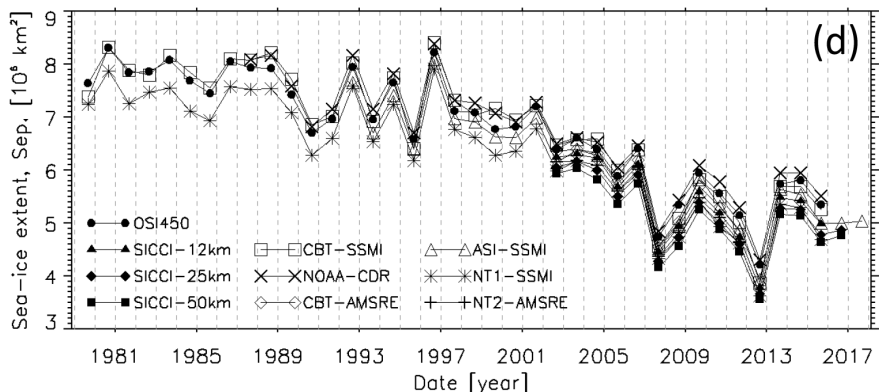

SIE summer $\mathrm{NH}$

Figure 6. Arctic sea-ice area (a, b) and extent $(\mathbf{c}, \mathbf{d})$ computed in $(\mathbf{a}, \mathbf{c})$ winter (March) and (b, d) summer (September) from the sea-ice concentration data sets used. See Table 2 for start and end months of the respective time series.

filtered and truncated version. Without the truncation the SIA of the group I products increases slightly, while the SIE does not change because the number of grid cells covered with $>15 \%$ sea ice is not influenced by the truncation (not shown).

We complement these SIA and SIE time series with maps of the multi-annual average sea-ice concentration difference for selected months for the AMSR-E measurement period: June 2002 to September 2011 (Sect. 3.3 and 3.4). We choose this period to be able to compare all 10 products for a similarly long time period. For these maps, we first re-grid the monthly mean sea-ice concentrations of all products, except SICCI-50km, onto the EASE-Grid version 2.0 with $50 \mathrm{~km}$ grid resolution using bilinear interpolation. Then we compute the multi-annual average sea-ice concentration for each month from which we subsequently calculate an ensemble median and the difference product minus ensemble median.

\subsection{Arctic sea-ice area and extent time series}

The SIA and SIE time series for the Arctic reveal a very similar overall development for the products extending back 

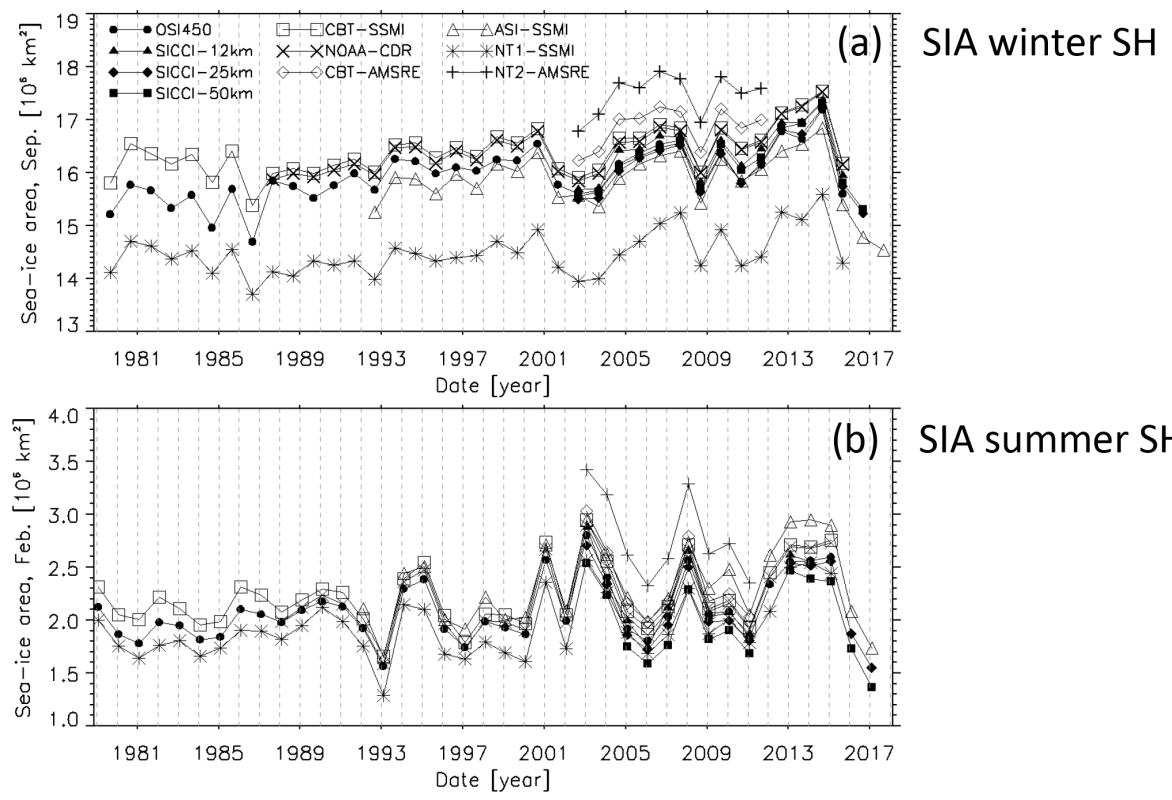

SIA summer SH
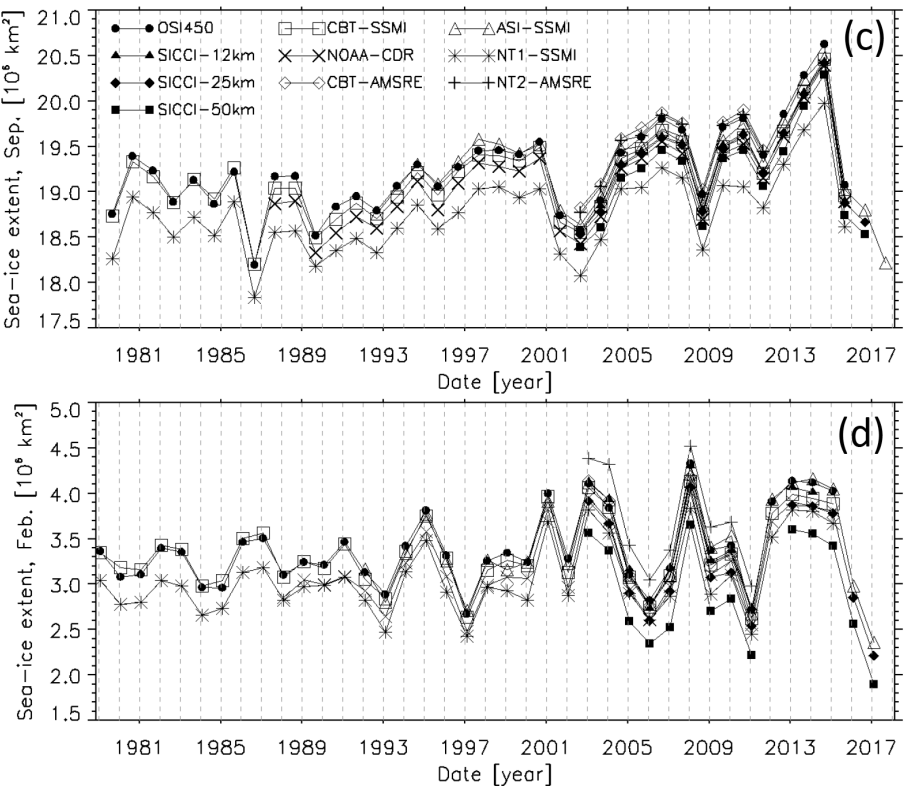

\section{SIE winter SH}

SIE summer SH

Figure 7. As Fig. 6 but for the Antarctic.

into the 1980s and 1990s (Fig. 6). This applies to (i) the overall negative trend in both quantities; (ii) the inter-annual variability as, for instance, during 1991-1997 and around 2007 and 2012 for SIA and SIE in September (Fig. 6b, d), or in 2011 for the relative minimum in March SIA and SIE (Fig. 6a, c); and (iii) the ranking between the products. NOAA CDR and CBT-SSMI provide the largest SIA and SIE in both March and September. NT1-SSMI provides the lowest SIA and SIE in September, while in March we find SIA and SIE from ASI-SSMI to be even lower. It is obvious that differences between products are smaller for SIE than for SIA as was also shown by Ivanova et al. (2014).
For the AMSR-E period, when SIA and SIE of all 10 products are available, the inter-annual variation is similar for all 10 products. We find ESA CCI products, CBT-AMSRE, and NT2-AMSR-E fall into the ranges of SIA and SIE given by the other products. An exception to this is SICCI$50 \mathrm{~km}$, which clearly provides the lowest SIE of all products in March (Fig. 6c). We will discuss this finding in Sect. 3.3.

\subsection{Antarctic sea-ice area and extent time series}

The SIA and SIE time series for the Antarctic reveal a similar overall development for products extending back into the 
1980s and 1990s (Fig. 7). This applies to (i) the overall positive trend until 2015 in both quantities; (ii) the inter-annual variability, for instance, during 2000-2003 for SIA and SIE in February (Fig. 7b, d), or in 2008 for the relative minimum in SIA and SIE in September (Fig. 7a, c); and (iii) the ranking between products. NOAA CDR and CBT-SSMI provide the largest SIA while NT1-SSMI provides the smallest SIA, being $\sim 1.8$ million $\mathrm{km}^{2}$ and $300000 \mathrm{~km}^{2}$ below the SIA of NOAA CDR and CBT-SSMI in September and February, respectively. OSI-450 and CBT-SSMI provide the largest SIE, exceeding the smallest SIE of NT1-SSMI by $\sim 500000 \mathrm{~km}^{2}$ and $\sim 300000 \mathrm{~km}^{2}$ in September and February, respectively (Fig. 7c, d). Inter-product differences are larger for SIA than SIE in September but not in February. For the AMSR-E period, the inter-annual variation is similar for all 10 products. In September, SIA and SIE of the ESA CCI products mostly fall between ASI-SSMI and OSI-450 (Fig. 7a, c). In February (Fig. 7b, d), SICCI-50km provides the smallest overall SIA and SIE while the SICCI-12km and SICCI-25km products agree closely with OSI-450. In contrast to the Arctic (compare Fig. 6), NT2-AMSR-E clearly provides the largest SIA in September and February (Fig. 7a, b). NT2-AMSR-E provides the largest SIE in February as well (Fig. 7d).

Figure $7 \mathrm{c}$ contains an example of discontinuities caused by the application of weather filters not adapted to sensor changes. Wintertime Antarctic OSI-450 and CBT-SSMI SIE agree with each other for the SMMR period. After 1987 the CBT-SSMI SIE is lower than the OSI-450 SIE by $\sim 150000 \mathrm{~km}^{2}$. This corresponds to the area of one-quarter of all $25 \mathrm{~km}$ grid cells at a latitude of $60^{\circ} \mathrm{S}$, the approximate average location of the Antarctic sea-ice edge in September. This change in SIE is concomitant with a jump in the weather filter sea-ice concentration from $11 \%$ to $14 \%$ (Fig. 2a). It is noteworthy that the $23.0 \mathrm{GHz}$ channels of the SMMR instrument were highly unstable from launch and eventually ceased to function on 11 March 1985 (Njoku et al., 1998). Thus, the water vapour part of the "classic" weather filter is unreliable in the early decade of the satellite data record. This is solved in the OSI-450 product by relying on explicit atmospheric correction of the brightness temperatures using - among others - water vapour fields from atmosphere reanalysis (see Lavergne et al., 2019). Another example of this kind (not shown) is a shift between OSI-450 SIE and NOAA CDR SIE by 50000 to $100000 \mathrm{~km}^{2}$ between 2007 and 2008 . This shift is concomitant with a discontinuity in the weather filter sea-ice concentration for NOAA CDR in March (Arctic, Fig. 1a) and September (Antarctic, Fig. 2a) during the transition from 2007 to 2008. This corresponds to when SSMIS (F17) is processed instead of SSM/I (F15). OSI-450 exhibits no discontinuity here.

\subsection{Arctic sea-ice concentration distribution differences}

In March, the difference between the sea-ice concentration of an individual product and the ensemble median of all 10 products (Fig. 8) remains within $\pm 5 \%$ over most of the Arctic Ocean, except for ASI-SSMI (Fig. 8h) and SICCI-12km (Fig. 8a). The largest differences between individual products and the ensemble median are located in the peripheral seas. Group II and IV (see Table 2) products have more sea ice than the ensemble median (Fig. 8e-g, j); differences can exceed $20 \%$. NT1-SSMI (Fig. 8i) has less sea ice than the ensemble median with negative differences greater than $10 \%$ or even $15 \%$ in magnitude in all peripheral seas. Differences of OSI-450 or SICCI-25km and the ensemble median are within $\pm 5 \%$ almost everywhere (Fig. 8b, d). SICCI-50km exhibits negative differences greater than $20 \%$ in magnitude along some of the coastlines, e.g. the Labrador Sea, the Irminger Sea, or the coastlines of the Pechora Sea and Barents Sea (Fig. 8c). A careful check of these areas in daily and monthly mean maps of the SICCI-50km sea-ice concentration reveals that for regions with a relatively narrow sea-ice cover stretching along coastlines, the coarse resolution of the $6.9 \mathrm{GHz}$ frequency channel entering the algorithm (see Table 2), in combination with land spillover filter and open water filter, can result in an unwanted complete removal of sea ice from the grid cells of the product. We are confident that this explains the particularly low SICCI-50km SIA and SIE shown in Fig. 6a and c for Arctic SIE in March.

For the matrices shown in Fig. 9 (and Fig. 12, Appendix G1-G6), we re-grid the monthly mean sea-ice concentration onto the EASE-Grid version 2.0 with $50 \mathrm{~km}$ grid resolution using bilinear interpolation, and we apply a common land mask (that of SICCI-50km) to all products. The differences between SIA and SIE values are computed from these gridded $50 \mathrm{~km}$ resolution, common land mask products. Figure 9a agrees with the results shown in Fig. 8. In winter (March), sea-ice concentration differences between members of groups I to III are $<1 \%$. Group III members NT1-SSMI and ASI-SSMI (see Table 2) exhibit less sea ice than the other groups. Group II and IV members exhibit higher seaice concentrations than the other two groups in winter and summer (September). In summer (Fig. 9d), sea-ice concentration differences remain $<2 \%$ between members of groups I and II but not within group III, where differences exceed $10 \%$. We refer to Appendix G for the respective results of the other months.

\subsection{Antarctic sea-ice concentration distribution differences}

In September (Fig. 10), most products show more sea ice than the ensemble median over high-concentration ice and less sea ice along the marginal ice zone. NT1-SSMI (Fig. 10i) exhibits considerably less sea ice than the ensemble 


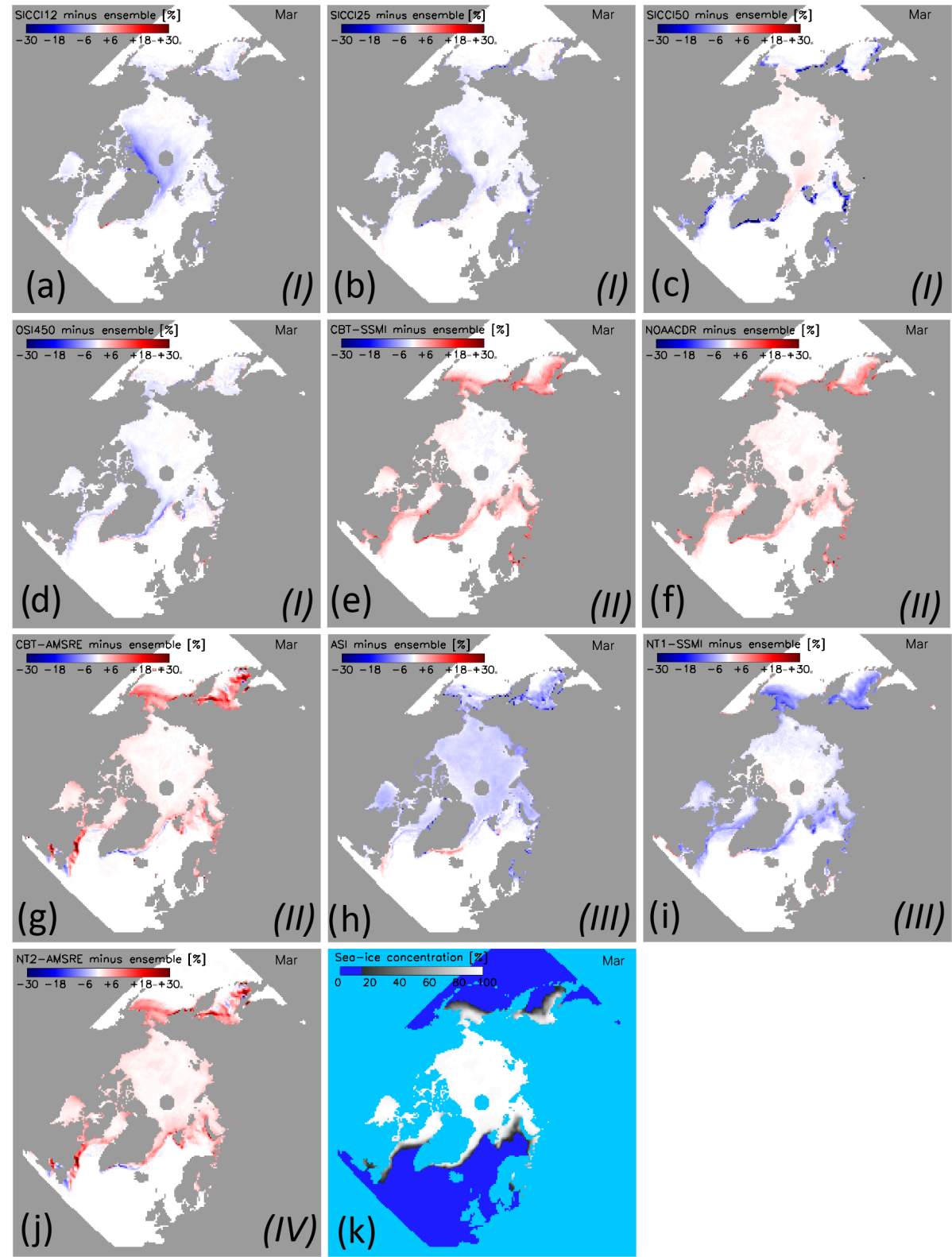

Figure 8. (a-j) Maps of the difference between the multi-annual average monthly SIC of the individual algorithms and the 10-algorithm ensemble median multi-annual average monthly SIC (k) for the Arctic in winter (March) 2003-2011. Differences are only computed for sea-ice concentration of both data sets $>15 \%$. Roman numbers I to IV denote the group assigned to the respective algorithm (see text for details).

median almost everywhere (see also Fig. 12a). ASI-SSMI (Fig. 10h) exhibits a distribution of sea-ice concentration differences that is reversed compared to most other products. CBT-AMSR-E and especially NT2-AMSR-E (Fig. 10g, j) show more sea ice than the ensemble median for most regions. This is evident in Fig. 12a as well.

In January (Fig. 11), the few, comparably small, highconcentration areas exhibit sea-ice concentration differences mostly below $\pm 5 \%$. Over the lower-concentration areas, i.e. mainly in the Weddell Sea and the Ross Sea, most products show less sea ice than the ensemble median with differences between $0 \%$ and $-6 \%$. NT1-SSMI has less sea ice while ASI-SSMI and particularly NT2-AMSR-E have more sea ice (see also Fig. 12d). Important to note are the negative differences of $\sim-10 \%$ along most of the Antarctic coast for SICCI-50km (Fig. 11c). Like for the Arctic, the coarse resolution of the $6.9 \mathrm{GHz}$ frequency channels combined with land spillover and open water filters can result in the unwanted removal of sea ice from grid cells (compare Fig. 8c and discussion of it) with the same influence on SICCI-50km SIA 

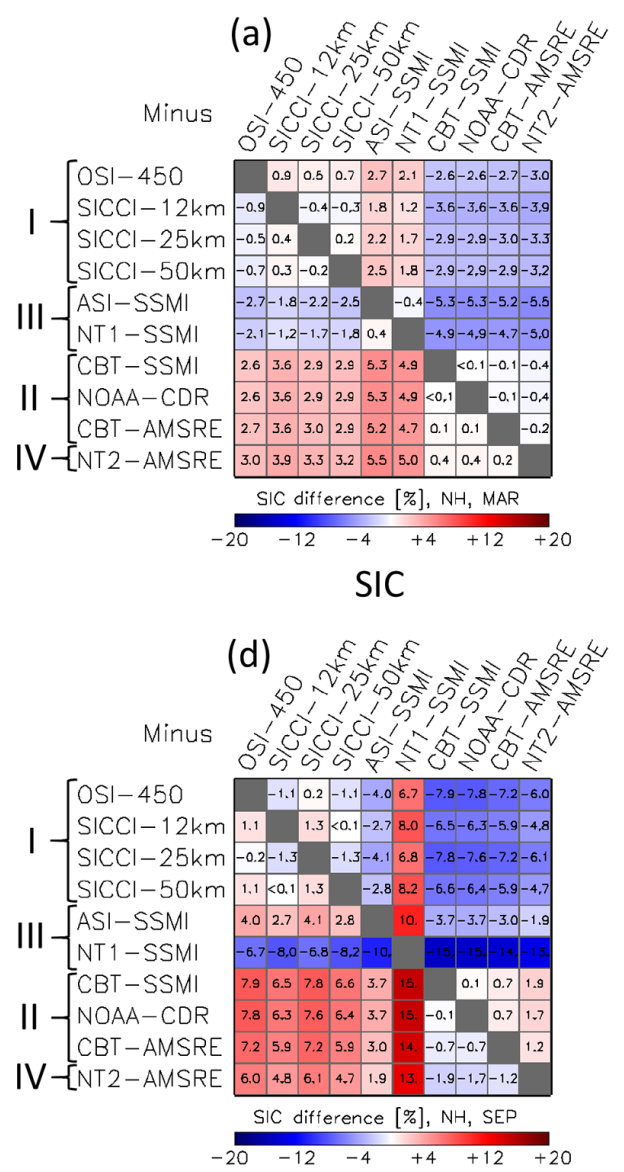

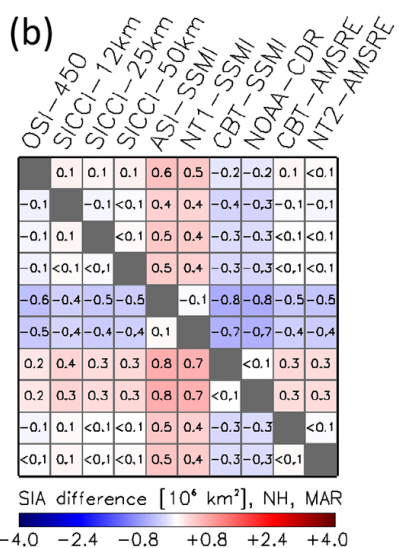

SIA

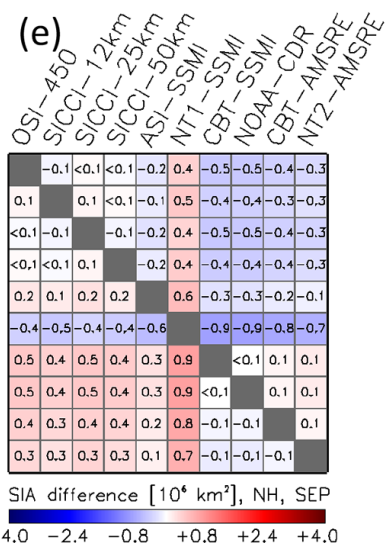

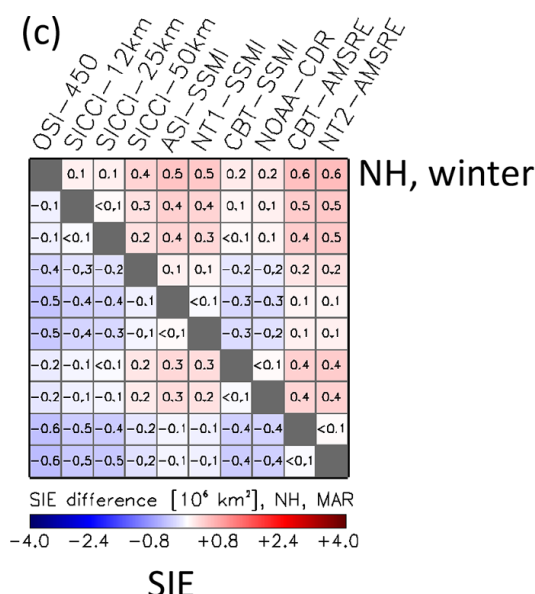

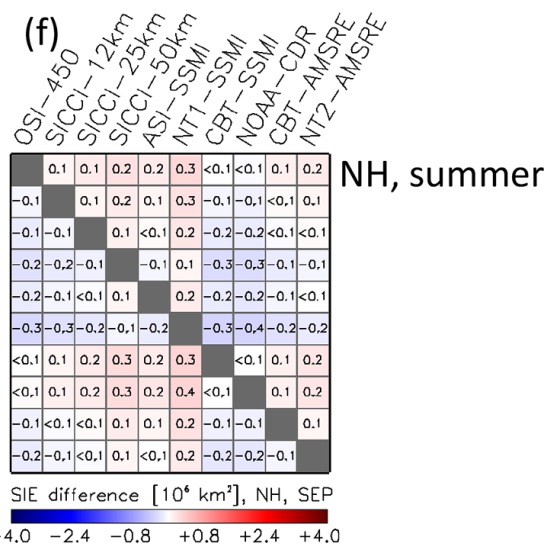

Figure 9. Differences (row minus column) between all 10 products of, from left to right, the average sea-ice concentration SIC, average SIA, and average SIE for the Arctic (NH) in winter $(\mathbf{a}-\mathbf{c})$ and summer $(\mathbf{d}-\mathbf{f})$. The averages are computed from monthly mean values of the respective months (March, September) of the AMSR-E period June 2002 to September 2011. All data are on the EASE-Grid 2.0 with $50 \mathrm{~km}$ grid resolution. The land mask of the SICCI-50km product is applied to all products. Roman numbers I to IV denote groups according to Table 2. For matrices of all remaining months, we refer to Figs. G1-G3 in Appendix G.

and SIE values (Fig. 7b, d). This is also evident in Fig. 12d where SICCI-50km exhibits the largest inter-product differences within group I.

For the results shown in Figs. 6-12 we used the truncated sea-ice concentration values as far as it concerns group I products. Repeating these computations with the nontruncated values, e.g. in September and March, does not change the results with respect to SIE. SIA increases by $\sim 50000 \mathrm{~km}^{2}$ in winter months and there is almost no impact in summer.

\subsection{Summary and discussion of sea-ice area and extent findings}

The inter-product mean sea-ice concentration differences (Figs. 8-12) are associated with a notable impact on SIA and SIE (Figs. 9 and 12). For summer SIE, inter-product differences are below $\sim 200000 \mathrm{~km}^{2}$ (Arctic, Fig. 9f) and below $\sim 300000 \mathrm{~km}^{2}$ (Antarctic, Fig. 12f) for most products. NT1-SSMI (Arctic) and SICCI-50km, NT1-SSMI, and
NT2-AMSR-E (Antarctic) show the largest differences here. For winter SIE, most inter-product differences are below $\sim 200000 \mathrm{~km}^{2}$ for the Antarctic (Fig. 12c); larger differences are mostly found for NT1-SSMI (see also Fig. 7c). For the Arctic (Fig. 9c), inter-product differences range between 100000 and $600000 \mathrm{~km}^{2}$ and seem to be associated with the type of algorithm and partly also the sensor.

For Arctic winter SIA (Fig. 9b), group III products provide systematically smaller values (by $\sim 400000 \mathrm{~km}^{2}$ ) than the other three groups while group II SSMI products provide systematically larger values (by $\sim 300000 \mathrm{~km}^{2}$ ). Group I and CBT-AMSR-E and NT2-AMSR-E exhibit the lowest interproduct SIA differences. For Arctic summer SIA (Fig. 9e), group II and IV products agree with each other within $100000 \mathrm{~km}^{2}$ but exceed group I SIA by $\sim 400000 \mathrm{~km}^{2}$. This is equal to $10 \%$ of the summer minimum Arctic SIA. For Antarctic summer SIA (Fig. 12e), NT2-AMSRE exceeds SIA of all other products by $\sim 400000 \mathrm{~km}^{2}$. This equals $20 \%$ of the summer minimum Antarctic SIA. 

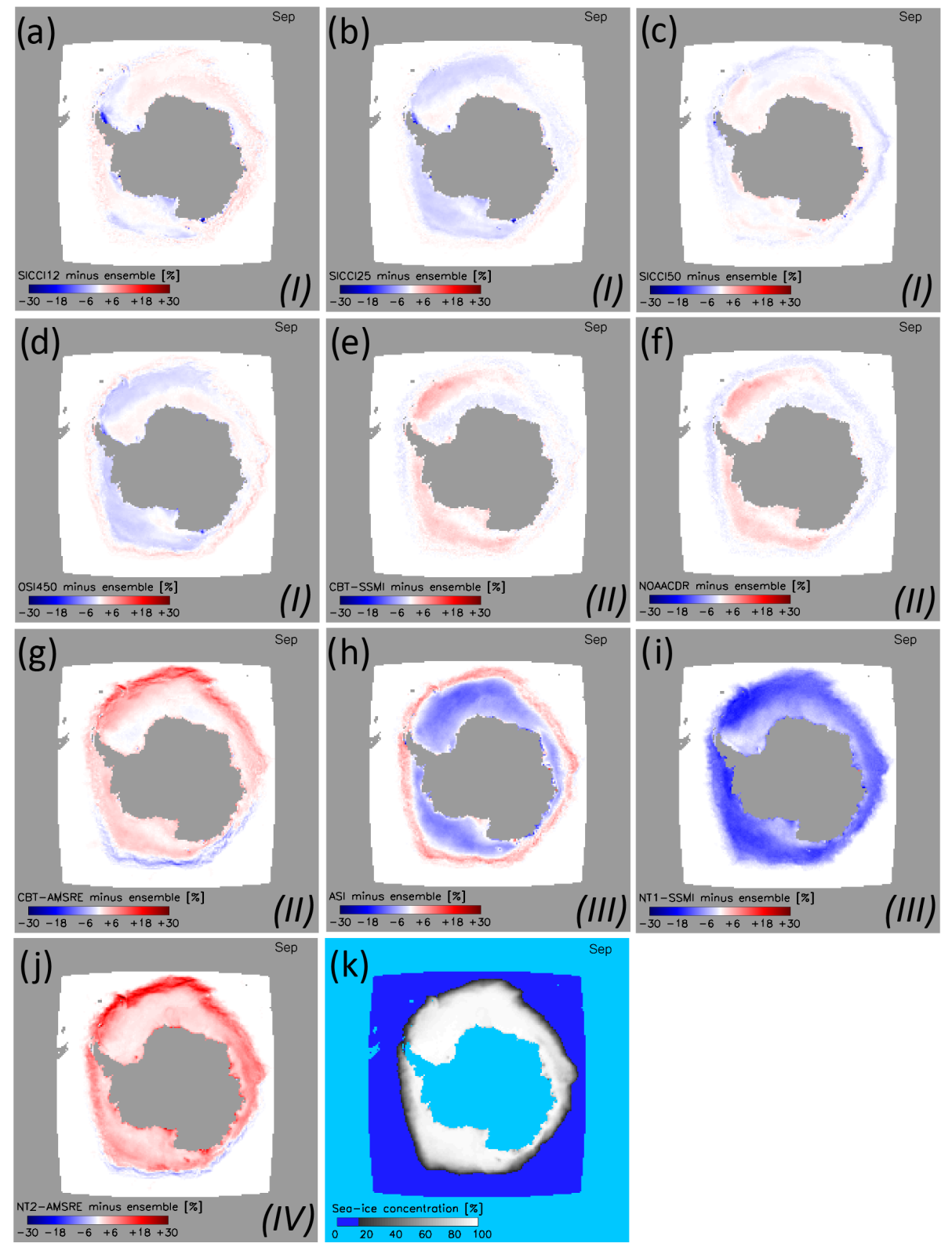

Figure 10. (a-j) Maps of the difference between the multi-annual average monthly SIC of the individual algorithms and the 10-algorithm ensemble median multi-annual average monthly SIC (k) for the Antarctic in winter (September) 2002-2011. Differences are only computed for sea-ice concentration of both data sets $>15 \%$. Roman numbers I to IV denote the group assigned to the respective algorithm (see text for details).

SIA differences between the other products are almost all $<200000 \mathrm{~km}^{2}$. For Antarctic winter SIA (Fig. 12b), NT2AMSR-E and NT1-SSMI stand out with very large systematic differences from all other products.

We summarize our findings from the matrices in Figs. 9 and 12 (see also Appendix G1-G6) as follows: (i) absolute and relative (to the respective minimum or maximum value) inter-product differences are smaller for SIE than for SIA. (ii) SIA and SIE derived from products of different algorithms of the same group (see Table 2) may differ consid- erably. (iii) Inter-product differences for SIA and SIE for the investigated CDRs are, on average, larger for the Arctic than the Antarctic.

We note that the grid resolution of the products is not necessarily compatible with the true spatial resolution because the footprints of the satellite sensor channels used in some of the algorithms are coarser (Table 2). This applies to NT1SSMI, CBT-SSMI, NOAA CDR, and OSI-450, i.e. the products at $25 \mathrm{~km}$ grid resolution based on SMMR, SSM/I, and SSMIS data. For these products, we expect that gradients in 

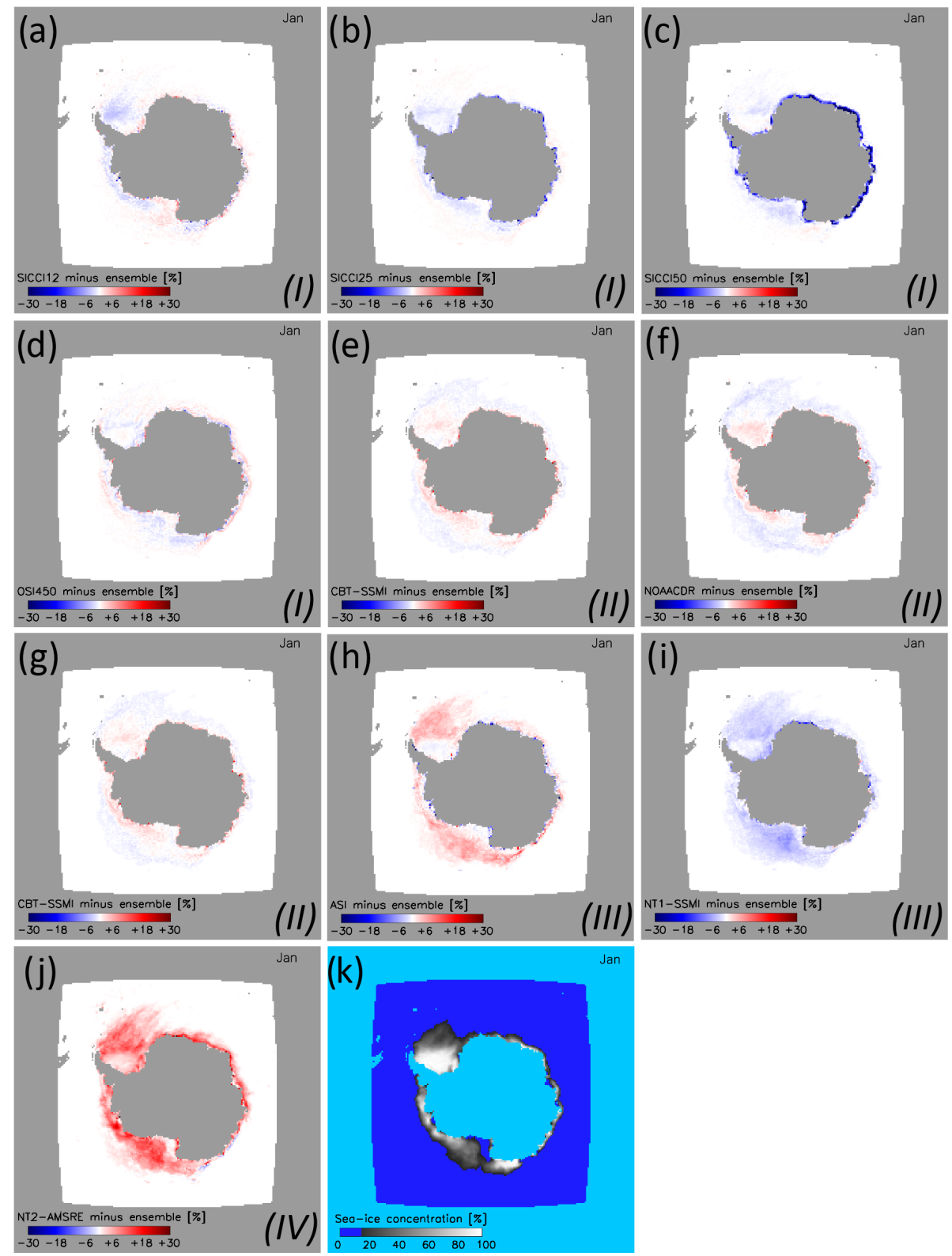

Figure 11. As Fig. 10 but in summer (January) 2003-2011.

the sea-ice concentration are more smeared than for products with a better match between footprint size and grid resolution such as, for instance, CBT-AMSR-E or SICCI-25km. This is illustrated for OSI-450 and SICCI-25km in Lavergne et al. (2019, Fig. 6). For a typical wintertime Antarctic ice edge at $65^{\circ} \mathrm{S}$ comprising half a compact and half an open sea-ice cover, this difference in the match of true resolution and grid resolution between SSM/I and AMSR-E products would result in a slightly larger SIE (by $\sim 200000 \mathrm{~km}^{2}$ ) derived from the SSM/I product. This is because a compact ice edge is smeared more in the SSM/I product, resulting in more grid cells with a sea-ice concentration $>15 \%$, the threshold used currently to compute SIE. In fact we find that during winter OSI-450 SIE exceeds SICCI-25km SIE by $\sim 100000 \mathrm{~km}^{2}$ in the Arctic (Fig. 9c) and by $\sim 200000 \mathrm{~km}^{2}$ in the Antarctic (Fig. 12c). Since the algorithms used for the sea-ice concentration retrieval for these two products are almost identical, the difference in SIE can well be attributed to the above-mentioned impact of differences between true and grid resolution. The second pair of almost identical algorithms is CBT-SSMI and CBT-AMSR-E. In the Arctic, in winter, CBT-SSMI SIE exceeds CBT-AMSR-E SIE by $\sim 400000 \mathrm{~km}^{2}$ (Fig. 9c) but in the Antarctic CBT-SSMI SIE is smaller than CBT-AMSR-E SIE by $\sim 100000 \mathrm{~km}^{2}$ (Fig. 12c). Differences in the algorithm itself and/or in the 

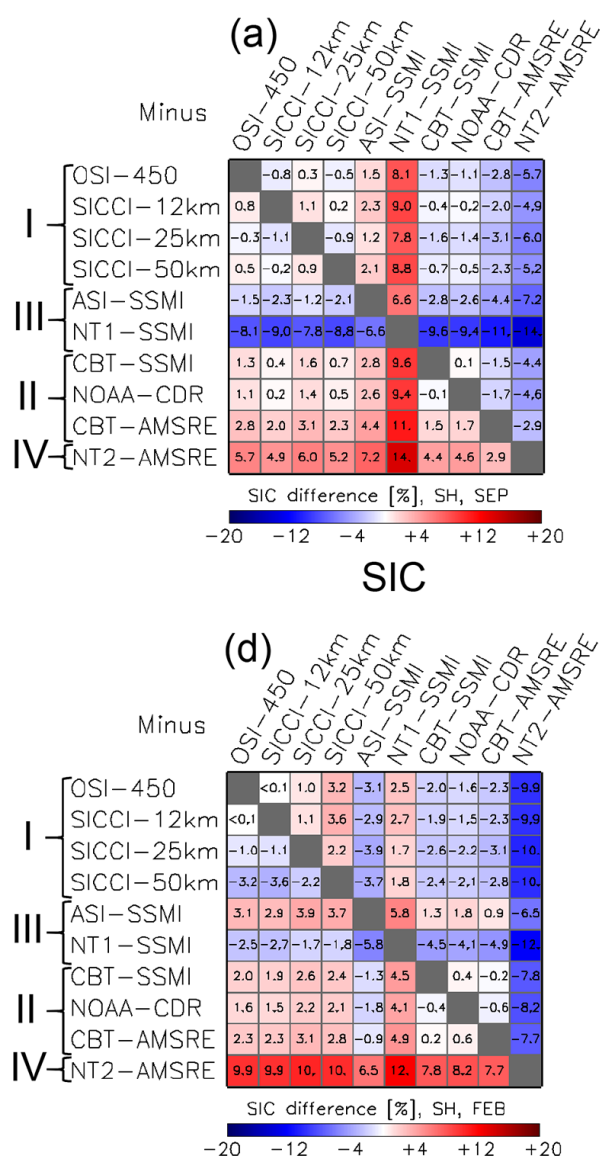

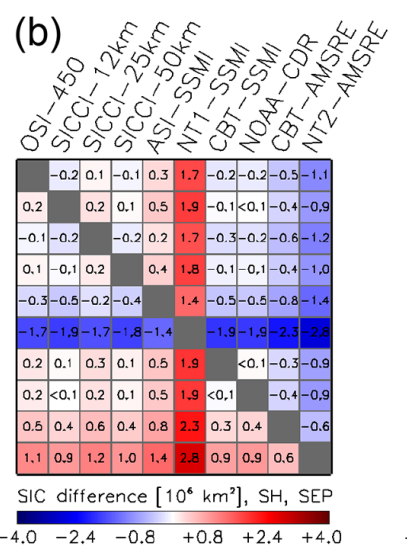

SIA

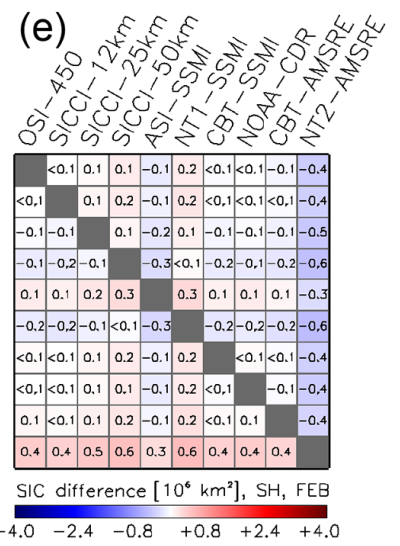

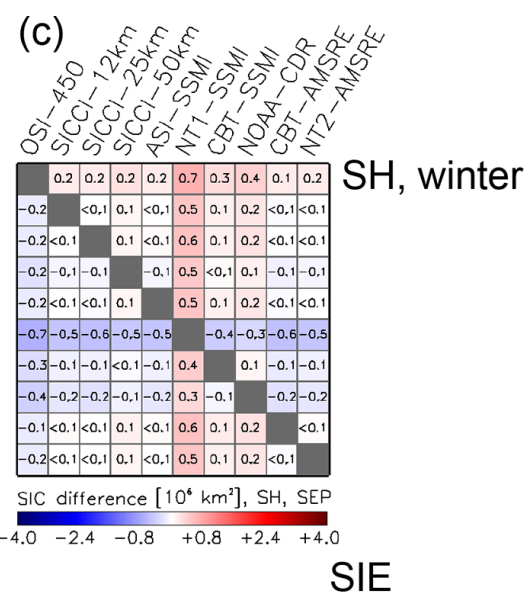

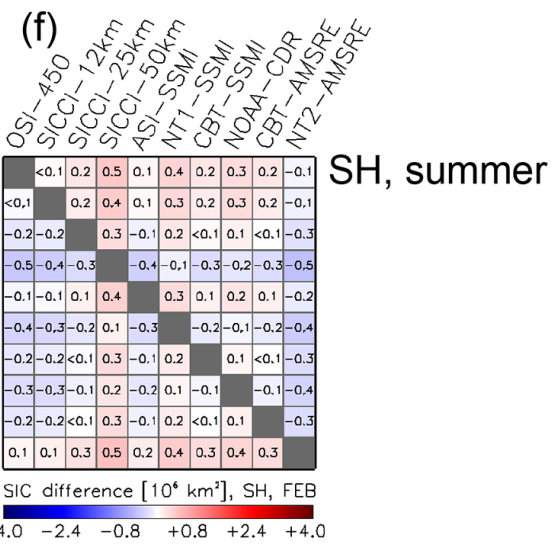

Figure 12. Differences (row minus column) between all 10 products of, from left to right, the average sea-ice concentration SIC, average SIA, and average SIE for the Antarctic (SH) in winter (a-c) and summer (d-f). The averages are computed from monthly mean values of the respective months (September, February) of the AMSR-E period June 2002 to September 2011. All data are on the EASE-Grid 2.0 with $50 \mathrm{~km}$ grid resolution. The land mask of the SICCI-50km product is applied to all products. Roman numbers I to IV denote groups according to Table 2. For matrices of all remaining months we refer to Figs. G4-G6 in Appendix G.

weather filter might be the cause. We refer to the discussion at the end of Sect. 3.2 in this context.

\section{Comparison with near-100 \% SIC reference data set}

In this section, we present results of the evaluation of the 10 products at $100 \%$ sea-ice concentration using the data described in Sect. 2.2. We note upfront that caution should be exercised when reporting and interpreting evaluation statistics like bias (mean value minus $100 \%$ ) or root-mean-square error near the $100 \%$ end of truncated sea-ice concentration products. This applies to the results presented in this section but also to Sect. 5. First, the bias of truncated products will necessarily be negative or zero (mean value lower than or equal to $100 \%$ ), even if the bias of the product was exactly $0 \%$ before truncation. Second, products whose nontruncated distribution is biased high (modal value larger than $100 \%$ ) will seemingly achieve better evaluation statistics after truncation because of the accumulation of values $>100 \%$ being folded to exactly $100 \%$. Both bias and RMSE of these products are smaller than those of products that do not overestimate at $100 \%$ sea-ice concentration. The larger the fraction of truncated values, the better the statistics. The values that accumulate at the $100 \%$ bin in the truncated product are in majority from the above- $100 \%$ range of the nontruncated distribution (note the value of $F_{99}$ in Fig. 3) and improve the evaluation statistics (bias and RMSE). In fact, under the hypothesis that the distribution of the retrieved seaice concentration is mostly Gaussian around the modal value before truncation, products with overestimation of the nontruncated distribution can be recognized by their abnormal (with respect to a Gaussian model) accumulation of values exactly at $100 \%$.

For more discussion and quantification of the error distribution of sea-ice concentration products and algorithms before truncation around $100 \%$ (and around $0 \%$ ), see Ivanova et al. (2015). 

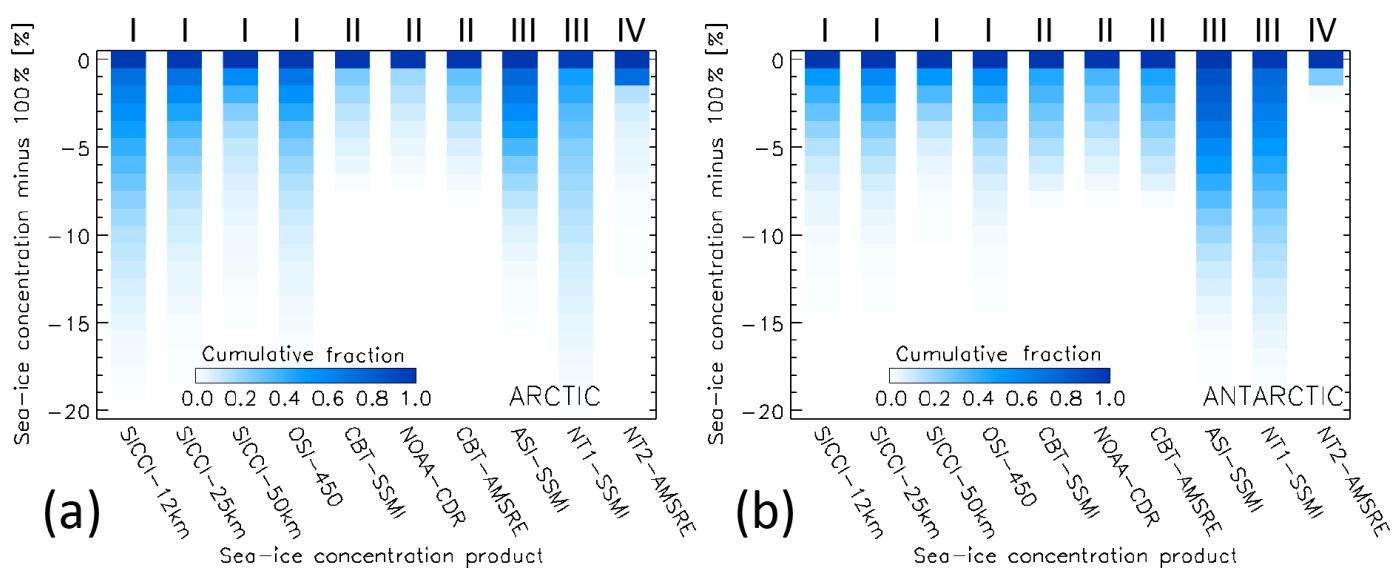

Figure 13. Cumulative distribution of the SIC difference to $100 \%$ at the near-100\% reference SIC locations for all 10 algorithms based on data of the years 2007 through 2011 for (a) the Arctic and (b) the Antarctic. Roman numbers at the top denote product groups (see Table 2).

\subsection{Arctic}

The distribution of the sea-ice concentration near $100 \%$ is shown for the Arctic for each product in Fig. 13a in the form of the cumulative fraction of the deviation (bias) from $100 \%$. As expected, the cumulative fraction increases towards 1.0 for all products. Considerable differences between the products are evident. Group I products (see Table 2) exhibit a cumulative fraction between $\sim 0.5$ and $\sim 0.7$ in bin $-1.5 \%$ $\ldots-0.5 \%$. Group II products and NT1-SSMI exhibit substantially lower fractions for this bin: between $\sim 0.2$ (NOAA CDR; see also $F_{99}$ in Fig. 3c) and $\sim 0.4$ (NT1-SSMI). Consequently, the change in cumulative fraction to the last bin is between 0.6 and 0.8 for group II and NT1-SSMI but only between 0.3 and 0.5 for group I. The respective $F_{99}$ values in Fig. 3 and Appendix $\mathrm{H}$ suggest that a large portion of the cumulative fraction in the last bin is in fact due to sea-ice concentrations $>100 \%$ being set to $100 \%$ (i.e. truncated). For NT2-AMSR-E, the cumulative fraction increases abruptly from $<0.1$ in bin $-2.5 \% \ldots-1.5 \%$ to $\sim 0.8$ in bin $-1.5 \% \ldots-0.5 \%$. This behaviour is completely different from all other products and confirms the results of Andersen et al. (2007) and Ivanova et al. (2015). For their inter-comparison of sea-ice concentration algorithms in the high Arctic, Andersen et al. (2007) extended the range within which the NT2 algorithm permits the retrieval of the sea-ice concentration to $120 \%$ in order to be able to properly compare all algorithms with respect to their precision close to $100 \%$. The original implementation of the NT2 algorithm is constrained to sea-ice concentrations up to $100 \%$. Ivanova et al. (2015) also aimed to compare the precision of several sea-ice concentration algorithms at $100 \%$ by means of computing the standard deviation of the sea-ice concentration at $100 \%$. They were, however, unable to obtain standard deviations with comparable statistics because of large positive biases for the NT2 and ASI algorithms and because of the truncation of sea-ice concentrations at $100 \%$. Only by construct- ing a reference sea-ice concentration of $75 \%$, were Ivanova et al. (2015) able to carry out a comparison of the sea-ice concentration standard deviation based on non-truncated sea-ice concentrations.

These cumulative distributions suggest that an intercomparison of the mean difference to $100 \%$, i.e. the bias, and its standard deviation, i.e. the precision, should be carried out by means of the Gaussian fit proposed in Sect. 2.1.4. Consequently, the mean sea-ice concentrations of the 10 products shown by the black symbols in Fig. 14a for the Arctic near-100\% reference sea-ice concentration locations are the modal values of the Gaussian fits. The error bars denote 1 standard deviation of this fit around the modal value. The blue symbols and error bars denote the respective mean and 1 standard deviation computed from the non-truncated group I sea-ice concentration products. All values shown here are summarized together with the results obtained from the truncated sea-ice concentration products in Table 3.

Figure 14a confirms our hypothesis that those products where the cumulative distributions seem to contain a large fraction of sea-ice concentrations larger than $100 \%$ set to $100 \%$ (Fig. 13a), i.e. the group II products, and NT1-SSMI are likely to overestimate the actual sea-ice concentration. The overestimation is particularly high for NOAA CDR with a modal sea-ice concentration of $\sim 103 \%$ (see also Table 3 ). The group I products exhibit modal sea-ice concentrations that are slightly below and closest to the near- $100 \%$ reference. The Gaussian fit also almost perfectly matches the actually observed non-truncated sea-ice concentration for SICCI$50 \mathrm{~km}$ in terms of the standard deviation (compare blue and black symbols in Fig. 14a and Table 3). The match is less accurate for OSI-450 and SICCI-25km.

In addition, Fig. 14a and Table 3 confirm our hypothesis that the group II products and NT1-SSMI are likely to have a standard deviation that is lowered by truncating sea-ice concentrations to a maximum of $100 \%$. This is illustrated by the standard deviations of the non-truncated and the truncated 
Table 3. Inter-comparison results to near-100\% SIC (RRDP2) for the Arctic (see Fig. 14a). The rows "Gaussian" show the mean difference of the modal value of Gaussian fit to satellite SIC $\leq 99 \%$ (compare Fig. 3) minus near-100\% reference SIC (RRDP2 SIC) \pm 1 sigma of the Gaussian fit (see Fig. 14a). The rows "Non-truncated" show the mean difference satellite SIC minus RRDP2 SIC \pm 1 standard deviation of the difference for SICCI and OSI-450 products. The rows "Truncated" show the mean difference of satellite SIC constrained to a maximum value of $100 \%$ minus RRDP2 SIC \pm 1 standard deviation of the difference. All values in these rows are given in percent sea-ice concentration. Values in rows denoting the periods 2007-2015 and 2007-2011 contain the number of valid data pairs. See text for meaning of * in the column "NT2-AMSR-E".

\begin{tabular}{|c|c|c|c|c|c|c|c|c|c|c|}
\hline Group & & 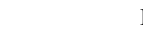 & & & & II & & & & IV \\
\hline $\mathrm{NH}$ & SICCI-12km & SICCI-25km & SICCI-50km & OSI-450 & CBT-SSMI & NOAA CDR & CBT-AMSR-E & ASI-SSMI & NT1-SSMI & NT2-AMSR-E \\
\hline 2007-2015 & 23262 & 23262 & 23262 & 23343 & 23343 & 23037 & - & 23343 & 23343 & - \\
\hline Gaussian & $-2.4 \pm 5.2$ & $-1.2 \pm 3.1$ & $-0.5 \pm 1.9$ & $-1.0 \pm 3.0$ & $+1.4 \pm 4.5$ & $+2.7 \pm 4.6$ & - & $-4.1 \pm 3.6$ & $+0.1 \pm 5.2$ & - \\
\hline Non-truncated & $-4.2 \pm 5.9$ & $-2.2 \pm 3.7$ & $-0.5 \pm 2.1$ & $-1.9 \pm 3.6$ & - & - & - & - & - & - \\
\hline Truncated & $-4.8 \pm 5.2$ & $-2.7 \pm 3.1$ & $-1.1 \pm 1.5$ & $-2.4 \pm 3.0$ & $-1.1 \pm 1.9$ & $-0.7 \pm 1.6$ & - & $-4.5 \pm 3.5$ & $-2.6 \pm 4.5$ & - \\
\hline 2007-2011 & 13351 & 13351 & 13351 & 13432 & 13432 & 13126 & 13344 & 13432 & 13432 & 13344 \\
\hline Gaussian & $-2.4 \pm 5.0$ & $-1.0 \pm 2.9$ & $-0.4 \pm 1.9$ & $-0.8 \pm 2.8$ & $+1.3 \pm 3.6$ & $+3.5 \pm 5.0$ & $+1.0 \pm 3.9$ & $-3.7 \pm 3.7$ & $+0.9 \pm 4.6$ & $-0.7 \pm 1.7^{*}$ \\
\hline Non-truncated & $-4.2 \pm 5.4$ & $-2.0 \pm 3.5$ & $-0.6 \pm 2.0$ & $-1.7 \pm 3.3$ & - & - & - & - & - & - \\
\hline Truncated & $-5.0 \pm 5.0$ & $-2.8 \pm 3.1$ & $-1.4 \pm 1.6$ & $-2.2 \pm 2.7$ & $-0.9 \pm 1.7$ & $-0.6 \pm 1.4$ & $-1.1 \pm 1.8$ & $-3.9 \pm 3.1$ & $-1.9 \pm 3.7$ & $-0.9 \pm 1.0$ \\
\hline
\end{tabular}

sea-ice concentration for group I products (Table 3). Under the assumption that the standard deviation of the Gaussian fit is a better measure of the spread in sea-ice concentrations near (but below) $100 \%$, we state that the CDRs of group I (SICCI-50km, OSI-450, and SICCI-25km) allow a better precision than group II products. We also confirm the findings of Lavergne et al. (2019) that the group I products are slightly - but significantly - biased low.

For ASI-SSMI and NT2-AMSR-E, the application of a Gaussian fit is potentially not justified given the way sea-ice concentrations are retrieved. ASI-SSMI is non-linear near $100 \%$ (Kaleschke et al., 2001) while no statement about the functional relationship of the input satellite data and the retrieved sea-ice concentrations can be made for NT2-AMSRE (Markus and Cavalieri, 2000; Brucker et al., 2014). Our analysis, however, results in a reasonable Gaussian fit for ASI-SSMI (see Appendix H, Fig. H1a). We are confident therefore that the values taken from the fit and shown in Fig. 14a and Table 3 can be used. In contrast, the NT2AMSR-E sea-ice concentration distribution does not allow reasonable application of a Gaussian fit (see Appendix H, Fig. H1j) and we do not report it along with the others in Fig. 14a. We note that Andersen et al. (2007) reported a mean NT2 sea-ice concentration of $\sim 105 \%$ with a standard deviation of $\sim 5 \%$ at near- $100 \%$ sea-ice concentrations for their unconstrained version of this algorithm.

\subsection{Antarctic}

For the Antarctic (Fig. 13b), we find more similarities in the cumulative fractions of the deviation (bias) from $100 \%$ than for the Arctic. Common to all products, except NT2-AMSR$\mathrm{E}$ and ASI-SSMI, is a notable step change in the cumulative fraction between bin $-1.5 \% \ldots-0.5 \%$ and the last bin. This step change is least pronounced for NT1-SSMI and most pronounced for NOAA CDR, exhibiting cumulative fractions of $\sim 0.8$ and $\sim 0.4$, respectively, in the last bin. Step changes are slightly larger for the two CBT products than for group I products (see also $F_{99}$ values in Fig. $3 d$, e). For ASI-SSMI the cumulative fraction levels off before the last bins (see also the $F_{99}$ value in Appendix H, Fig. H2a). A total of $93 \%$ of the ASI-SSMI sea-ice concentrations at the near-100\% reference sea-ice concentration locations are below $99.5 \%$. The distribution for NT2-AMSR-E is extremely narrow. About $75 \%$ of the NT2-AMSR-E sea-ice concentrations at the near- $100 \%$ reference sea-ice concentration locations are above $99.5 \%$. This behaviour is, like for the Arctic, completely different from all other products and agrees with the findings of Ivanova et al. (2015); see also our discussion in Sect. 4.1.

Group I and II products provide a modal sea-ice concentration which deviates by less than $\sim 1 \%$ from $100 \%$ (Fig. 14b, Table 4). While group II products tend to exhibit a modal sea-ice concentration $>100 \%$, group I products exhibit modal sea-ice concentrations $<100 \%$. Modal sea-ice concentrations obtained with the Gaussian fit agree within $0.5 \%$ with the actually measured mean sea-ice concentration derived from the non-truncated values of group I products (compare black and blue symbols in Fig. 14b). Respective standard deviations match better in the Antarctic than the Arctic and are systematically smaller for the truncated than the non-truncated results (compare black and blue bars in Fig. 14a and b as well as Tables 3 and 4). For group II products, using the Gaussian fit method suggests standard deviations between $\sim 4.5 \%$ and $\sim 5.5 \%$ while using the truncated values results in a standard deviation between $2.0 \%$ and $2.5 \%$. Following our assumption in Sect. 4.1, we state a better precision for group I products (SICCI-50km, SICCI$25 \mathrm{~km}$, and OSI-450) than group II products. Similarly but to a lesser extent than in the Arctic, group I products are slightly biased low with respect to the validation data set. 

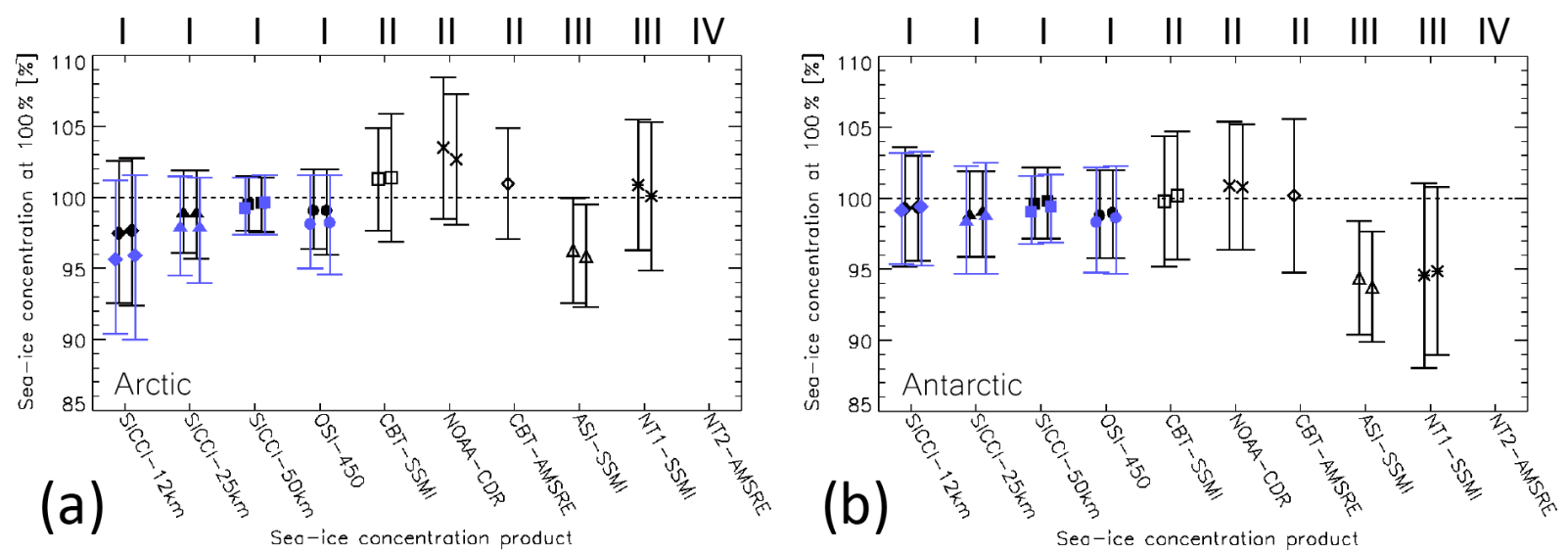

Figure 14. Summary of the results of the inter-comparison to the near-100\% reference SIC (RRDP2) for (a) the Arctic and (b) the Antarctic. Shown for each sea-ice concentration product in black is the centre of the Gaussian fit of the sea-ice concentration $\leq 99 \%$ at the respective RRDP2 locations (see Fig. 4). Bars denote \pm 1 standard deviation of the Gaussian fit. For symbol pairs (all products but CBT-AMSR-E and NT2-AMSR-E) the left symbol is based on data of the years 2007-2011 and the right one on data of the years 2007-2015. Blue symbols denote the mean non-truncated sea-ice concentration at the near-100\% reference SIC for OSI-450 and SICCI products; blue bars denote the respective sea-ice concentration standard deviation. Roman numbers at the top denote product groups (see Table 2). No values are shown for NT2-AMSR-E because a Gaussian fit could not be adequately applied.

Table 4. As Table 3 but for the Antarctic (see Fig. 14b).

\begin{tabular}{|c|c|c|c|c|c|c|c|c|c|c|}
\hline \multirow{2}{*}{$\begin{array}{l}\text { Group } \\
\mathrm{SH}\end{array}$} & \multicolumn{4}{|c|}{ I } & \multicolumn{3}{|c|}{ II } & \multicolumn{2}{|c|}{ III } & \multirow{2}{*}{$\frac{\text { IV }}{\text { NT2-AMSR-E }}$} \\
\hline & SICCI-12km & SICCI-25km & SICCI-50km & OSI-450 & CBT-SSMI & NOAA CDR & CBT-AMSR-E & ASI-SSMI & NT1-SSMI & \\
\hline 2007-2015 & 6397 & 6397 & 6397 & 6449 & 6449 & 6430 & - & 6449 & 6449 & - \\
\hline Gaussian & $-0.7 \pm 3.7$ & $-1.1 \pm 3.0$ & $-0.3 \pm 2.5$ & $-1.1 \pm 3.1$ & $+0.2 \pm 4.5$ & $+0.8 \pm 4.4$ & & $-6.2 \pm 3.9$ & $-5.1 \pm 5.9$ & \\
\hline Non-truncated & $-0.7 \pm 4.0$ & $-1.4 \pm 4.0$ & $-0.7 \pm 2.4$ & $-1.5 \pm 3.8$ & - & - & - & - & - & - \\
\hline Truncated & $-1.9 \pm 2.9$ & $-2.3 \pm 3.0$ & $-1.3 \pm 1.7$ & $-2.3 \pm 2.9$ & $-1.7 \pm 2.4$ & $-1.3 \pm 2.1$ & - & $-6.5 \pm 4.0$ & $-6.0 \pm 5.5$ & - \\
\hline 2007-2011 & 5896 & 5896 & 5896 & 5896 & 5896 & 5877 & 5896 & 5896 & 5896 & 5896 \\
\hline Gaussian & $-0.6 \pm 4.2$ & $-1.1 \pm 3.0$ & $-0.3 \pm 2.5$ & $-1.1 \pm 3.1$ & $-0.2 \pm 4.6$ & $+0.9 \pm 4.5$ & $+0.2 \pm 5.4$ & $-5.6 \pm 4.0$ & $-5.4 \pm 6.5$ & $-0.2 \pm 3.2^{*}$ \\
\hline Non-truncated & $-0.7 \pm 3.9$ & $-1.5 \pm 3.8$ & $-0.8 \pm 2.4$ & $-1.5 \pm 3.7$ & - & - & - & - & - & - \\
\hline Truncated & $-2.1 \pm 2.9$ & $-2.6 \pm 3.1$ & $-1.6 \pm 1.9$ & $-2.2 \pm 2.8$ & $-1.7 \pm 2.4$ & $-1.3 \pm 2.1$ & $-1.8 \pm 2.5$ & $-6.4 \pm 4.0$ & $-5.8 \pm 5.5$ & $-0.3 \pm 0.5$ \\
\hline
\end{tabular}

\subsection{Summary and discussion of the evaluation near $100 \%$}

In near- $100 \%$ sea-ice concentration conditions, most retrieval algorithms will naturally retrieve some distribution of values around $100 \%$ sea-ice concentration, i.e. also values $>100 \%$. However, these values are almost never accessible to the user and thus generally not accessible for validation. Here, we used the availability of these "off-range" estimates in the group I products to demonstrate how the entire distribution around $100 \%$ can effectively be reconstructed a posteriori from the products with truncated sea-ice concentration distributions (Fig. 3, Appendix H). This Gaussian fit methodology allows us to go deeper in the analysis of near$100 \%$ conditions. Indeed, if the analysis had been limited to the truncated distributions only (Fig. 13), algorithms that overestimate sea-ice concentration (modal value of the nontruncated distribution larger than $100 \%$ ) would obtain better validation statistics (smaller bias and RMSE) than products without such overestimation. The larger the overestimation, the better the statistics would be. Using the Gaussian fit, we unveil a possible overestimation of several sea-ice concentration products, including NT1-SSMI, CBT-SSMI, and NOAA CDR in the Arctic and NOAA CDR (but only slightly) in the Antarctic. This Gaussian fit methodology also confirms that group I products are slightly low biased in the Arctic (see Lavergne et al., 2019). We find the worst of these biases in the Arctic for SICCI-12km, which was not openly distributed at the end of the ESA CCI Sea Ice Phase 2 project, partly based on these results.

Our results suggest that group I products, i.e. the three CDRs OSI-450, SICCI-25km, and SICCI-50km, are more accurate and have a higher precision than the fourth CDR investigated: NOAA CDR; this applies to both hemispheres. Group I products can be regarded as being superior, in terms of the precision and accuracy, to NT1-SSMI and CBT-SSMI as well. Our results furthermore confirm earlier work (Andersen et al., 2007; Ivanova et al., 2015) that the accuracy of NT2 algorithm products near $100 \%$ cannot be quantitatively assessed. We hypothesize that this is merely caused by the fact that sea-ice concentrations are constrained to a maximum of $100 \%$ by the algorithm concept. This is fundamentally different from the other nine products investi- 
gated. In the iterative retrieval used in the NT2 algorithm, sea-ice concentrations are only allowed to converge at $100 \%$ from one side, i.e. $<100 \%-$ in contrast to other iterative algorithms such as the polynya signature simulation method (PSSM) (Markus and Burns, 1995). Another element of the NT2 algorithm, which complicates quantitative assessment of the accuracy near $100 \%$ sea-ice concentration, is the usage of model atmospheres to create lookup tables from which the sea-ice concentration is retrieved. This approach likely reduces the natural variability of the obtained sea-ice concentration. We refer to Brucker et al. (2014) for more details of NT2 algorithm sea-ice concentration uncertainty.

The results of the comparison in Sect. 4.1 and 4.2 are based on winter data (see Sect. 2.2). But also during winter temperatures can get close to $0^{\circ} \mathrm{C}$, influencing the brightness temperatures used to compute the sea-ice concentration and questioning the assumption of freezing conditions for generation of the near- $100 \%$ reference sea-ice concentration data set. By using the co-located air temperature from ERAInterim reanalysis data included in the RRDP2 data set (Pedersen et al., 2019), we repeated the analyses for cold cases, i.e. air temperatures below $-10^{\circ} \mathrm{C}$. We find that biases between satellite and reference sea-ice concentrations change by less than $0.1 \%$ for all products except NT1-SSMI. For NT1-SSMI constraining the analyses to cold cases yields a bias reduction by $\sim 0.4 \%$ for the Arctic and $\sim 0.7 \%$ for the Antarctic, indicating that this particular algorithm is more sensitive than others to variability of air temperature.

\section{Comparison with ship-based visual sea-ice cover observations}

In this section, we present the results of the evaluation of the 10 products at intermediate sea-ice concentrations by means of an inter-comparison to the visual ship-based observations described in Sect. 2.3. Upfront we note the limitations of the manual ship-based visual sea-ice cover observations used here. They were collected by a myriad of different observers with different levels of experience for this task. For an untrained observer it is relatively straightforward to estimate the total sea-ice concentration for closed ice conditions, i.e. $>80 \%$, or very open ice conditions, i.e. $<30 \%$. It is more difficult, however, to estimate whether sea ice covers $40 \%$ or $50 \%$ of the $1 \mathrm{~km}$ radius area around the ship. Therefore, we can expect a reduced accuracy for ship observations of the intermediate sea-ice concentration range from $\sim 30 \%$ to $\sim 80 \%$. At the same time, this is possibly the sea-ice concentration range where the different spatial scales of the two kinds of observations compared here have the largest impact on the results. Note that Worby and Comiso (2004) reported an uncertainty estimate between $5 \%$ and $10 \%$ for the total sea-ice concentration based on observations of the same scene by different observers. To the best knowledge of the authors, papers about a better quantification of the accuracy of these observations have not yet been published.

In addition, ship observations were collected under different weather and daylight conditions as well as during ship transits with different speeds. The first two points influence the visibility and change the visual appearance of sea ice and openings and can result in a larger spread of an observed sea-ice concentration value around the actual value. Different weather conditions also have an influence on the size of the area actually observed around the ship that is difficult to quantify. This observation area is supposed to be of a $1 \mathrm{~km}$ radius, but it can be assumed that it is smaller in the case of poor-visibility conditions than it is in case of clear-sky, goodvisibility conditions; visibility is not regularly reported along with the ice observations. A single observation of the sea-ice conditions takes a certain amount of time, which is a function of the experience of the observer. The observation area around the ship's track represented by a single observation is hence a function of the ships' speed and of the experience of the observer. As long as ice conditions do not change for a few kilometres this does not matter, but in highly heterogeneous ice conditions, this can be important. Therefore, there is a variable representativity of the observed sea-ice conditions around and along the ship's track (see Sect. 6.1.4).

Ships often tend to avoid thick and deformed sea ice and ship-track forecasts are often optimized accordingly (e.g. Pizzolato et al., 2016; Kuuliala et al., 2017). Ship-based observations therefore often represent the thinner ice categories and/or conditions encountered in leads or openings. These are frozen over with sea ice in winter but are open water in summer. Therefore, particularly during summer or episodes of warmer weather, the sea-ice concentrations from the small-scale ship-based observations are likely lower than from the larger-scale satellite microwave radiometry. According to Ivanova et al. (2015), microwave radiometry tends to underestimate sea-ice concentrations over very thin $(<15 \mathrm{~cm})$ ice. This suggests that during winter, sea-ice concentrations from ship-based observations could be, contrary to summer, slightly higher than from satellite microwave radiometry.

A systematic quantification of the uncertainty in shipbased sea-ice observations has not been carried out yet and is beyond our scope. Even though we do not use single shipbased observations but follow Beitsch et al. (2015) and average over all ship-based sea-ice observations along the ship's track of $1 \mathrm{~d}$, discarding days with less than three observations (see Sect. 2.3), we cannot rule out that some of these daily average observations are biased because of the reasons discussed above.

\subsection{Arctic}

Overall, for the Arctic, all 10 products compare reasonably well to the ship-based observations (Fig. 15, Table 5). At high concentrations $(>\sim 80 \%)$, group I products and ASI- 

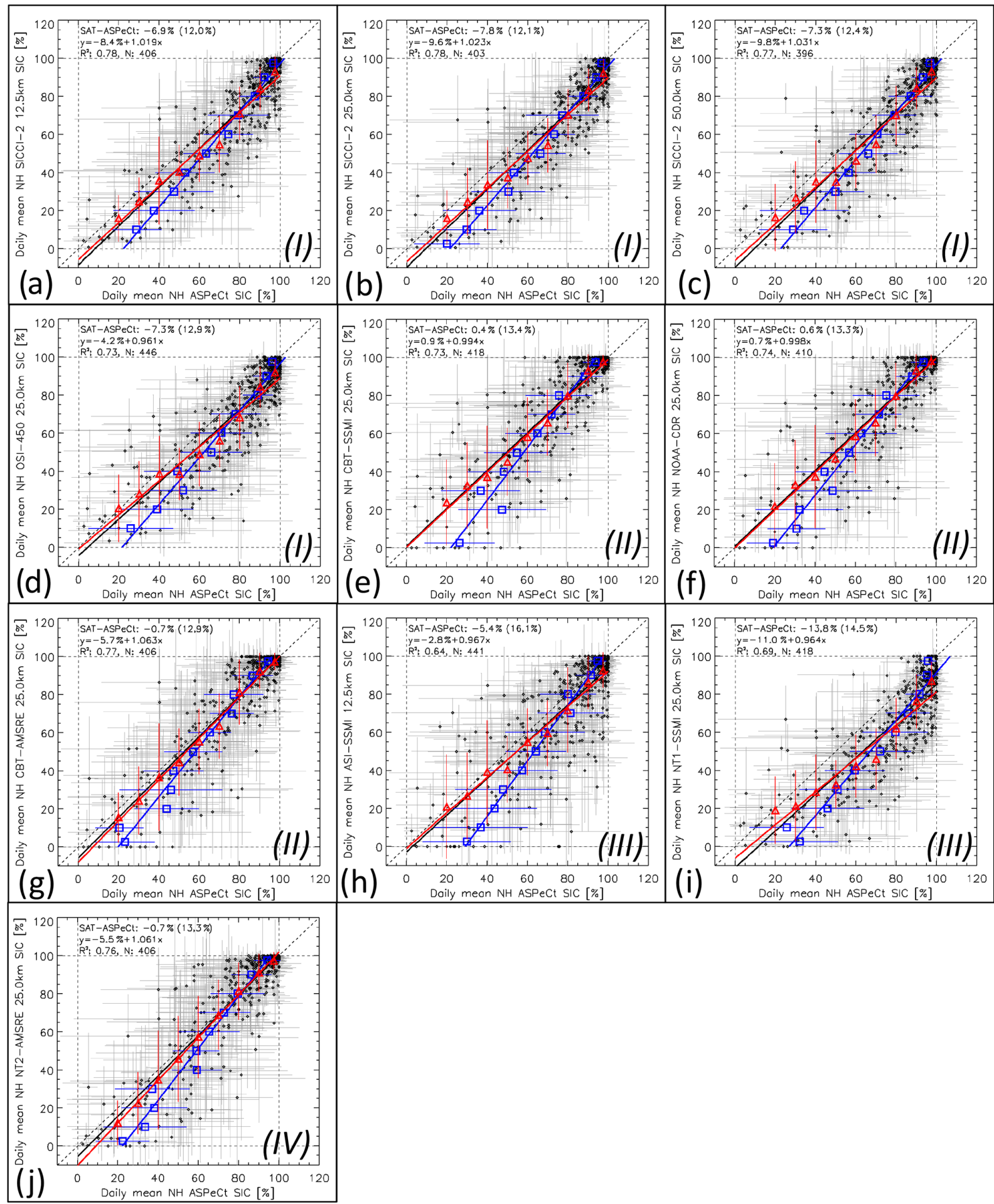

Figure 15. Scatterplots of co-located daily average SIC from visual ship-based observations (ASPeCt, $x$ axis; note that these are Ice Watch/ASSIST for the Arctic) and the 10 satellite SIC algorithm products (SAT, $y$ axes) for the Arctic during the years 2002-2011. Red symbols denote the average satellite SIC binned into $10 \%$ ASPeCt SIC intervals (except $0 \% \ldots 5 \%$ and $95 \% \ldots 100 \%$, where $5 \%$ bins are used). Blue symbols denote the average ASPeCt SIC binned into $10 \%$ satellite SIC intervals. Error bars denote 1 standard deviation of the average. Dotted lines denote the identity line. Solid lines denote the linear regression of the respective value pairs. The mean difference and the standard deviation, the linear regression equation, the number of valid data pairs $(N)$, and the squared linear correlation coefficient $\left(R^{2}\right)$ are given in the top left of every image for the daily SIC values. Roman numbers I-IV denote the group assigned to the respective algorithm (see text for details). 
Table 5. Summary of the statistics of the comparison between daily mean ship-based and satellite SIC data (see Fig. 15, black symbols) for - from top to bottom - the entire year, only winter and only summer. DIFF is the mean difference satellite minus ship-based SIC, and SD is the respective standard deviation; $R^{2}$ is the squared linear correlation coefficient. All concentration values are given in percent.

\begin{tabular}{|c|c|c|c|c|c|c|c|c|c|c|}
\hline \multirow{2}{*}{$\begin{array}{l}\text { Group } \\
\text { All year }\end{array}$} & \multicolumn{4}{|c|}{ I } & \multicolumn{3}{|c|}{ II } & \multicolumn{2}{|c|}{ III } & \multirow{2}{*}{$\frac{\text { IV }}{\text { NT2-AMSR-E }}$} \\
\hline & SICCI-12km & SICCI-25km & SICCI-50km & OSI-450 & CBT-SSMI & NOAA CDR & CBT-AMSR-E & ASI-SSMI & NT1-SSMI & \\
\hline DIFF & -6.9 & -7.8 & -7.3 & -7.3 & +0.4 & +0.6 & -0.7 & -5.4 & -13.8 & -0.7 \\
\hline $\mathrm{SD}$ & 12.0 & 12.1 & 12.4 & 12.9 & 13.4 & 13.3 & 12.9 & 16.1 & 14.5 & 13.3 \\
\hline$R^{2}$ & 0.784 & 0.781 & 0.775 & 0.734 & 0.737 & 0.745 & 0.778 & 0.647 & 0.693 & 0.767 \\
\hline \multicolumn{11}{|l|}{ Winter } \\
\hline DIFF & -7.4 & -7.4 & -6.2 & -7.4 & $<|0.1|$ & -0.2 & -1.5 & -8.6 & -14.2 & -0.3 \\
\hline SD & 12.6 & 11.8 & 11.8 & 12.8 & 10.9 & 11.6 & 12.6 & 17.4 & 13.8 & 11.5 \\
\hline$R^{2}$ & 0.558 & 0.594 & 0.606 & 0.591 & 0.595 & 0.587 & 0.551 & 0.429 & 0.507 & 0.595 \\
\hline \multicolumn{11}{|l|}{ Summer } \\
\hline DIFF & -6.7 & -8.0 & -7.9 & -7.3 & +0.7 & +0.9 & -0.3 & -3.7 & -13.6 & -0.9 \\
\hline SD & 11.7 & 12.3 & 12.7 & 12.9 & 14.5 & 14.0 & 13.1 & 15.1 & 14.9 & 14.1 \\
\hline$R^{2}$ & 0.814 & 0.793 & 0.780 & 0.754 & 0.734 & 0.750 & 0.806 & 0.722 & 0.702 & 0.771 \\
\hline
\end{tabular}

SSMI (Fig. 15a-d, h) exhibit the most symmetric distributions around the identity line. NT1-SSMI (Fig. 15i) shows an asymmetric distribution with a considerable fraction of satellite sea-ice concentrations even below $60 \%$, translating into a difference between satellite- and ship-based seaice concentrations of up to $40 \%$. Group II and IV products (Fig. 15e-g, j) show an asymmetric distribution with more high satellite-based than high ship-based sea-ice concentrations. Most products have more data pairs below the identity line; i.e. satellite-based are smaller than ship-based sea-ice concentrations as illustrated by a negative overall bias and regression lines located below the identity line for six of the 10 products (Table 5). Group II and IV products provide the smallest absolute overall bias of $<1 \%$. Biases are larger for group I, but at the same time the standard deviation of the difference (SD) is smallest for group I products. The highest correlations are obtained for CBT-AMSR-E and group I products, except OSI-450. We find the best linear fits, i.e. slopes closest to the identity line, however, for CBT-SSMI and NOAA CDR.

How do results of the entire year compare to those obtained separately for winter or summer months (see Fig. 5 for differences in the location of the ship-based observations)? For all products, the correlation is lower in winter than summer and the entire year. This can be explained by fewer observations during winter in general and by substantially fewer low sea-ice concentrations; most observations during winter are $>75 \%$. Except for ASI-SSMI, the differences in the bias between summer, winter, and the entire year are small (mostly $<1 \%$ ). All products except SICCI- $12 \mathrm{~km}$ and ASI-SSMI provide a lower SD in winter than summer. Compared to the other groups, group I exhibits the smallest SD in summer while group II does so in winter. OSI-450 stands out with the smallest inter-seasonal change in bias and SD of only $\sim 0.1 \%$ (Table 5; see also Sect. 6.1.4).

We want to better visualize the average distribution of the two data sets and investigate the partitioning of the data into sea-ice concentration bins of $10 \%$ width - the average accuracy of the ship-based sea-ice concentration observations. For this purpose we bin sea-ice concentrations of one data set, e.g. ship observations, into $10 \%$ wide bins and compute the mean sea-ice concentration of the other data set (Fig. 15, red symbols) and vice versa (blue symbols). The binned values and associated regression lines illustrate even better the above-mentioned asymmetry in the distribution of the data pairs. For instance, NT1-SSMI (Fig. 15i) sea-ice concentration range between $60 \%$ and $100 \%$ over a ship-based observations range of $80 \%$ to $100 \%$. Consequently, the average NT1-SSMI sea-ice concentration for the ship observation bin $95 \%-100 \%$ is $\sim 85 \%$ (uppermost red triangle), while the average ship-based sea-ice concentration for the NT1SSMI bin $95 \%-100 \%$ is $~ 95 \%$ (uppermost blue square). For two equally well-distributed data sets, one would expect that red and blue symbols and regression lines are close to each other. This is not the case and we refer to Sect. 6.1.4 for more discussion of this issue.

\subsection{Antarctic}

The scatterplots of the daily average along-track mean seaice concentrations for the Antarctic (Fig. 16) reveal, for seaice concentrations $>\sim 80 \%$, mostly symmetric distributions for seven of the 10 products. NT1-SSMI (Fig. 16i) has considerably more low than high sea-ice concentration values (compare Fig. 15i). NT2-AMSR-E (Fig. 16j) has almost no data points below the identity line at $>\sim 80 \%$ with data pairs concentrated at $100 \%$ satellite sea-ice concentration. A considerable drop in the count of data values above the identity line at lower concentrations results in a highly asymmetric distribution at concentrations below $\sim 50 \%$. Group II products have the lowest overall biases (Table 6) but slopes of the linear regression are considerably steeper than the identity line (Fig. 16e-g) in contrast to group III products (Fig. 16h, i) and OSI-450 (Fig. 16d). We find the largest bias for NT1- 


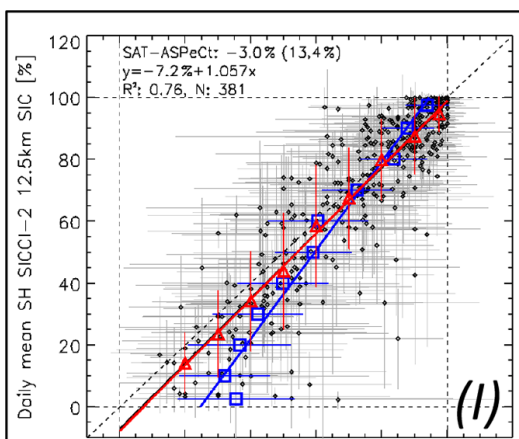

(a) $\begin{array}{cccccc}20 & 40 & 60 & 80 & 100 & 120 \\ \text { Doily mean SH ASPeCt SIC [\%] }\end{array}$
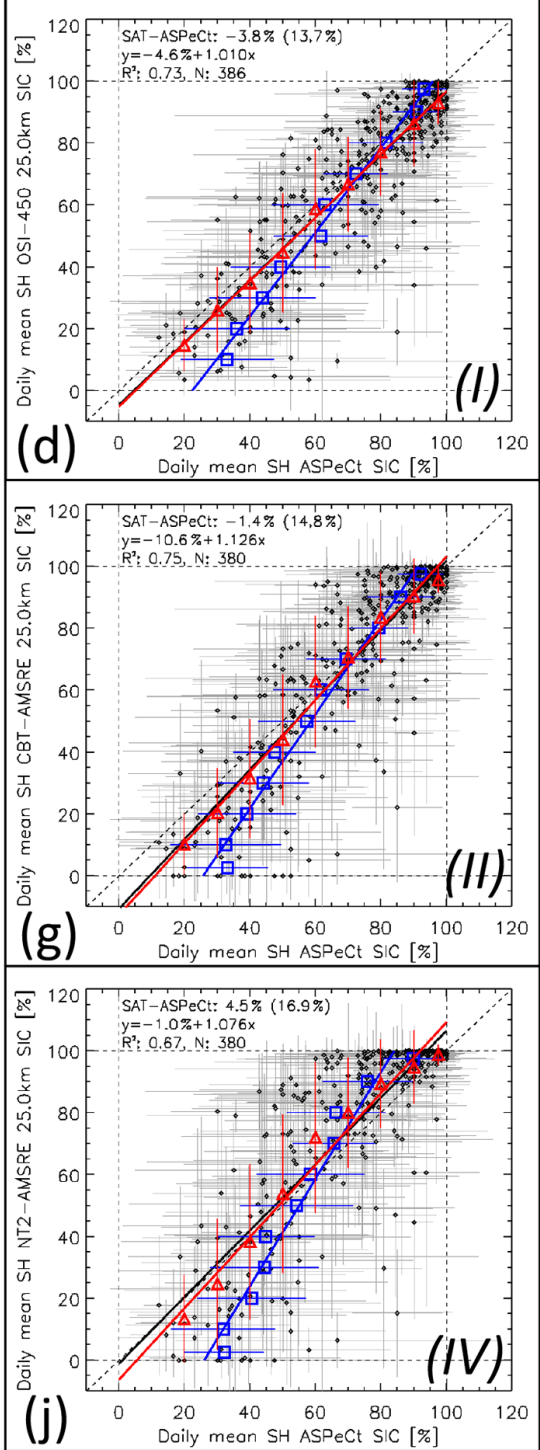

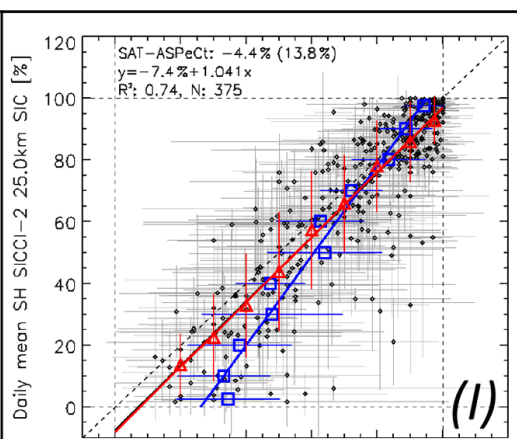

(b) $\begin{array}{lllll}20 & 40 & 60 & 80 & 100 \\ \text { Doily mean SH ASPeCt SIC [\%] }\end{array}$
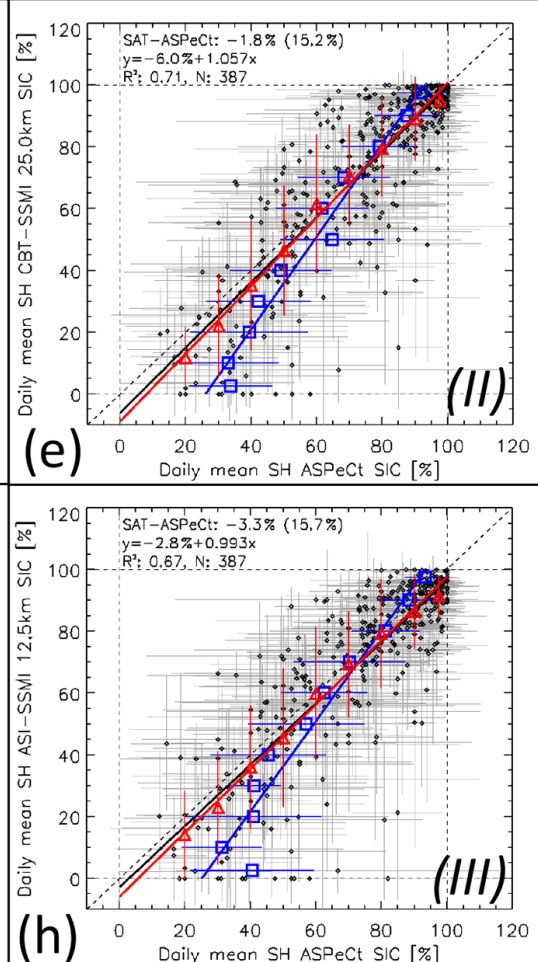
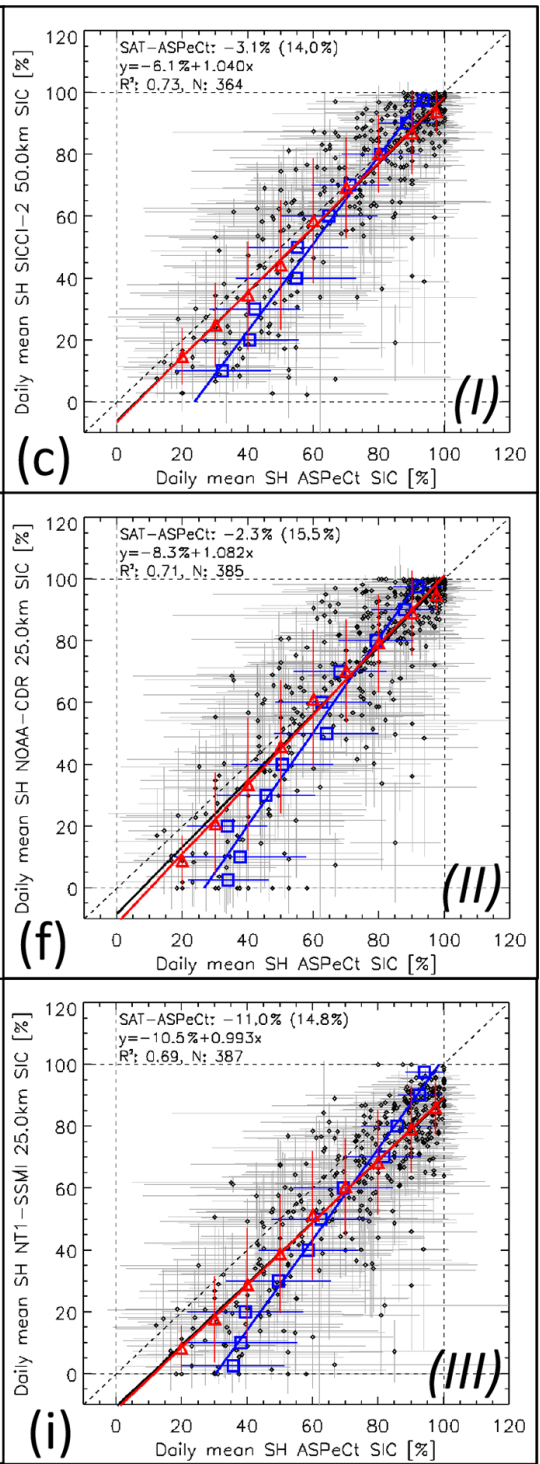
Table 6. As Table 5 but for the Antarctic (see Fig. 16, black symbols).

\begin{tabular}{|c|c|c|c|c|c|c|c|c|c|c|}
\hline \multirow{2}{*}{$\begin{array}{l}\text { Group } \\
\text { All year }\end{array}$} & \multicolumn{4}{|c|}{ I } & \multicolumn{3}{|c|}{ II } & \multicolumn{2}{|c|}{ III } & \multirow{2}{*}{$\frac{\text { IV }}{\text { NT2-AMSR-E }}$} \\
\hline & SICCI-12km & SICCI-25km & SICCI-50km & OSI-450 & CBT-SSMI & NOAA CDR & CBT-AMSR-E & ASI-SSMI & NT1-SSMI & \\
\hline DIFF & -3.0 & -4.4 & -3.1 & -3.8 & -1.8 & -2.3 & -1.4 & -3.3 & -11.0 & +4.5 \\
\hline SD & 13.4 & 13.8 & 14.0 & 13.7 & 15.2 & 15.5 & 14.8 & 15.7 & 14.8 & 16.9 \\
\hline$R^{2}$ & 0.763 & 0.745 & 0.737 & 0.733 & 0.711 & 0.716 & 0.755 & 0.671 & 0.698 & 0.679 \\
\hline \multicolumn{11}{|l|}{ Winter } \\
\hline DIFF & -1.6 & -2.7 & -2.6 & -3.2 & -1.6 & -2.0 & +0.2 & -3.6 & -11.6 & +3.8 \\
\hline SD & 9.8 & 9.6 & 10.5 & 10.5 & 10.7 & 11.0 & 9.5 & 10.6 & 11.7 & 10.7 \\
\hline$R^{2}$ & 0.771 & 0.771 & 0.741 & 0.731 & 0.748 & 0.751 & 0.753 & 0.659 & 0.700 & 0.732 \\
\hline \multicolumn{11}{|l|}{ Summer } \\
\hline DIFF & -3.9 & -5.6 & -3.4 & -4.2 & -2.0 & -2.5 & -2.5 & -3.1 & -10.6 & +5.0 \\
\hline SD & 15.3 & 16.1 & 16.0 & 15.6 & 17.7 & 17.9 & 17.4 & 18.4 & 16.6 & 20.0 \\
\hline$R^{2}$ & 0.698 & 0.666 & 0.675 & 0.667 & 0.643 & 0.651 & 0.693 & 0.614 & 0.640 & 0.621 \\
\hline
\end{tabular}

SSMI: $-11.0 \%$. NT2-AMSR-E shows a considerable positive bias: $+4.5 \%$. We find highest correlations between shipand satellite-based observations for group I products and CBT-AMSR-E, the lowest SD values for group I products as well.

In contrast to the Arctic, correlations between ship- and satellite-based sea-ice concentrations are smaller in summer than winter when correlations are even higher than for the entire year for most products (Table 6). For all products, except group III, biases are smaller in winter than summer by mostly $<2 \%$. NT2-AMSR-E is the only product with a positive bias in both seasons. We find the largest inter-seasonal bias change for CBT-AMSR-E (2.7\%) and SICCI-25km (2.9\%) and the smallest for CBT-SSMI $(0.4 \%)$. For all products, the SD is smaller by $3 \%-5 \%$ (larger by $2 \%-3 \%$ ) compared to the entire year in winter (in summer). Inter-seasonal SD changes are hence considerably larger in the Antarctic than in the Arctic (compare Tables 5 and 6).

Binning the sea-ice concentrations like described in Sect. 5.1 (red and blue symbols in Fig. 16) leads to the following main observations. (1) All products - except NT1SSMI and NT2-AMSR-E - have the best agreement with ship-based observations in the sea-ice concentration range from $60 \%$ to $80 \%$. (2) All products underestimate shipbased sea-ice concentrations for concentrations $<\sim 50 \%$. (3) The negative bias of $\sim 10 \%$ observed for NT1-SSMI applies to the entire sea-ice concentration range. (4) NT2AMSR-E is the only product overestimating ship-based seaice concentrations considerably; this overestimation reaches $10 \%$ for the range $60 \%-80 \%$. Apart from that, we find, like for the Arctic, that blue regression lines exhibit a considerably steeper slope than the red ones, suggesting that in the Antarctic the distribution of the data over the range 0-100\% is also asymmetric (see Sect. 6.1.4).

\subsection{Summary and discussion of comparison against ship-based observations}

Group II products provide the smallest overall difference from the ship-based observations: around $0 \%$ (Arctic) and around $-2 \%$ (Antarctic). Group I products provide differences around $-7.5 \%$ (Arctic) and $-3.5 \%$ (Antarctic). Group I and II products share similar average correlations $\left(R^{2}\right)$ in the Arctic, 0.77 and 0.76, and in the Antarctic, 0.74 and 0.72 . Standard deviations for group I products are smaller - by $1 \%$ in the Arctic and by $2 \%$ in the Antarctic - than for group II products. On average, these results are more accurate than those obtained for group III and IV products. We refrain from giving a ranking or recommendation as to which product is the best when compared to ship-based observations.

We find the lowest correlation for ASI-SSMI (group III) in both hemispheres. However, it is the product with the largest improvement in the inter-comparison results between winter and summer in the Arctic: correlation increases and difference and standard deviation decrease. This could be attributed to the higher fraction of intermediate sea-ice concentrations during summer for which the comparably fine grid resolution of $12.5 \mathrm{~km}$ of the ASI-SSMI product could be advantageous. There is evidence that this behaviour is coupled to the usage of the near- $90 \mathrm{GHz}$ channels because we observed a similar, albeit less pronounced, behaviour for SICCI- $12 \mathrm{~km}$, which also employs near- $90 \mathrm{GHz}$ data and is provided at $12.5 \mathrm{~km}$ grid resolution (Table 2). Because in the Antarctic the sea-ice cover is more open year-round, it is plausible that we did not find similar behaviour there for these two products.

There are a few points to discuss. First of all, Figs. 15 and 16 reveal quite a high relative occurrence of sea-ice concentrations in the range from $95 \%$ to $100 \%$. This might have biased our results. We therefore repeated our comparison by discarding all data pairs with daily mean sea-ice concentrations $\geq 95 \%$. The main results (not shown) are an overall increase in the differences by about $2 \%$ and in the standard 
deviations by $\sim 1 \%$ (group I) and $2 \%-3 \%$ (group II) and a reduction of the correlation by $\sim 0.08$. Ranking between groups is otherwise not changed. Secondly, the results obtained for group I products are based on the truncated sea-ice concentrations. Using the non-truncated data does not considerably change our findings (not shown). Differences between satellite-based and ship-based sea-ice concentrations decrease by between $0 \%$ and $0.3 \%$ with a concomitant increase in the standard deviation of up to $0.2 \%$; this applies primarily to winter when the fraction of near- $100 \%$ seaice concentrations is large. Thirdly, application of the Gaussian fit method (see Sects. 2.1.4 and 6.1.3) seems inappropriate given the sea-ice concentration range considered in this inter-comparison. Even if it were, we can assume that differences and standard deviations obtained for the other products would change by less than $1 \%$. All these changes would be small compared to the accuracy of the ship-based sea-ice concentrations (see Sect. 2.3, beginning of Sects. 5, and 6.1.4).

In Figs. 15 and 16, several of the products exhibit points along the $y=0 \%$ sea-ice concentration line, i.e. conditions where sea ice is reported by the ship while the satellite estimates exactly $0 \%$. This applies mostly to group II products and ASI-SSMI (Fig. 15e-h). These points with zero daily mean sea-ice concentration are very likely the result of the weather filters applied (Sect. 2.1.3), which, in addition to removing false sea ice caused by atmospheric effects, also remove true sea ice (Ivanova et al., 2015; Lavergne et al., 2019). The combination of explicit atmospheric correction and dynamic tuning of the weather filter in group I products seems to reduce the occurrence of such cases notably (Figs. 15a-d; 16a-d).

\section{Discussion and conclusions}

\subsection{Discussion}

\subsubsection{Observed differences in sea-ice area and extent}

Time series of SIA and SIE have long been used to derive conclusions about the past development of the sea-ice cover and to even extrapolate its future development. In order to do so, such time series need to be sufficiently long, consistent and accurate. A long, consistent time series is typically obtained using a fundamental climate data record of brightness temperatures as input for the retrieval, as is done for group I product OSI-450, to ensure that inter-sensor differences are as small as possible. Our paper suggests that additional steps might be required, for instance dynamic retrieval of tie points and dynamic adaptation of weather filters (see Sect. 6.1.2), to reach the goal of a long-term consistent sea-ice concentration data set to be used to compute long-term consistent time series of SIA and SIE.
Meier and Steward (2019) suggested a method to obtain an estimate of SIE and NSIDC sea-ice index accuracy, which they found to be $\sim 50000 \mathrm{~km}^{2}$ under certain circumstances for the Arctic. They also pointed out, however, that there is a clear bias (or spread) of $500000 \mathrm{~km}^{2}$ to 1 million $\mathrm{km}^{2}$ between SIE estimates from different products (see also Ivanova et al., 2014). Therefore, as long as one does not know which product provides the best representation of the actual sea-ice cover, one is left alone with a relatively precise estimate of the SIE, which might be biased, however, by an amount an order of magnitude larger. Notz (2014) found that the SIE and its trend provide a limited metric for the performance of numerical models. Petty et al. (2018) suggested that predictions of the September Arctic sea-ice minimum in area and extent would benefit from giving more weight to SIA. Niederdrenk and Notz (2018) concluded that observational uncertainty is the main source of uncertainty for estimating at which level of global warming the Arctic will lose its summer sea-ice cover. In the light of these findings, the inter-product differences in SIA and SIE resulting from our study provide useful information about which algorithm or group of algorithms is particularly well suited for investigations of SIA and SIE in just one hemisphere year-round or for an individual season. Because we were able to estimate the effect of the mismatch between true and grid resolution and of the interpolation across the observation gap around the North Pole and could further rule out influences of different land masks, we are confident that the inter-product differences observed mostly originate from differences in how the algorithms handle surface emissivity variations or variations in the atmospheric influence.

\subsubsection{The role of weather filters}

We illustrated that the weather filters implemented in each of the 10 products have quite different behaviour, despite the fact they all use the same gradient ratios of brightness temperature frequency channels. Potential users should be aware of this. We confirm that the dynamic open water filters designed for group I products (see Table 2) have a stable impact on the lower part of the sea-ice concentration, cutting through it at about $10 \%$ SIC. This is across the months and changes of sensors (and thus frequencies, calibration, etc.) and for both hemispheres. We refer to Lavergne et al. (2019) for discussions about how this consistency could be improved further. The analysis also sheds light on how the other six products perform in terms of stability. Here, we are interested in both the temporal consistency of the weather filter effects (e.g. jumps across satellite series, across months, across climate-induced trends) and the absolute level at which they cut through the sea-ice concentration distribution, especially with respect to the $15 \%$ threshold embedded in the SIE and SIA curves shown in Figs. 6 and 7. Group II products all cut around $15 \%$, sometimes below, sometimes above, but in general at a higher sea-ice concentration than group I products 
(Figs. 1 and 2). We observed evidence for an actual impact of weather filter cut-off sea-ice concentration variation over time in the SIE time series in winter in the Antarctic (Fig. 7c). We believe Figs. 1 and 2 are new illustrations that data products can differ in many ways. Such time series, adapted from Lavergne et al. (2019), are an effective tool for data producers and users to assess the temporal consistency of sea-ice concentration data products.

\subsection{The impact of truncating sea-ice concentrations at $100 \%$}

The analysis of the validation at $100 \%$ conditions (Sect. 4) raises a critical question to be discussed in the future among data producers and with the data users: given that sea-ice concentration products are used following application of a $100 \%$ sea-ice concentration threshold, is it better to have algorithms (slightly) overshoot the sea-ice concentration distribution or should data producers aim at an unbiased nontruncated distribution? To let algorithms overshoot will return fewer below-100\% estimates in the product files, which might be positive for large areas of the inner sea-ice cover during winter. However, one consequence of this (hypothetically) shifted sea-ice concentration distribution with modal values $>100 \%$ is that the sea-ice concentration in areas with a true $<100 \%$ sea ice concentration, i.e. $99 \%$ or even $98 \%$, might be set to $100 \%$. Such areas could contain leads. According to Marcq and Weiss (2012) about $70 \%$ of the upward ocean-atmosphere heat exchange occurs through leads, even though these cover only $1 \%$ to $2 \%$ of the central Arctic Ocean. Assuming a heat transfer through thick ice of $5 \mathrm{~W} \mathrm{~m}^{-2}$ and through a lead of $400 \mathrm{~W} \mathrm{~m}^{-2}$ (e.g. Marcq and Weiss, 2012, near-surface air temperature difference of $30 \mathrm{~K}$ ) a heat flux calculation yields $5 \mathrm{~W} \mathrm{~m}^{-2}$ for $100 \%$ and $\sim 9 \mathrm{~W} \mathrm{~m}^{-2}$ for $99 \%$ true sea-ice concentration, an increase by $80 \%$. Using sea-ice concentrations of an algorithm with a modal value at $101 \%$ or higher might therefore result in a substantial underestimation of the surface heat flux. Integrated over the sea-ice-covered central Arctic Ocean (area $\sim 7$ million $\mathrm{km}^{2}$ ) this underestimation could be as high as $2.4 \times 10^{12} \mathrm{MJ} \mathrm{d}^{-1}$.

To aim at an unbiased algorithm might help with a better sensitivity to small openings (but note the RMSE of non-truncated retrievals ranges between $2 \%$ and $5 \%$ for the various algorithms studied here); however, the product grid will have more below-100\% estimates. Our analysis, supported by the Gaussian fit method, introduces the question and opens the discussion, but does not provide an answer.

\subsection{Observed differences to ship-based observations}

One of the innovations of the products of group I (see Table 2) is the self-optimizing capability of the algorithms to adopt to seasonally changing sea-ice conditions, i.e. the transition between winter and summer. If ship-based sea-ice ob-
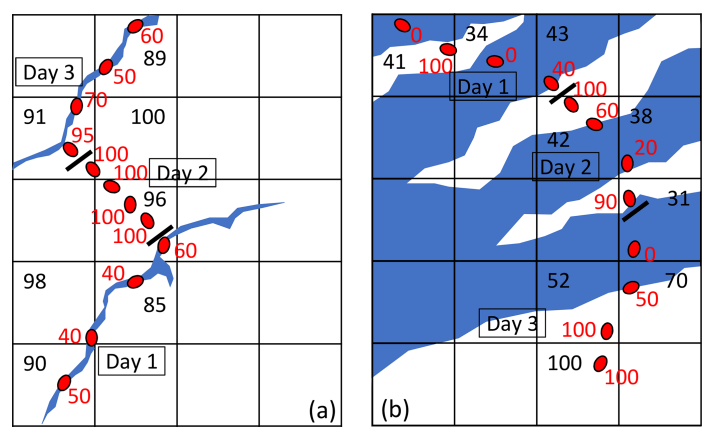

Figure 17. Illustration of the representativity of ship-based observations (red ellipses and numbers) compared to gridded satellite observations (black grid and numbers) for (a) close pack ice with leads and (b) an open sea-ice cover in the marginal ice zone. Size of ellipses is in scale with the grid cell size of $25 \mathrm{~km}$ by $25 \mathrm{~km}$. Short black bars denote transitions between days. See also Table 7 .

servations are as reliable in summer as they are in winter, then a comparison of the differences and standard deviations obtained in winter and summer could reveal how well an algorithm deals with the seasonally changing sea-ice conditions. If we focus on sea-ice concentrations $<95 \%$ to avoid the clustering of data pairs near $100 \%$ during winter, we find the CDRs of the group I products, SICCI- $25 \mathrm{~km}$, SICCI$50 \mathrm{~km}$, and OSI-450, to stand out with winter-to-summer changes in the difference between ship- and satellite-based sea-ice concentrations around $0.2 \%$, compared to $\sim 3.5 \%$ for group II products in the Arctic. Respective changes in the standard deviation range between $0.1 \%$ and $5.2 \%$ for group II but are near $\sim 2.7 \%$ for group I CDRs. In the Antarctic, the smallest winter-to-summer differences of $\sim 0.3 \%$ are obtained for group I products SICCI- $12 \mathrm{~km}$ and OSI-450, compared to $\sim 2.5 \%$ for group II products. These provide a winter-to-summer change in standard deviation of $\sim 6.5 \%$, while SICCI- $12 \mathrm{~km}$ and OSI-450 exhibit values of $\sim 4.0 \%$. These results suggest that most group I products compare with the ship-based sea-ice observations more consistently across seasons than the other products.

It is noteworthy, however, to keep in mind the difference in scales and observational limitations between ship-based and satellite-based observations of the sea-ice concentration - as illustrated in Fig. 17. For the pack ice-lead case (Fig. 17a, Table 7a), the variation in the ship-based observations depends strongly on the fraction of thin ice. For leads covered by open water, satellite sea-ice concentrations tend to exceed shipbased concentrations. This could explain the banana-shaped distribution of data pairs for the SH (Fig. 16). For leads covered by thin ice, it is the other way round. Ship observations would reveal a total sea-ice concentration of $100 \%$, while most of the tested algorithms underestimate the true sea-ice concentration in the presence of thin ice (Cavalieri, 1994; Comiso and Steffen, 2001; Ivanova et al., 2015). This could explain the larger fraction of ship-based sea-ice concentra- 
Table 7. Summary of hypothetic daily average sea-ice concentrations from Fig. 17 for the pack ice case (a) and the marginal ice zone (MIZ) (b). The left two columns show sea-ice concentrations as shown in Fig. 17; the middle two columns show the effect of sea-ice concentration underestimation for thin ice; and the right two columns show the effect of sea-ice concentration overestimation, e.g. thick ice with a wet snow cover (top), or of sea-ice concentration underestimation, e.g. MIZ during end of summer (bottom).

\begin{tabular}{|c|c|c|c|c|c|c|}
\hline \multirow[t]{2}{*}{ (a) Pack ice } & \multicolumn{2}{|c|}{ Lead is open water } & \multicolumn{2}{|c|}{$\begin{array}{l}\text { Lead is thin ice; satellite } \\
\text { underestimates by } 20 \%\end{array}$} & \multicolumn{2}{|c|}{$\begin{array}{l}\text { Lead is open water; } \\
\text { ice surface properties cause } 5 \% \\
\text { overestimation on } 50 \% \text { of the ice }\end{array}$} \\
\hline & Ship & Satellite & Ship & Satellite & Ship & Satellite \\
\hline Day 1 & 48 & 92 & 100 & 98 & 48 & 96 \\
\hline Day 2 & 100 & 95 & 100 & 99 & 100 & 98 \\
\hline Day 3 & 68 & 90 & 100 & 97 & 68 & 95 \\
\hline \multirow[t]{2}{*}{ (b) MIZ } & & & \multicolumn{2}{|c|}{$\begin{array}{c}50 \% \text { of sea ice is thin ice; satellite } \\
\text { underestimates by } 20 \%\end{array}$} & \multicolumn{2}{|c|}{$\begin{array}{l}50 \% \text { of sea ice is soaked wet; } \\
\text { satellite fails to see this as ice }\end{array}$} \\
\hline & Ship & Sat & Ship & Satellite & Ship & Satellite \\
\hline Day 1 & 35 & 40 & 35 & 36 & 35 & 20 \\
\hline Day 2 & 67 & 38 & 67 & 35 & 67 & 19 \\
\hline Day 3 & 63 & 63 & 63 & 57 & 63 & 44 \\
\hline
\end{tabular}

tions near $100 \%$ as is particularly pronounced, e.g. for NT1SSMI (Fig. 15i) and, in general, the larger range of satellite versus ship-based sea-ice concentrations at comparably high concentrations. For the marginal ice zone (Fig. 17b, Table $7 \mathrm{~b}$ ), it is more likely that most products provide smaller sea-ice concentrations than observed from a ship. During winter, a considerable fraction of the sea ice might be thin ice - causing underestimation as stated above. During summer, a considerable fraction of the sea ice might be too wet to be recognized as ice by satellite microwave radiometry - causing an underestimation as well (see e.g. Worby and Comiso, 2004; Ozsoy-Cicek et al., 2009). In addition, low ice concentrations are often filtered by the weather filters applied (see Sect. 2.1.3). This results in a substantially larger range of ship-based sea-ice concentrations at comparably low satellite sea-ice concentrations. Furthermore, this also results in a larger fraction of low ice concentration values for the satellite-based than the ship-based observations. This explains why mean ship-based sea-ice concentrations per binned satellite sea-ice concentration (blue symbols in Figs. 15 and 16) are shifted so much to the right compared to the red symbols; this is also evident from the larger fraction of data pairs below than above the identity line for sea-ice concentrations below $60 \%-80 \%$.

We note that another data set of a different kind of shipbased observations of Arctic sea-ice conditions is available at the Arctic and Antarctic Research Institute (AARI) and has recently been used for a sea-ice concentration algorithm inter-comparison study using an approach different from the one used in our paper (Alekseeva et al., 2019). We might extend our inter-comparison studies to their data set in the future.

\subsection{Conclusions}

Recently, three new global sea-ice concentration (SIC) climate data records (CDRs) have been released. They are described in Lavergne et al. (2019). These products, SICCI$25 \mathrm{~km}$, SICCI-50km, and OSI-450, utilize a dynamic, selfoptimizing hybrid sea-ice concentration algorithm, which is applied to satellite microwave brightness temperature measurements of the SMMR, SSM/I, and SSMIS instruments (OSI-450) or the AMSR-E and AMSR2 instruments (SICCI$25 \mathrm{~km}$ and SICCI-50km); see Table 1 for instruments and frequencies. Within this paper, these new products are evaluated by means of an inter-comparison to seven other sea-ice concentration products (see Table 2 for acronyms, satellite sensors and frequencies used, and assignment to groups of algorithms I-IV) and with independent sea-ice cover data.

We find a very good and consistent agreement in interannual variation in the monthly mean SIA and SIE time series for both hemispheres for the overlap periods of the respective products used at their native grid resolution. We can explain unexpected low SIE of SICCI-50km during Arctic winter and Antarctic summer by the coarse resolution of the $6.9 \mathrm{GHz}$ frequency observations combined with too aggressive filtering of near-coastal and potentially weatherinfluenced grid cells near coastlines, which removed a substantial number of grid cells with ice. We note that SIE differences are to be expected simply from the different grid resolutions. When inter-comparing products on the same grid $(50 \mathrm{~km})$ applying the same land mask, the products of group I provide quite similar values of SIC, SIA, and SIE for both hemispheres, during times of both maximum and minimum sea-ice cover. Overall differences are $<1.0 \%$ for SIC and $<100000 \mathrm{~km}^{2}$ (Arctic) and $<200000 \mathrm{~km}^{2}$ (Antarctic) for 
both SIA and SIE. We find a similarly good agreement for the products CBT-SSMI and NOAA CDR of group II (see Table 2), as can be expected from the design of NOAA CDR (see Appendix F and Peng et al., 2013). We find the largest differences for NT1-SSMI and NT2-AMSR-E: NT1-SSMI provides less sea ice than other products, particularly in summer in the Arctic and winter in the Antarctic; NT2-AMSR-E provides more sea ice than other products in the Antarctic. Based on our results we state that it matters which algorithm and/or product is used for monitoring the polar sea-ice cover as long as one is interested in absolute values; similarity of trends has been shown elsewhere (e.g. Ivanova et al., 2014; Comiso et al., 2017a).

Results quoted in the previous paragraph rely on computations applying the often-used $15 \%$ SIC threshold (e.g. Gloersen et al., 1992). Our investigations suggest that it might be worth starting to reconsider this threshold because, as illustrated in our paper, the weather filters applied might have inter-sensor jumps and fail to cut at a constant sea-ice concentration across the different satellite sensors used. For example, sea-ice concentrations from sensor A might be cut by the weather filter at $14 \%$ while these might be cut at $17 \%$ for a subsequent sensor B. As a result, more sea ice is removed for sensor B, and the sea-ice extent computed from sea-ice concentration data of sensor B is systematically smaller than that computed from sensor A. We observe evidence for this in our results. A more thorough analysis of trends over subperiods observed by the 10 products could reveal other such impacts. This impact is likely to be particularly pronounced in the peripheral seas with a comparably large fraction of the marginal ice zone, such as the Bering Sea or the Barents Sea. Note that the OSI-450 algorithm provides a particularly stable weather-filter-induced sea-ice concentration cut-off at $\sim 10 \%$ across the sensors used.

Sea-ice concentrations are retrieved from satellite microwave brightness temperatures using an empirical physical algorithm, which usually involves a limited set of tie points. However, the natural variability of surface properties relevant for microwave remote sensing of sea ice is large and these tie points can only be an average signature associated with a significant spread. As a result, sea-ice concentrations retrieved by such algorithms naturally vary around (below and above) $100 \%$ even though the actual sea-ice concentration is exactly $100 \%$. The natural variability of the sea-ice surface properties and the linearity of most algorithms suggest that the spread of retrieved sea-ice concentrations around $100 \%$ follows a Gaussian distribution. However, all 10 products examined here either truncate sea-ice concentrations at $100 \%$, i.e. fold retrieved values $>100 \%$ to exactly $100 \%$, or do simply not allow retrieval of SIC $>100 \%$ (NT2-AMSR-E) and the natural variability cannot be assessed. We develop a Gaussian fit method to reconstruct the full distribution of seaice concentrations around $100 \%$. We demonstrate its performance on the group I products (as these provide, for the first time, both the non-truncated and truncated values) and sub- sequently use it to reconstruct non-truncated sea-ice concentration distributions for the remaining six products (Fig. 3, and Appendix H, Figs. H1 and H2). Based on our results we conclude that it is worthwhile to rethink the concept of truncation at $100 \%$ (but also at $0 \%$ SIC) and critically reassess evaluation results at the two ends of the sea-ice concentration distribution. Indeed, we argue that direct evaluation of truncated data sets gives misleading information on the accuracy of the sea-ice concentration data and favours those data sets that overestimate sea-ice concentrations. Such overestimation has direct implications on the ability of a given seaice concentration data set to observe small openings in an otherwise complete sea-ice cover. We invite the sea-ice concentration data producers and users to take this into consideration and discuss the implications towards future versions of such data products.

Data availability. All sea-ice concentration products except SICCI-12km are publicly available from the sources provided in the respective sections of the Supplement and the reference list. The SICCI-12km product is available from Thomas Lavergne upon request. The standardized ship-based observations are available from the Integrated Climate Data Center (ICDC): http://icdc.cen. uni-hamburg.de/1/daten/cryosphere/seaiceparameter-shipobs/ (last access date: 12 April 2019). The RRDP2 data set is publicly available from the source specified in the reference list. 
Appendix A: The EUMETSAT OSI SAF-ESA CCI algorithm suite

The four products OSI-450, SICCI-12km, SICCI-25km, and SICCI-50km have in common that they are based on a hybrid, self-tuning, self-optimizing sea-ice concentration algorithm (Lavergne et al., 2019). This algorithm is applied to brightness temperature (TB) observations of the SMMR, SSM/I, and SSMIS instruments for OSI-450, providing a fully revised version of the OSI-409 CDR (Tonboe et al., 2016). This algorithm is applied to brightness temperatures measured by the AMSR-E and AMSR2 instruments for the SICCI CDRs. Apart from the input satellite data the processing chains are the same for these four products. The algorithm is a generalization of the Comiso bootstrap frequency mode algorithm (Appendix C) and of the Bristol algorithm (Smith and Barret, 1994; Smith 1996) and is described in detail in Lavergne et al. (2019). Two algorithms that each combine three frequency channels (e.g. $\sim 19 \mathrm{GHz}$ at vertical polarization and $\sim 37 \mathrm{GHz}$ at both horizontal and vertical polarizations) are respectively optimized to provide the best accuracy in open water (the $B_{\mathrm{OW}}$ algorithm) and consolidated ice (the $B_{\mathrm{CI}}$ algorithm) conditions. The sea-ice concentrations obtained with each of the two optimized algorithms are merged linearly into a hybrid sea-ice concentration SIC $_{\text {hybrid }}$ according to the general formula

$$
\begin{aligned}
& \left\{\begin{array}{ll}
w_{\mathrm{OW}}=1 ; & \text { for } B_{\mathrm{OW}}<0.7 \\
w_{\mathrm{OW}}=0 ; & \text { for } B_{\mathrm{OW}}>0.9 \\
w_{\mathrm{OW}}=1-\frac{B_{\mathrm{OW}}-0.7}{0.2} ; & \text { for } B_{\mathrm{OW}} \in[0.7 ; 0.9]
\end{array} ;\right. \\
& \mathrm{SIC}_{\text {hybrid }}=w_{\mathrm{OW}} \times B_{\mathrm{OW}}+\left(1-w_{\mathrm{OW}}\right) \times B_{\mathrm{CI}} .
\end{aligned}
$$

For sea-ice concentrations below $70 \%$, $\mathrm{SIC}_{\text {hybrid }}$ relies completely on $B_{\mathrm{OW}}$ and for sea-ice concentrations above $90 \%$ it relies entirely on $B_{\mathrm{CI}}$. The $B_{\mathrm{OW}}$ and $B_{\mathrm{CI}}$ algorithms can be regarded as a generalized version of the Comiso bootstrap and Bristol algorithms, in the sense that they combine the three different brightness temperature channels used by the two algorithms in a three-dimensional TB space and optimize their data projection plane for the best accuracy.

In this paper, we use the sea-ice concentration CDR derived from SMMR, SSM/I, and SSMIS data: OSI450 (https://doi.org/10.15770/EUM_SAF_OSI_0008, OSI SAF, 2017) and two sea-ice concentration CDRs derived from AMSR-E and AMSR2 data: SICCI-25km (https:// doi.org/10.5285/f17f146a31b14dfd960cde0874236ee5, Pedersen et al., 2017a) and SICCI-50km (https://doi.org/10. 5285/5f75fcb0c58740d99b07953797bc041e, Pedersen et al., 2017b).

While SICCI-25km is based on brightness temperatures measured at $\sim 19$ and $\sim 37 \mathrm{GHz}$, similar to OSI- 450 , SICCI$50 \mathrm{~km}$ is based on brightness temperatures measured at $\sim 7$ and $\sim 37 \mathrm{GHz}$. OSI-450 and SICCI-25km come at $25 \mathrm{~km}$ grid resolution while SICCI-50km has $50 \mathrm{~km}$ grid resolution. In addition, we use a fourth product, SICCI- $12 \mathrm{~km}$, which is provided at $12.5 \mathrm{~km}$ grid resolution and is based on brightness temperatures measured by AMSR-E and AMSR2 at $\sim 19$ and $\sim 90 \mathrm{GHz}$. Here, we use a prototype of SICCI$12 \mathrm{~km}$, which was produced during the ESA CCI Sea Ice project, but was not released publicly (partly based on the results presented in this paper). All these data sets have daily temporal resolution and are provided on polar EASE-Grid version 2.0 (Brodzik et al., 2012, 2014).

\section{Appendix B: The ARTIST sea-ice (ASI) algorithm}

The ARTIST Sea Ice (ASI) algorithm (Kaleschke et al., 2001; Spreen et al., 2008) is a modified hybrid of the near$90 \mathrm{GHz}$ algorithm (Svendsen et al., 1987) and the NASA Team algorithm (see Appendix D). Water and ice are distinguished at high resolution by the TB polarization difference $(P)$ at $\sim 90 \mathrm{GHz}:$

$$
P=\mathrm{TB}_{90}^{\mathrm{V}}-\mathrm{TB}_{90}^{\mathrm{H}} \text {. }
$$

The basic equations for the ASI algorithm are based on the near-90 GHz algorithm of Svendsen et al. (1987):

$P=a \times\left(C \times \Delta \epsilon_{\text {ice }} \times T_{\text {ice }}+(1-C) \times \Delta \epsilon_{\text {water }} \times T_{\text {water }}\right)$,

with the atmospheric influence $a=\left(1.1 \times e^{-\tau}-0.11\right) \times e^{-\tau}$; $C$ is the total sea-ice concentration, $T$ is the temperature, $\Delta \epsilon$ is the difference in surface emissivity between vertical and horizontal polarization for the ice or water surface fraction, and $\tau$ is the total atmospheric optical depth for Arctic conditions at this frequency and viewing conditions. For ice-free $(C=0)$ and totally ice-covered $(C=1)$ conditions, Eq. (B1) yields the tie points for open water $P_{\text {water }}=$ $a_{\text {water }} \times \Delta \epsilon_{\text {water }} \times T_{\text {water }}$ and sea ice $P_{\text {ice }}=a_{\text {ice }} \times \Delta \epsilon_{\text {ice }} \times T_{\text {ice }}$. Taylor expansions of Eq. (B1) around $C=0$ and $C=1$ lead to a pair of equations for $P$, in which the atmospheric influences $a_{\text {water }}$ and $a_{\text {ice }}$ can be substituted with the aid of the tie point equations - provided that the variation in the atmospheric influence is small over water or ice (see Spreen et al., 2008). After substitution one obtains

$$
C=\left(\frac{P}{P_{\text {water }}}-1\right) \times\left(\frac{\Delta \epsilon_{\text {water }} \times T_{\text {water }}}{\Delta \epsilon_{\text {ice }} \times T_{\text {ice }}-\Delta \epsilon_{\text {water }} \times T_{\text {water }}}\right)
$$

for $C \rightarrow 0$,

$C=\frac{P}{P_{\text {ice }}}+\left(\frac{P}{P_{\text {ice }}}-1\right) \times\left(\frac{\Delta \epsilon_{\text {water }} \times T_{\text {water }}}{\Delta \epsilon_{\text {ice }} \times T_{\text {ice }}-\Delta \epsilon_{\text {water }} \times T_{\text {water }}}\right)$ for $C \rightarrow 1$.

According to Svendsen et al. (1987) the ratio of the surface emissivity differences can be set to a constant value $(-1.14)$. With this simplification and by assuming that the 
atmospheric influence inherent in $P$ is a smooth function of the sea-ice concentration, one can use a 3rd-order polynomial function to interpolate between the solutions of Eqs. (B2) and (B3) to obtain sea-ice concentrations between 0 and 1 as a function of $P$ :

$C(P)=d_{3} \times P^{3}+d_{2} \times P^{2}+d_{1} \times P+d_{0}$.

The coefficients $d_{i}$ are derived with a linear equation system based on Eqs. (B2) and (B3) and their first derivatives (Spreen et al., 2008).

The larger, compared to the lower frequencies used in most products (see Table 2), weather influence at $\sim 90 \mathrm{GHz}$ frequencies by atmospheric water content and surface wind speed can cause substantial overestimation of the sea-ice concentration over open water and within the ice edge (Kern, 2004; Andersen et al., 2006). Over open water, the weather influence is reduced by combining sea-ice concentrations obtained with Eq. (B4) with the NASA Team algorithm (NTA; see also Appendix D) sea-ice concentrations following

$$
\begin{aligned}
& C=C_{\mathrm{ASI}} \text { for } C_{\mathrm{NTA}}>5 \%, \\
& C=0 \% \text { for } C_{\mathrm{NTA}} \leq 5 \% .
\end{aligned}
$$

Hence, the ASI algorithm is a hybrid of the near-90GHz algorithm (Eqs. B1-B4) and the NTA (Kaleschke et al., 2001; Ezraty et al., 2007; Fanny Girard-Ardhuin, IFREMER, Brest, France, personal communication, 3 June 2019).

We use the ASI algorithm sea-ice concentration product provided via the Integrated Climate Data Center: https://icdc. cen.uni-hamburg.de (last access date: 27 February 2019). This product is processed at the French Institute for Exploitation of the Sea (IFREMER) from SSM/I and SSMIS data and provided via ICDC after application of a running $5 \mathrm{~d}$ median filter, further reducing spurious weather-influenced seaice concentration in the open water (Kern et al., 2010), on a polar-stereographic grid with $12.5 \mathrm{~km}$ grid resolution (at $70^{\circ}$ latitude). We abbreviate these data as ASI-SSMI.

\section{Appendix C: The Comiso bootstrap algorithm}

The Comiso bootstrap algorithm (Comiso, 1986; Comiso et al., 1997, 2003; Comiso and Nishio, 2008) combines TB observations at either two different frequencies (frequency mode, 37 and $19 \mathrm{GHz}$, vertical polarization) or at two different polarizations (polarization mode, $37 \mathrm{GHz}$, vertical and horizontal polarization). It is based on the observation that brightness temperatures measured at these frequencies/polarizations over closed sea ice tend to cluster along a line (ice line) while those over open water tend to cluster around a single point in the respective two-dimensional brightness temperature space. The total sea-ice concentration is computed using

$C=\frac{\mathrm{TB}_{f}^{\mathrm{V}}-\mathrm{TB}_{f, \mathrm{OW}}^{\mathrm{V}}}{\mathrm{TB}_{f, I}^{\mathrm{P}}-\mathrm{TB}_{f, \mathrm{OW}}^{\mathrm{V}}}$, with the brightness temperature measured at vertical polarization and frequency $f=37 \mathrm{GHz}$ (polarization mode) or $f=19 \mathrm{GHz}$ (frequency mode): $\mathrm{TB}_{f}^{\mathrm{V}}$, the open water tie point $\mathrm{TB}_{f, \mathrm{OW}}^{\mathrm{V}}$ at vertical polarization and the same frequency as $\mathrm{TB}_{f}^{\mathrm{V}}$ and the intersection of the ice line with a line from the open water tie point through the observed brightness temperature: $\mathrm{TB}_{f, I}^{\mathrm{P}}=A \times \frac{B-W}{Q-A}+B$. Scalars $A$ and $B$ are functions of the ice tie points for first-year ice (FYI) and multiyear ice (MYI) at $37 \mathrm{GHz}$ at vertical and horizontal polarization (polarization mode) or at 19 and $37 \mathrm{GHz}$, both with vertical polarization (frequency mode). $Q$ and $W$ are functions of the actually observed brightness temperature and the water tie point at the respective frequencies and polarizations. The two algorithms (frequency and polarization mode) are combined so that only the polarization mode is used in highconcentration conditions, and otherwise the frequency mode is used.

We use daily gridded sea-ice concentrations derived with the Comiso bootstrap (CBT) algorithm from SMMR, SSM/I, and SSMIS instruments, as processed at NASA Goddard Space Flight Center (GSFC) and made available at https: //nsidc.org/data/nsidc-0079 (last access: 7 February 2019). They are on a polar-stereographic grid with $25 \mathrm{~km}$ grid resolution (at $70^{\circ}$ latitude). We abbreviate these data as CBTSSMI. For practical reasons, we access these GSFC CBTSSMI fields from the NOAA sea-ice concentration CDR (Appendix F) files, where they are provided as additional data (Meier and Windnagel, 2018). The GSFC CBT-SSMI sea-ice concentration data set involves manual filtering, especially at the beginning of the record (SMMR period).

In addition, we use daily gridded sea-ice concentrations derived with this algorithm from AMSR-E data (Comiso et al., 2003; Comiso and Nishio, 2008) as provided by NSIDC (AE_SI25.003, Cavalieri et al., 2014, https://nsidc.org/data/ ae_si25/versions/3, last access date: 26 April 2018) on the same polar-stereographic grid. The AMSR-E Comiso bootstrap algorithm sea-ice concentration is referred to as CBTAMSR-E throughout this paper. Note that the NSIDC product AE_SI25.003 does not contain CBT-AMSR-E sea-ice concentrations itself. It contains the NT2 sea-ice concentration and the difference "Comiso bootstrap minus NT2 sea-ice concentration". Therefore, we needed to compute the CBTAMSR-E sea-ice concentration by adding the NT2 sea-ice concentration to that difference.

\section{Appendix D: The NASA Team algorithm}

The NASA Team algorithm (Cavalieri et al., 1984, 1992, 1999) combines the large difference of the normalized brightness temperature polarization difference at $19 \mathrm{GHz}$, $\mathrm{PR}=\frac{\mathrm{TB}_{19}^{\mathrm{V}}-\mathrm{TB}_{19}^{\mathrm{H}}}{\mathrm{TB}_{19}^{\mathrm{V}}+\mathrm{TB}_{19}^{\mathrm{H}}}$, between water and ice, with the observation that the normalized brightness temperature frequency difference between 37 and $19 \mathrm{GHz}$ at vertical polarization, 
$\mathrm{GR}=\frac{\mathrm{TB}_{3}^{\mathrm{V}}-\mathrm{TB}_{19}^{\mathrm{V}}}{\mathrm{TB}_{37}^{\mathrm{V}}+\mathrm{TB}_{19}^{\mathrm{V}}}$, is negative for MYI and close to zero or slightly positive for FYI and open water. The total sea-ice concentration is derived as the sum of the fractions of MYI and FYI, which is constrained to a maximum of 1 :

$$
\begin{aligned}
& C_{\mathrm{FYI}}=\frac{F_{0}+F_{1} \times \mathrm{PR}+F_{2} \times \mathrm{GR}+F_{3} \times \mathrm{PR} \times \mathrm{GR}}{D}, \\
& C_{\mathrm{MYI}}=\frac{M_{0}+M_{1} \times \mathrm{PR}+M_{2} \times \mathrm{GR}+M_{3} \times \mathrm{PR} \times \mathrm{GR}}{D}, \\
& \text { with } D=D_{0}+D_{1} \times \mathrm{PR}+D_{2} \times \mathrm{GR}+D_{3} \times \mathrm{PR} \times \mathrm{GR},
\end{aligned}
$$

where coefficients $F_{i}, M_{i}$, and $D_{i}$ include the tie point information.

We use daily gridded sea-ice concentrations derived with the NASA Team (NT1) algorithm from SMMR, SSM/I, and SSMIS instruments, as processed at NASA Goddard Space Flight Center (GSFC), and made available at https://nsidc. org/data/nsidc-0051 (last access: 7 February 2019). They are on a polar-stereographic grid with $25 \mathrm{~km}$ grid resolution (at $70^{\circ}$ latitude). We abbreviate these data as NT1-SSMI. For practical reasons, we access these GSFC NT1-SSMI fields from the NOAA sea-ice concentration CDR (Appendix F) files, where they are provided as additional data (Meier et al., 2017; Meier and Windnagel, 2018). The GSFC NT1-SSMI sea-ice concentration data set involves manual filtering, especially at the beginning of the record (SMMR period).

\section{Appendix E: The enhanced NASA Team algorithm (NT2)}

Inter-comparison studies such as those of Comiso and Steffen (2001) and Comiso et al. (1997) led to the development of the enhanced NASA Team algorithm (NT2) (Markus and Cavalieri, 2000; Comiso et al., 2003) to mitigate effects such as layering in snow on sea ice on the accuracy of the seaice concentrations obtained with NT1. NT2 is conceptually different from the other algorithms presented here. The three relevant parameters (see below) are modelled as a function of sea-ice concentration in steps of $1 \%$ for 12 different atmospheric states using a radiative transfer model. The seaice concentration resulting in the minimum cost function between modelled and observed values of these parameters is taken as the retrieved total sea-ice concentration. The three parameters used are selected such that the influence of layering in snow on sea ice is mitigated.

$$
\begin{aligned}
\Delta \mathrm{GR}= & \frac{\mathrm{TB}_{90}^{\mathrm{H}}-\mathrm{TB}_{19}^{\mathrm{H}}}{\mathrm{TB}_{90}^{\mathrm{H}}+\mathrm{TB}_{19}^{\mathrm{H}}}-\frac{\mathrm{TB}_{90}^{\mathrm{V}}-\mathrm{TB}_{19}^{\mathrm{V}}}{\mathrm{TB}_{90}^{\mathrm{V}}+\mathrm{TB}_{19}^{\mathrm{V}}} \\
\mathrm{PR}_{19}^{\text {rotated }}= & -\frac{\mathrm{TB}_{37}^{\mathrm{V}}-\mathrm{TB}_{19}^{\mathrm{V}}}{\mathrm{TB}_{37}^{\mathrm{V}}+\mathrm{TB}_{19}^{\mathrm{V}}} \\
& \times \sin \theta_{19}+\frac{\mathrm{TB}_{19}^{\mathrm{V}}-\mathrm{TB}_{19}^{\mathrm{H}}}{\mathrm{TB}_{19}^{\mathrm{V}}+\mathrm{TB}_{19}^{\mathrm{H}}} \times \cos \theta_{19} \\
\mathrm{PR}_{90}^{\text {rotated }}= & -\frac{\mathrm{TB}_{37}^{\mathrm{V}}-\mathrm{TB}_{19}^{\mathrm{V}}}{\mathrm{TB}_{37}^{\mathrm{V}}+\mathrm{TB}_{19}^{\mathrm{V}}} \\
& \times \sin \theta_{90}+\frac{\mathrm{TB}_{90}^{\mathrm{V}}-\mathrm{TB}_{90}^{\mathrm{H}}}{\mathrm{TB}_{90}^{\mathrm{V}}+\mathrm{TB}_{90}^{\mathrm{H}}} \times \cos \theta_{90}
\end{aligned}
$$

The rotation is done in the space given by $\mathrm{PR}_{19}$ and $\mathrm{GR}$ (see Appendix D) or by $\mathrm{PR}_{90}$ and $\mathrm{GR}$ for $\mathrm{PR}_{19}^{\text {rotated }}$ and $\mathrm{PR}_{90}^{\text {rotated }}$, respectively, at an angle $\Theta$ chosen such that the ice lines in the respective space are parallel to the GR axis.

We use daily gridded NT2 sea-ice concentrations derived from AMSR-E data as provided by NSIDC: AE_SI25.003 (Cavalieri et al., 2014, https://nsidc.org/data/ ae_si25/versions/3, last access date: 26 April 2018) on a polar-stereographic grid with $25 \mathrm{~km}$ grid resolution. We abbreviate these data as NT2-AMSR-E.

\section{Appendix F: The NOAA NSIDC sea-ice concentration CDR}

The NOAA NSIDC sea-ice concentration CDR combines sea-ice concentrations computed with the NT1 algorithm (Appendix D) with those computed with the CBT algorithm (Appendix C), via

$C=\left(C_{\mathrm{NT} 1}, C_{\mathrm{CBT}}\right)$

within the ice edge. The ice edge is defined by the CBT seaice concentration of $10 \%$. The generation and characteristics of the NOAA NSIDC CDR as well as details about filters (see also Sect. 2.1) and about the statistical uncertainty estimate provided with the product are described in Peng et al. (2013) and Meier and Windnagel (2018). We use the daily gridded sea-ice concentration data of NOAA NSIDC CDR version 3 , named NOAA CDR in this paper, provided by NSIDC on a polar-stereographic grid with $25 \mathrm{~km}$ grid resolution (Meier et al., 2017, https://nsidc.org/data/g02202/versions/3, last access date: 7 February 2019).

It is important to note that the data sets NT1-SSMI (Appendix D) and CBT-SSMI (Appendix C), both from GSFC, are not used as input in the NOAA NSIDC CDR. Instead, sea-ice concentrations are computed at NSIDC using reimplementations of the two algorithms, which allow for a fully automated and transparent processing as required for a CDR, and combined with Eq. (F1). One of the key differences between the NSIDC and GSFC versions is that the 
NSIDC ones do not involve manual editing and start with SSM/I in July 1987.

Appendix G: Matrices of sea-ice concentration, area, and extent differences

This subsection contains the full set of matrices of differences between all 10 products of the overall hemispheric average monthly mean sea-ice concentration of the AMSR-E measurement period and of the respective overall monthly mean sea-ice area (SIA) and extent (SIE) in Figs. G1-G6. 
$\mathrm{NH}$ SIC

Minus

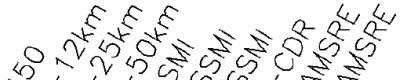

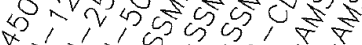

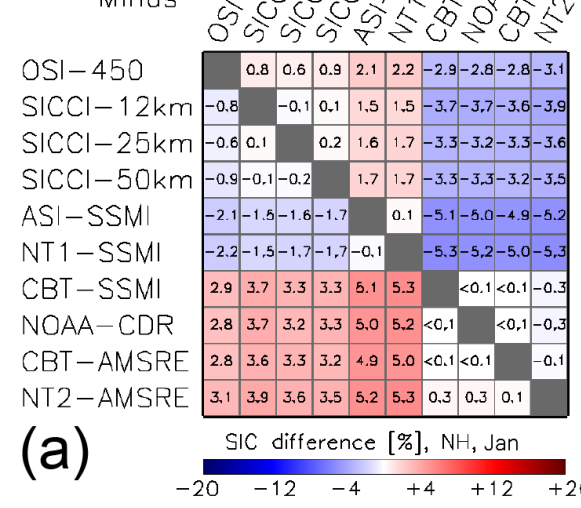

(b)
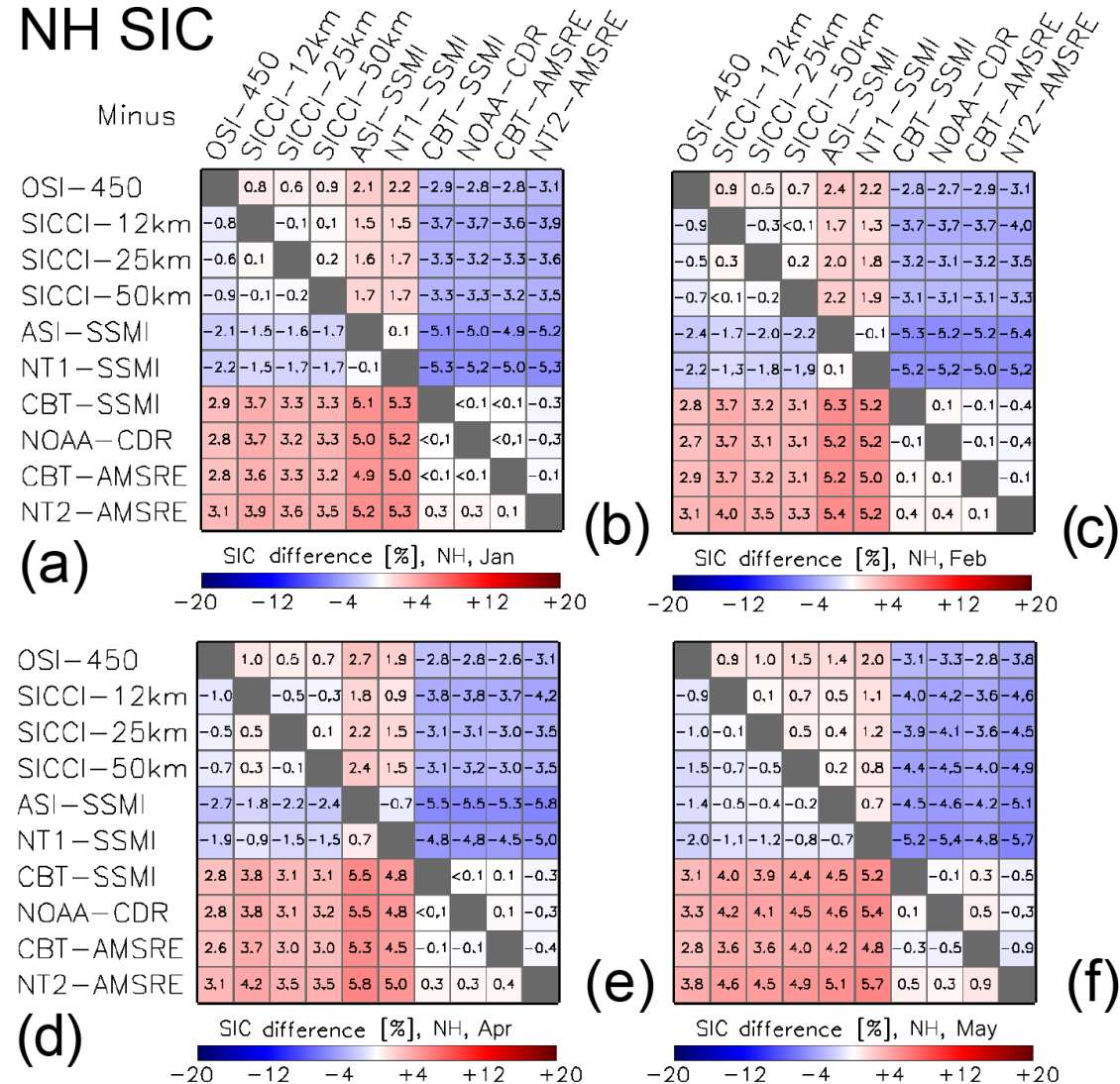

(c)

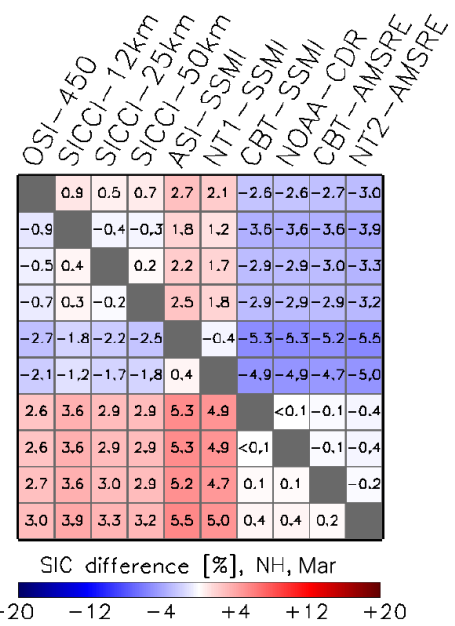

$0 S I-450$ $\begin{array}{llllll}-20 & -12 & -4 & +4 & +12 & +20\end{array}$

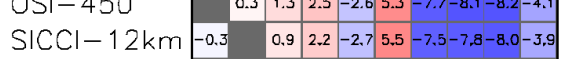

SICCI-25km $-1.3-0.9 \quad 1.2-3.54 .8-8.2-8.6-8.9-4.8$

SICCl-50km $-2.5-2.2-1.2 \quad-4.63 .8-9.5-9.9-10 .-5.8$

ASI-SSMI

NT1-SSMI

CBT-SSMI

NOAA-CDR

CBT-AMSRE

NT2-AMSRE

\begin{tabular}{|l|l|l|l|l|l}
\hline 2.6 & 2.7 & 3.5 & 4.5 & 8.1 & $-4.9-5.3-5.4-1.2$ \\
\hline
\end{tabular}

$-5.3-5.5-4.8-3.8$

\begin{tabular}{|l|l|l|l|l|l|}
\hline-5.3 & -3.5 & -4.8 & -3.8 & -8.1 & \\
\hline 7.7 & 7.5 & 8.2 & 9.5 & 4.9 & 13. \\
8.1 & 7.8 & 8.6 & 9.9 & 5.3 & 13. \\
\hline 8.2 & 8.0 & 8.9 & 10 & 5.4 & 3
\end{tabular}

$-0.3-0.43 .6$

\begin{tabular}{|l|lll|lll|l|l|l|l|}
8.2 & 8.0 & 8.9 & 10. & 5.4 & 13. & 0.4 & 0.1 & & 4.2 \\
\hline 4.1 & 3.9 & 4.8 & 5.9 & 1.2 & 9.6 & -3.5 & -4.0 & -4.2
\end{tabular}

(g)

SIC difference [\%], $\mathrm{NH}$, Jul

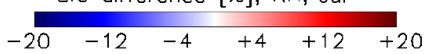

OSI-450

\begin{tabular}{l|l|l|l|l|l|l|}
0.1 & 0.5 & 0.1 & -0.6 & 6.6 & $-5.0-4.8-5.0-3.4$ \\
\hline
\end{tabular}

SICCl-12km $-0.1 \quad 0.3<0.1-0.76 .6-5.1-4.8-5.1-3.6$

SICCl-25km $-0.5-0.3 \quad-0.3-1.06 .3-5.3-5.0-5.4-3.8$

SICCl-50km $-0.1<0.10 .3 \quad-0.66 .7-5.1-4.8-4.9-3.4$

AS $|-S S M|$

NT1-SSMI

\begin{tabular}{l|l|l|l|l}
\hline 0.6 & 0.7 & 1.0 & 0.6 \\
\hline
\end{tabular}

CBT-SSMI

$-5.6-6.6-5.3-6.7-7$.

$7.2-4.4-4.2-4.3-2.8$

NOAA-CDR

\begin{tabular}{|l|l|l|l|l|l}
5.0 & 5.1 & 5.3 & 5.1 & 4.4 \\
\hline 4.8 & 4.8 & 5.0 & 4.3 & 4.2 & 11.4
\end{tabular}

\begin{tabular}{ll|l|l|}
$0.3<0.1$ & 1.6 \\
\hline
\end{tabular}

CBT-AMSRE

NT2-AMSRE

(j)

\begin{tabular}{|l|l|l|l|l|l|l|l|l|l}
4.8 & 4.8 & 5.0 & 4.3 & 4.2 & 1 \\
5.0 & 5.1 & 5.4 & 4.9 & 4.3 & 1 \\
\hline 3.4 & 3.6 & 3.8 & 3.4 & 2.8 & 10.
\end{tabular}

3.4

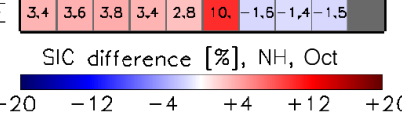

(e)

(h)

(k)

\begin{tabular}{|l|l|l|l|l|l|l|}
\hline 0.9 & 1.0 & 1.5 & 1.4 & 2.0 & -3.1 & $-3.3-2.8-3.8$ \\
\hline
\end{tabular}

$\begin{array}{llllllll}-0.9 & 0.1 & 0.7 & 0.5 & 1.1 & -4.0-4.2-3.6-4.6\end{array}$

\begin{tabular}{llll|l|l|l}
\hline-1.0 & -0.1 & 0.5 & 0.4 & 1.2 & $-3.9-4.1-3.6-4.5$ \\
\hline
\end{tabular}

\begin{tabular}{lll|l|l|l}
\hline-1.5 & $-0.7-0.5$ & 0.2 & 0.8 & $-4.4-4.5-4.0-4.9$ \\
\hline
\end{tabular}

$-2.0-1.1-1.2-0.8-0.7 \quad-5.2-5.4-4.8-5.7$

\begin{tabular}{llllllllllll}
3.1 & 4.0 & 3.9 & 4.4 & 4.5 & 5.2 & -0.1 & 0.3 & -0.5 \\
\hline
\end{tabular}

\begin{tabular}{lllll|l|l|l|l|l|}
3.3 & 4.2 & 4.1 & 4.5 & 4.6 & 5.4 & 0.1 & 0.5 & -0.3 \\
\hline
\end{tabular}

\begin{tabular}{lllllll|l|l|ll}
2.8 & 3.6 & 3.6 & 4.0 & 4.2 & 4.8 & -0.3 & -0.5 & -0.8 \\
\hline
\end{tabular}

SIC difference [\%], NH, May

(f)

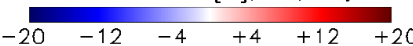

\begin{tabular}{l|l|l|l|l|l|l|l|}
0.2 & 1.3 & 2.5 & -1.7 & 1.4 & $-5.4-5.7-5.3-5.6$ \\
\hline
\end{tabular}

\begin{tabular}{lllll|l}
-0.2 & 1.1 & 2.4 & -1.9 & 1.4 & $-5.6-5.8-5.2-5.6$
\end{tabular}

$-1.3-1.1 \quad 1.2-2.90 .5-6.4-6.7-6.2-6$.

$-2.6-2.4-1.2 \quad-3.8-0.5-7.6$

$\begin{array}{lllllll}1.7 & 1.9 & 2.9 & 3.8 & 3.2 & -3.7-3.9-3.4-3.8\end{array}$

\begin{tabular}{ll|l|l|l|l|l|l|l|l}
\hline-1.4 & -1.4 & -0.5 & 0.5 & -3.2
\end{tabular}

\begin{tabular}{ll|l|l|l|l|l|l|l|l|}
\hline 5.4 & 5.6 & 6.4 & 7.5 & 3.7 & 7.0 & -0.2 & 0.2 & -0.1 \\
\hline
\end{tabular}

\begin{tabular}{llllll|ll|l|l|}
5.7 & 5.8 & 6.7 & 7.8 & 3.9 & 7.3 & 0.2 & 0.5 & 0.1 \\
\hline
\end{tabular}

$\begin{array}{lllllllllll}5.3 & 5.2 & 6.2 & 7.2 & 3.4 & 6.7 & -0.2 & -0.5 & -0.2\end{array}$

$\begin{array}{llllllllllll}5.6 & 5.6 & 6.5 & 7.5 & 3.8 & 7.1 & 0.1 & -0.1 & 0.2\end{array}$

SIC difference [\%], $\mathrm{NH}$, Jun

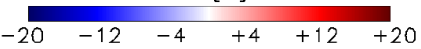

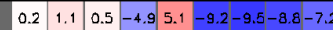

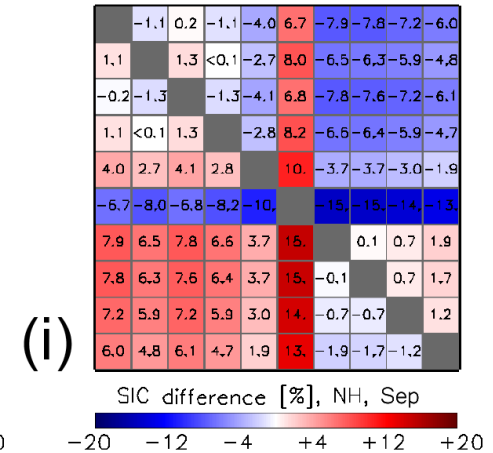

SIC difference [\%], $\mathrm{NH}$, Aug
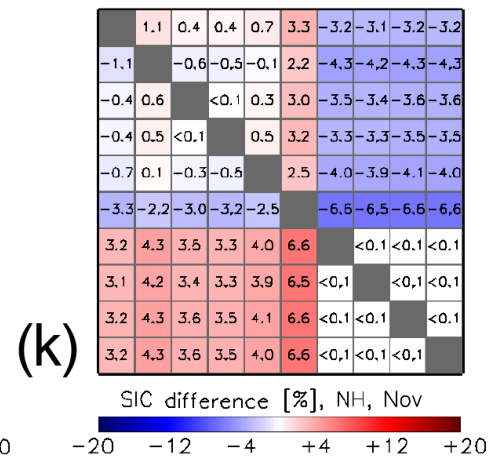

$-1.4-0.5-0.4-0.2 \quad 0.7-4.5-4.6-4.2-5.7$

\begin{tabular}{|l|l|l|l|l|l|l|l|l|l|}
\hline 3.8 & 4.6 & 4.5 & 4.9 & 5.1 & 5.7 & 0.5 & 0.3 & 0.9 \\
\hline
\end{tabular}

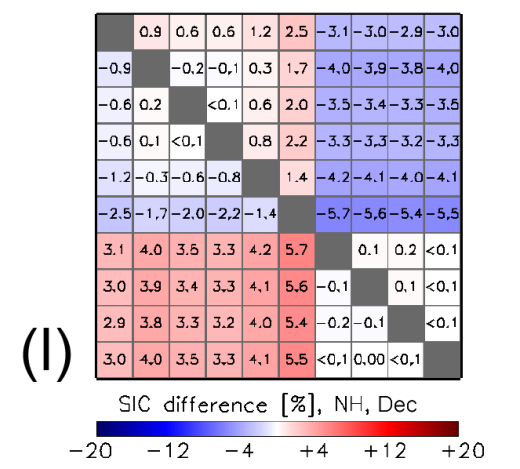

Figure G1. Differences between all 10 products of the average sea-ice concentration for the Arctic. The averages are computed from monthly mean values of the respective months of the AMSR-E period June 2002 to September 2011. All data are on the EASE-Grid 2.0 with $50 \mathrm{~km}$ grid resolution. The land mask of the SICCI-50km product is applied to all products. 


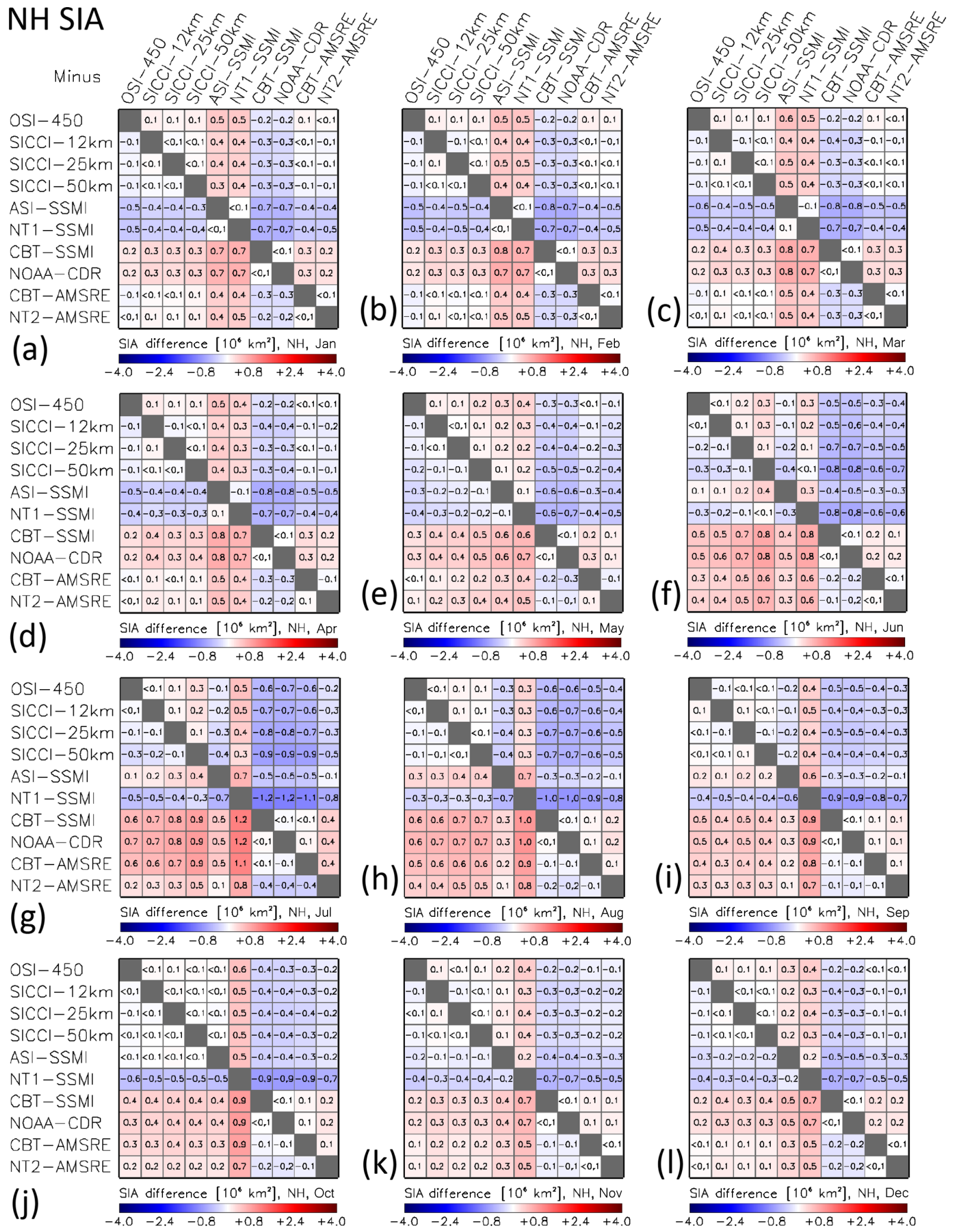

Figure G2. Differences between all 10 products of the average sea-ice area (SIA) for the Arctic. The differences are computed from monthly mean SIA of the respective months of the AMSR-E period June 2002 to September 2011. All data are on the EASE-Grid 2.0 with $50 \mathrm{~km}$ grid resolution. The land mask of the SICCI-50km product is applied to all products. 


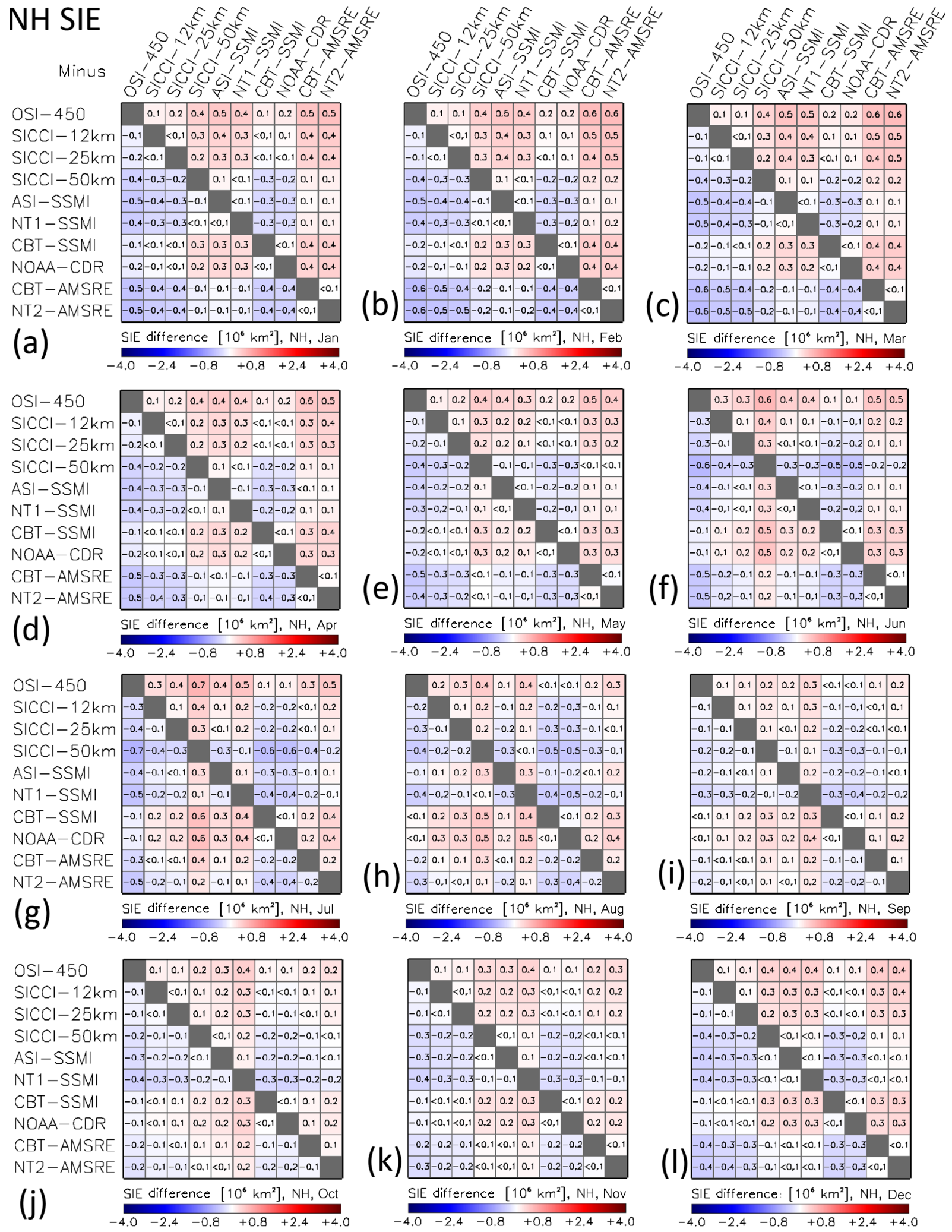

Figure G3. Differences between all 10 products of the average sea-ice extent (SIE) for the Arctic. The differences are computed from monthly mean SIE of the respective months of the AMSR-E period June 2002 to September 2011. All data are on the EASE-Grid 2.0 with $50 \mathrm{~km}$ grid resolution. The land mask of the SICCI-50km product is applied to all products. 


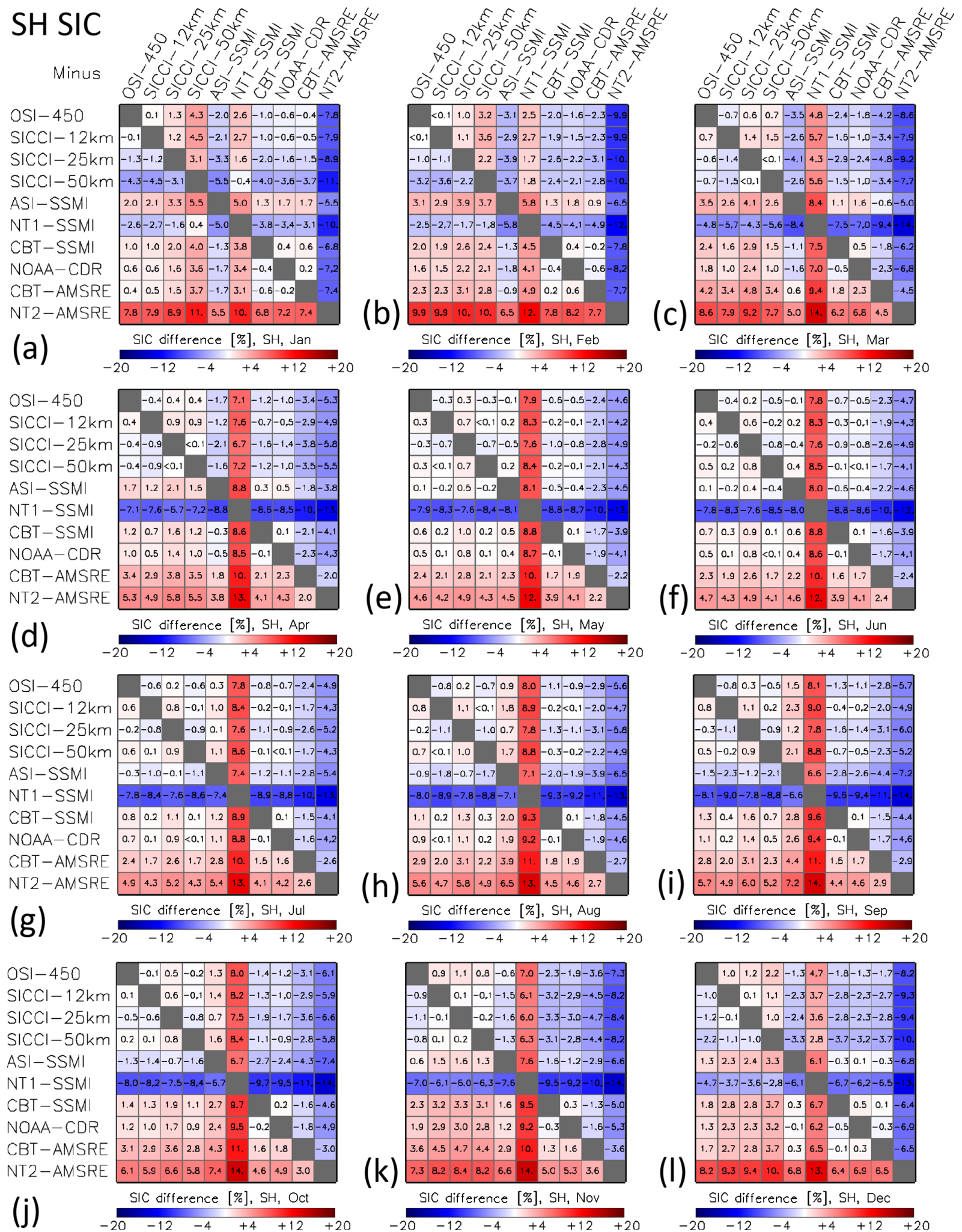

Figure G4. As Fig. G1 but for the Antarctic. 
SH SIA

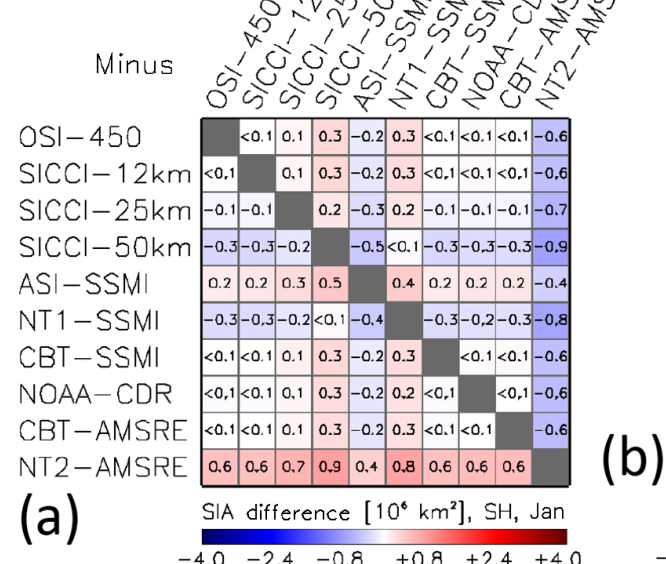

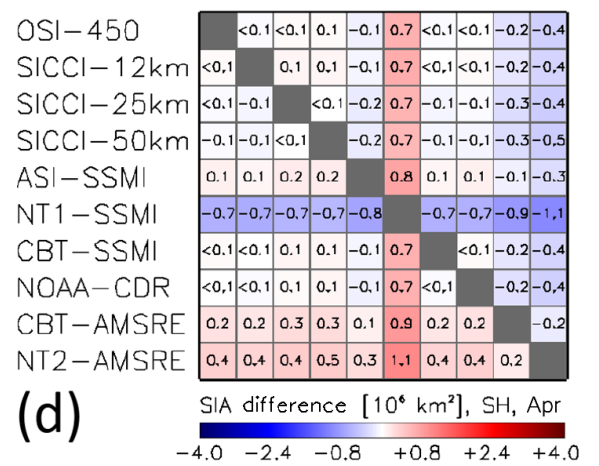

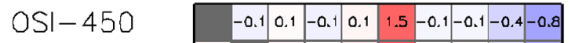
$\mathrm{SICCl}-12 \mathrm{~km} \quad 0.1 \quad 0.2<0.10 .2 \quad 1.6<0.1<0.1-0.3-0.7$ $\mathrm{SICCl}-25 \mathrm{~km}-0.1-0.2 \quad-0.2<0.11 .4-0.2-0.1-0.4-0.9$ $\mathrm{SICCl}-50 \mathrm{~km} \quad 0.1<0.10 .2 \quad 0.2 \quad 1.6<0.1<0.1-0.3-0.7$ ASI-SSMI $\quad-0.1-0.2<0.1-0.2 \quad 1.4-0.2-0.2-0.5-0.8$

NT1 - SSM

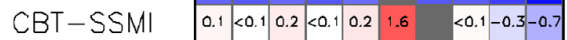
\begin{tabular}{l|llllllllll} 
NOAA-CDR & 0.1 & 0.1 & 0.1 & $<0.1$ & 0.2 & 1.5 & $<0.1$ & -0.3 & -0.8 \\
\hline
\end{tabular} \begin{tabular}{lllllllllll} 
CBT-AMSRE & 0.4 & 0.3 & 0.4 & 0.3 & 0.5 & 1.8 & 0.3 & 0.3 & -0.5 \\
\hline
\end{tabular} \begin{tabular}{l|llllllllll} 
NT2-AMSRE & 0.8 & 0.7 & 0.9 & 0.7 & 0.9 & 2.3 & 0.7 & 0.8 & 0.5 \\
\hline
\end{tabular}

(g) SIA difference $\left[10^{6} \mathrm{~km}^{2}\right], \mathrm{SH}$, Jul

OSI-450 <0.1 $0.1<0.10 .2 \quad 1.7-0.2-0.2-0.6-1.2$ $\mathrm{SICCl}-12 \mathrm{~km}<0.1 \quad 0.1<0.10 .3 \quad 1.7-0.2-0.2-0.5-1,2$ SICCl-25km $-0.1-0.1 \quad-0.20 .1 \quad 1.6-0.4-0.3-0.7-1.3$ $\mathrm{SICCl}-50 \mathrm{~km}<0.1<0.10 .2 \quad 0.3 \quad 1.7-0.2-0.1-0.5-1$, ASI-SSMI $\quad-0.2-0.3-0.1-0.5 \quad 1.4-0.5-0.4-0.8-1.4$ NT1 - SSMI

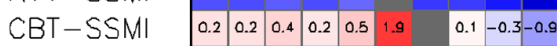
\begin{tabular}{l|lllllllll} 
NOAA-CDR & 0.2 & 0.2 & 0.3 & 0.1 & 0.4 & 1.9 & -0.1 & $-0.4-1,0$ \\
\hline
\end{tabular} \begin{tabular}{l|lllllllll} 
CBT-AMSRE & 0.6 & 0.5 & 0.7 & 0.5 & 0.8 & 2.2 & 0.3 & 0.4 & -0.6
\end{tabular} \begin{tabular}{llllllllllll} 
NT2-AMSRE & 1.2 & 1.2 & 1.3 & 1.1 & 1.4 & 2.8 & 0.9 & 1.0 & 0.6 \\
\hline
\end{tabular} (j)

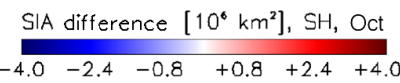

(b)

(e)

(h)

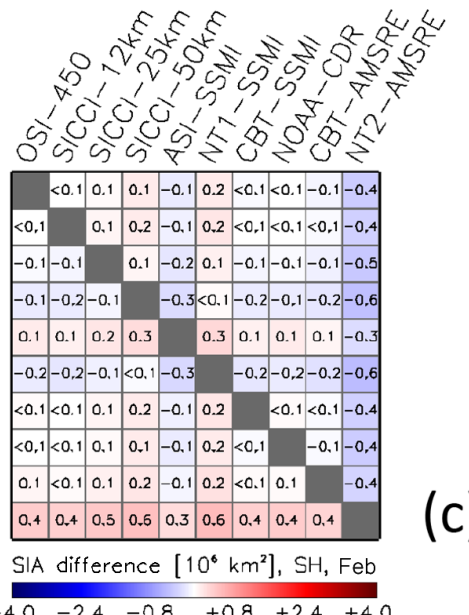

(c)

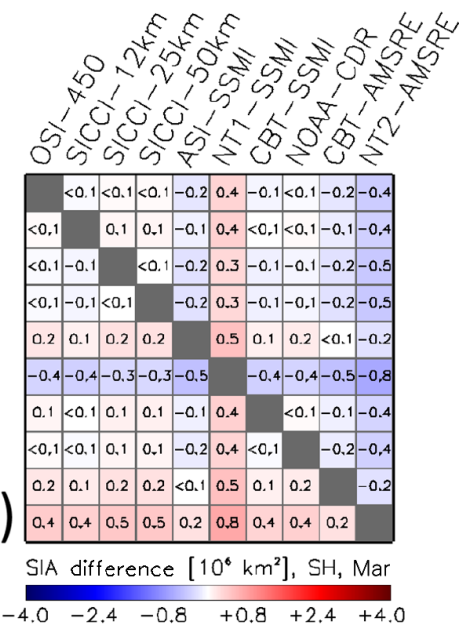

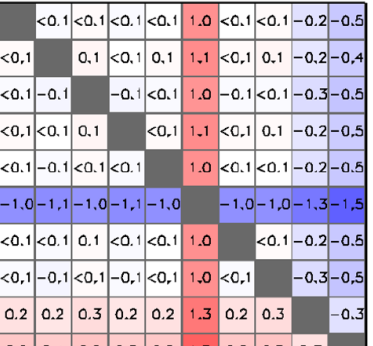

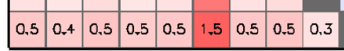

SIA difference $\left[10^{6} \mathrm{~km}^{2}\right], \mathrm{SH}$, May $\begin{array}{llllll}-4.0 & -2.4 & -0.8 & +0.8 & +2.4 & +4.0\end{array}$

(f)

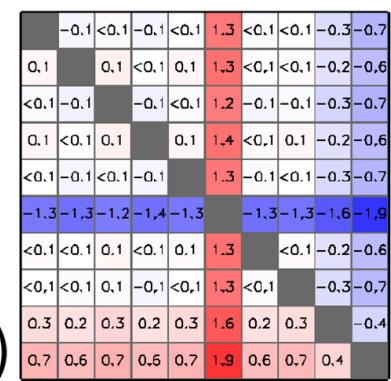

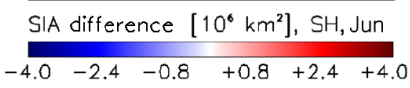

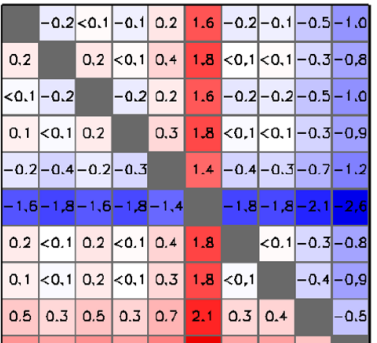

\begin{tabular}{l|l|l|l|l|l|l|l|l}
1.0 & 0.8 & 1.0 & 0.9 & 1.2 & 2.6 & 0.8 & 0.9 & 0.5 \\
\hline
\end{tabular}

SIA difference $\left[10^{6} \mathrm{~km}^{2}\right], \mathrm{SH}$, Aug

(i)

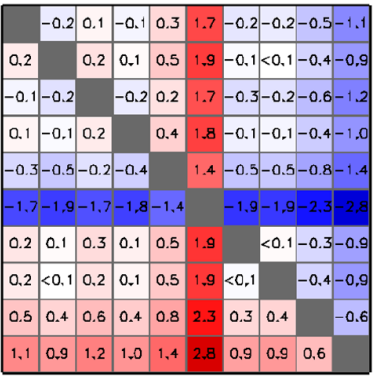

SIA difference $\left[10^{6} \mathrm{~km}^{2}\right]$, SH, Sep $\begin{array}{llllll}-4.0 & -2.4 & -0.8 & +0.8 & +2.4 & +4.0\end{array}$ $\begin{array}{llllll}-4.0 & -2.4 & -0.8 & +0.8+2.4 & +4.0\end{array}$

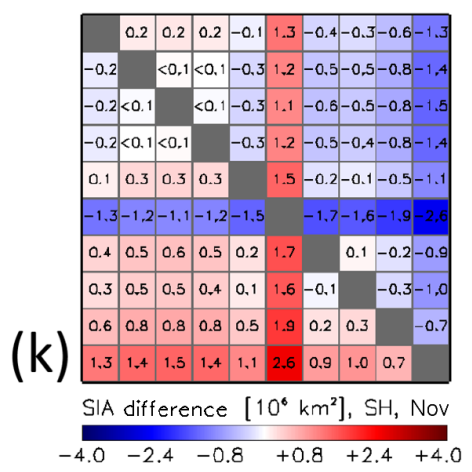

\begin{tabular}{ll|l|l|l|l|l|l|l|l|l|l|l|}
\hline 0.2 & 0.2 & 0.3 & -0.2 & 0.7 & -0.2 & -0.1 & $-0.2-1.1$ \\
\hline
\end{tabular} $\begin{array}{llllllll}-0.2 & <0.1 & 0.2 & -0.4 & 0.6 & -0.3-0.3-0.3-1.3\end{array}$ $-0.2<0.1 \quad 0.1-0.40 .6-0.4-0.3-0.3-1.3$ $-0.3-0.2-0.1 \quad-0.50 .4-0.5-0.4-0.5-1.4$ $\begin{array}{lllllllllll}0.2 & 0.4 & 0.4 & 0.5 & 0.9 & <0.1 & 0.1<0.1 & -0.9\end{array}$ $-0.7-0.6-0.6-0.4-0.9 \quad-0.9-0.8-0.9-1.9$ \begin{tabular}{lllllllllll}
\hline 0.2 & 0.3 & 0.4 & 0.5 & $<0.1$ & 0.9 & 0.1 & $<0.1$ & -0.9
\end{tabular} \begin{tabular}{llllllllll}
0.1 & 0.3 & 0.3 & 0.4 & -0.1 & 0.8 & -0.1 & $-0.1-1.0$ \\
\hline
\end{tabular} \begin{tabular}{lllllllllll}
\hline 0.2 & 0.3 & 0.3 & 0.5 & $<0.1$ & 0.9 & $<0.1$ & 0.1 & -0.9
\end{tabular} (I) \begin{tabular}{llllllllll}
0.2 & 0.3 & 0.3 & 0.5 & $<.1$ & 0.9 & $<.1$ & 0.1 & & -0.0 \\
1.1 & 1.3 & 1.3 & 1.4 & 0.9 & 1.9 & 0.9 & 1.0 & 0.9 \\
\hline
\end{tabular} SIA difference $\left[10^{6} \mathrm{~km}^{2}\right], \mathrm{SH}$, Dec $\begin{array}{rrrrrr}-4.0 & -2.4 & -0.8 & +0.8 & +2.4 & +4.0\end{array}$

Figure G5. As Fig. G2 but for the Antarctic. Note the larger range of the SIA differences compared to the Arctic. 


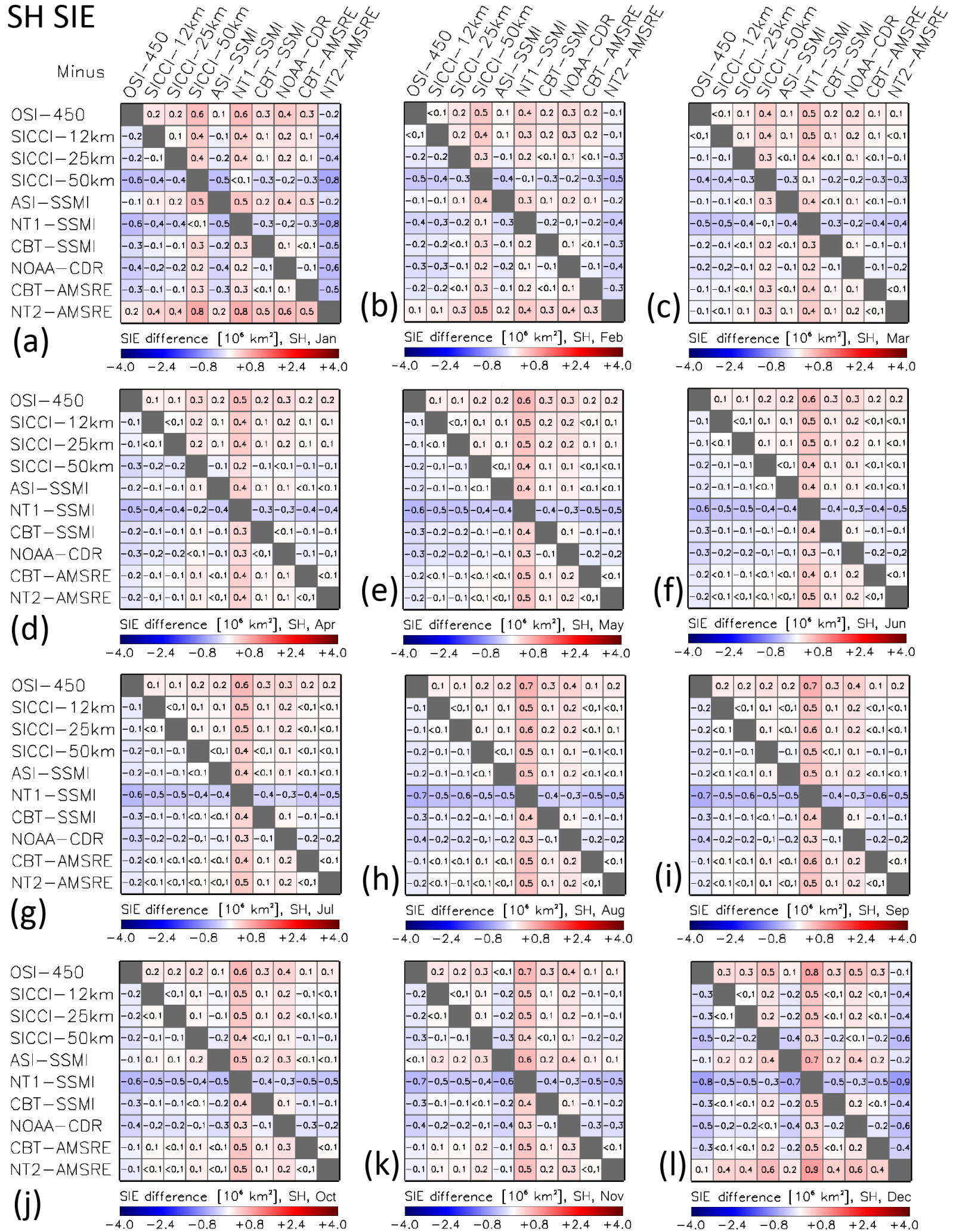

Figure G6. As Fig. G3 but for the Antarctic. Note the larger range of the SIE differences compared to the Arctic. 


\section{Appendix H: Gaussian fits for all 10 products}

This subsection contains the two sets of Gaussian fits obtained for the Arctic (Fig. H1) and Antarctic (Fig. H2) based on the methodology described in Sect. 2.1.4; see also Fig. 3). These are the fits obtained from data of the overlap period between the AMSR-E measurement period and the RRDP2 near- $100 \%$ reference sea-ice concentration data set period, that is in winter of the years 2007-2011. 

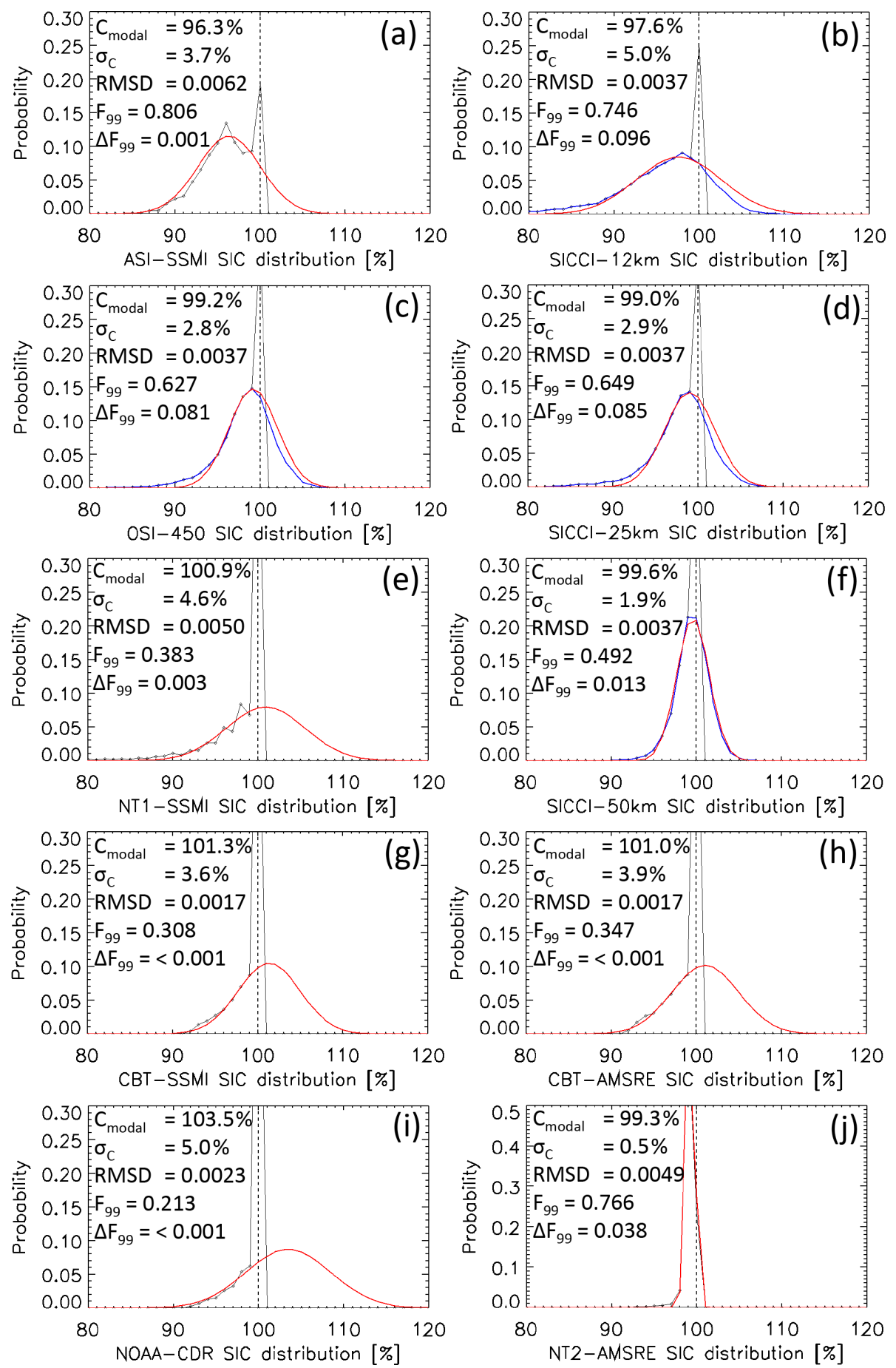

Figure H1. Sea-ice concentration distribution at RRDP2 near-100\% reference sea-ice concentration locations in the Arctic during winter for 2007-2011. Black symbols and lines show values cut off at $100 \%$; blue lines denote the original distribution (for OSI-450, SICCI-12km, SICCI-25km, and SICCI-50km); red lines denote the distribution resulting from the Gaussian fit to values of the distribution $\leq 99 \%$. In each image the modal sea-ice concentration (centre of the Gaussian fit: $C_{\text {modal }}$ ), the standard deviation of the fit $\sigma_{\mathrm{C}}$ and fit parameters with respect to the fraction of the distribution $\leq 99 \%\left(F_{99}, \Delta F_{99}\right.$; see text in Sect. 2.1.4 for a more detailed explanation), and the root-mean-squared difference (RMSD) between original and fitted probability are given. 

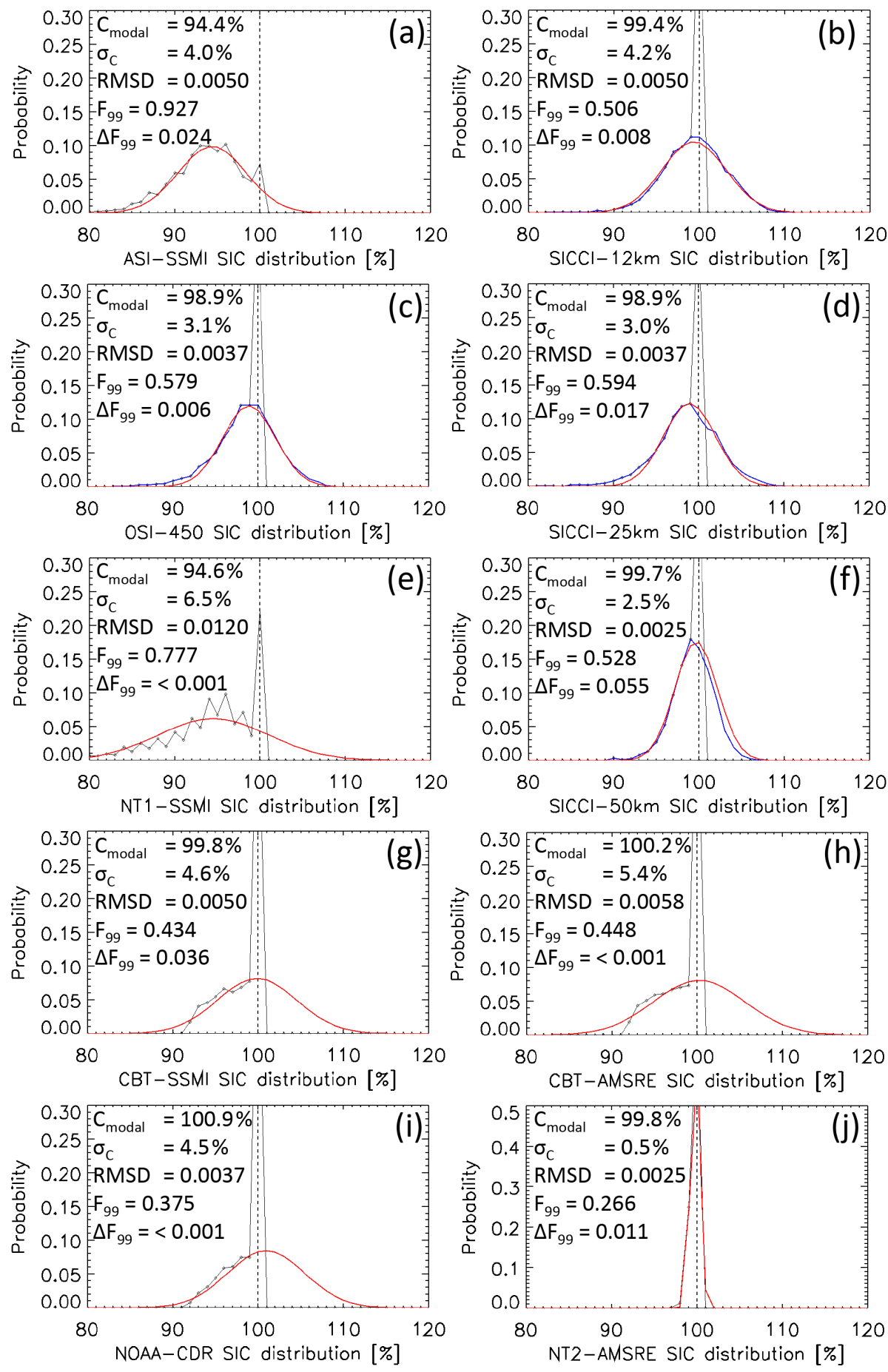

Figure H2. As Fig. H1 but for the Antarctic. 
Author contributions. SK led the writing in most sections, with contributions by TL (Sects. 2.1, 6.1, 6.2), LTP (Sects. 1, 2.1), DN (Sects. 1, 3), and RTT (Sects. 2.1, 6.2). AMS and TL contributed to the concept and work of Sect. 2.1.3. TL contributed to the concept and work of Sect. 2.1.4. RS and LTP produced and provided the RRDP2 data set and consulted its usage (Sect. 2.2). DN and TL contributed to concept and work as well as design of the figures in Sect. 3. SK performed the data analysis and inter-comparison with contributions to the interpretation of the results from all co-authors.

Competing interests. The authors declare that they have no conflict of interest.

Acknowledgements. We are very grateful for the very helpful comments given by the two anonymous reviewers, by Francois Massonnet, and by the scientific editor Chris Derksen.

Financial support. The work presented here was funded by EUMETSAT (through the Second Continuous Developments and Operation Phase of OSI SAF), ESA (through the Climate Change Initiative Sea_Ice_cci project), and the German Research Foundation (DFG) Excellence Initiative CLISAP under grant EXC 177/2. The publication itself is funded by the Deutsche Forschungsgemeinschaft (DFG, German Research Foundation) under Germany's Excellence Strategy - EXC 2037 "CLiCCS - Climate, Climatic Change, and Society" - project number: 390683824, contribution to the Center for Earth System Research and Sustainability (CEN) of the University of Hamburg.

Review statement. This paper was edited by Chris Derksen and reviewed by Francois Massonnet and two anonymous referees.

\section{References}

Alekseeva, T. Tikhonov, V., Frolov, S., Repina, I., Raev, M., Sokolova, J., Sharkov, E., Afanasieva, E., and Serovetnikov, S.: Comparison of Arctic sea ice concentration from the NASA Team, ASI, and VASIA2 algorithms with summer and winter ship data, Remote Sens., 11, 2481, https://doi.org/10.3390/rs11212481, 2019.

Andersen, S., Tonboe, R. T., Kern, S., and Schyberg, H.: Improved retrieval of sea ice total concentration from spaceborne passive microwave observations using Numerical Weather Prediction model fields: An intercomparison of nine algorithms, Remote Sens. Environ., 104, 374-392, 2006.

Andersen, S., Pedersen, L. T., Heygster, G., Tonboe, R. T., and Kaleschke, L.: Intercomparison of passive microwave sea ice concentration retrievals over the high concentration Arctic sea ice, J. Geophys. Res., 112, C08004, https://doi.org/10.1029/2006JC003543, 2007.

Beitsch, A., Kern, S., and Kaleschke, L.: Comparison of SSM/I and AMSR-E sea ice concentrations with ASPeCt ship obser- vations around Antarctica, IEEE T. Geosci. Remote, 53, 1985 1996, https://doi.org/10.1109/TGRS.2014.2351497, 2015.

Brodzik, M. J., Billingsley, B., Haran, T., Raup, B., and Savoie, M. H.: EASE-Grid 2.0: Incremental but Significant Improvements for Earth-Gridded Data Sets, ISPRS Int. J. Geo-Inf., 1, 32-45, https://doi.org/10.3390/ijgi1010032, 2012.

Brodzik, M. J., Billingsley, B., Haran, T., Raup, B., and Savoie, M. H.: Correction: Brodzik, M.J., et al. EASE-Grid 2.0: Incremental but Significant Improvements for Earth-Gridded Data Sets, originally published in: ISPRS Int. J. Geo-Inf. 2014, 1, 32-45, ISPRS Int. J. Geo-Inf., 3, 1154-1156, 2014.

Brucker, L., Cavalieri, D. J., Markus, T., and Ivanoff, A.: NASA Team 2 sea ice concentration algorithm retrieval uncertainty, IEEE T. Geosci. Remote, 52, 7336-7352, https://doi.org/10.1109/TGRS.2014.2311376, 2014.

Cavalieri, D. J.: A microwave technique for mapping thin sea ice, J. Geophys. Res., 99, 12561-12572, 1994.

Cavalieri D. J., Gloersen, P., and Campbell, W. J.: Determination of Sea Ice Parameters With the NIMBUS 7 SMMR, J. Geophys. Res., 89, 5355-5369, 1984.

Cavalieri, D. J., Crawford, J., Drinkwater, M., Emery, W. J., Eppler, D. T., Farmer, L. D., Goodberlet, M., Jentz, R., Milman, A., Morris, C., Onstott, R., Schweiger, A., Shuchman, R., Steffen, K., Swift, C. T., Wackerman, C., and Weaver, R. L.: NASA sea ice validation program for the DMSP SSM/I: final report NASA Technical Memorandum 104559, National Aeronautics and Space Administration, Washington, DC, 126 pp., 1992.

Cavalieri, D. J., St. Germain, K. M., and Swift, C. T.: Reduction of weather effects in the calculation of sea ice concentration with the DMSP SSM/I, J. Glaciol., 41, 455-464, 1995.

Cavalieri, D. J., Parkinson, C. L., Gloersen, P., Comiso, J. C., and Zwally, H. J.: Deriving long-term time series of sea ice cover from satellite passive-microwave multisensor data sets, J. Geophys. Res., 104, 15803-15814, https://doi.org/10.1029/1999JC900081, 1999.

Cavalieri, D. J., Markus, T., Hall, D. K., Gasiewski, A. J., Klein, M., and Ivanoff, A.: Assessment of EOS Aqua AMSR-E Arctic sea ice concentrations using Landsat-7 and airborne microwave imagery, IEEE T. Geosci. Remote, 44, 3057-3069, https://doi.org/10.1109/TGRS.2006.878445, 2006.

Cavalieri, D. J., Markus, T., Hall, D. K., Ivanoff, A., and Glick, E.: Assessment of AMSR-E Antarctic winter sea-ice concentrations using Aqua MODIS, IEEE T. Geosci. Remote, 48, 3331-3340, https://doi.org/10.1109/TGRS.2010.2046495, 2010.

Cavalieri, D. J., Markus, T., and Comiso, J. C.: AMSR-E/Aqua daily L3 $25 \mathrm{~km}$ brightness temperature and sea ice concentration polar grids, version 3, Boulder, Colorado USA, NASA National Snow and Ice Data Center Distributed Arctive Archive Center, https://doi.org/10.5067/AMSR-E/AE_SI25.003, 2014.

Cho, K., Sasaki, N., Shimoda, H., Sakata, T., and Nishio, F.: Evaluation and improvement of SSM/I sea ice concentration algorithms for the Sea of Okhotsk, J. Remote Sens. Jpn., 16, 47-58, 1996.

Comiso, J. C.: Characteristics of arctic winter sea ice from satellite multispectral microwave observations, J. Geophys. Res., 91, 975-994, 1986.

Comiso, J. C.: Large Decadal Decline of the Arctic Multiyear Ice Cover, J. Climate, 25, 1176-1193, https://doi.org/10.1175/JCLID-11-00113.1, 2012. 
Comiso, J. C. and Nishio, F.: Trends in the sea ice cover using enhanced and compatible AMSR-E, SSM/I, and SMMR data, J. Geophys. Res., 113, C02S07, https://doi.org/10.1029/2007JC004257, 2008.

Comiso, J. C. and Steffen, K.: Studies of Antarctic sea ice concentrations from satellite data and their applications, J. Geophys. Res., 106, 31361-31385, 2001

Comiso, J. C., Cavalieri, D. J., Parkinson, C. L., and Gloersen, P.: Passive microwave algorithms for sea ice concentration: A comparison of two techniques, Remote Sens. Environ., 60, 357-384, 1997.

Comiso, J. C., Cavalieri, D. J., and Markus, T.: Sea ice concentration, ice temperature, and snow depth, using AMSR-E data, IEEE T. Geosci. Remote, 41, 243-252, https://doi.org/10.1109/TGRS.2002.808317, 2003.

Comiso, J. C., Meier, W. N., and Gersten, R. A.: Variability and trends in the Arctic Sea ice cover: Results from different techniques, J. Geophys. Res.-Oceans, 122, 6883-6900, https://doi.org/10.1002/2017JC012768, 2017a.

Comiso, J. C., Gersten, R. A., Stock, L. V., Turner, J., Perez, G. J., and Cho, K.: Positive trends in the Antarctic sea ice cover and associated changes in surface temperature, J. Climate, 30, 22512267, https://doi.org/10.1175/JCLI-D-16-0408.1, 2017b.

Ezraty, R., Girard-Ardhuin, F., Piollé, J.-F., Kaleschke, L., and Heygster, G.: Arctic and Antarctic sea ice concentration and Arctic sea ice drift estimated from special sensor microwave data Users's Manual, Version 2.1, IFREMER, Brest, France, February 2007.

Gloersen, P., Campbell, W., Cavalieri, D. J., Comiso, J. C., Parkinson, C. L., and Zwally, H. J.: Arctic and Antarctic sea ice, 19781987: satellite passive-microwave observations and analysis, Scientific and technical information program, NASA SP-511, National Aeronautics and Space Administration (NASA), Washington, DC, 1992.

Ivanova, D. P., Gleckler, P. J., Taylor, K. E., Durack, P. J., and Marvel, K. D.: Moving beyond the total sea ice extent in gauging model biases, J. Clim., 29, 8965-8987, https://doi.org/10.1175/JCLI-D-16-0026.1, 2017.

Ivanova, N., Johannessen, O. M., Pedersen, R. T., and Tonboe, R. T.: Retrieval of Arctic sea ice parameters by satellite passive microwave sensors: A comparison of eleven sea ice concentration algorithms, IEEE T. Geosci. Remote, 52, 7233-7246, https://doi.org/10.1109/TGRS.2014.2310136, 2014.

Ivanova, N., Pedersen, L. T., Tonboe, R. T., Kern, S., Heygster, G., Lavergne, T., Sørensen, A., Saldo, R., Dybkjær, G., Brucker, L., and Shokr, M.: Inter-comparison and evaluation of sea ice algorithms: towards further identification of challenges and optimal approach using passive microwave observations, The Cryosphere, 9, 1797-1817, https://doi.org/10.5194/tc9-1797-2015, 2015.

Kaleschke, L., Lüpkes, C., Vihma, T., Haarpaintner, J., Bochert, A., Hartmann, J., and Heygster, G.: SSM/I sea ice remote sensing for mesoscale ocean-atmosphere interaction analysis, Can. J. Remote Sens., 27, 526-537, 2001.

Kern, S.: ESA-CCI Phase 2 standardized manual visual ship-based sea-ice observations, v01, https://doi.org/10.26050/WDCC/ESACCIPSMVSBSIO, 2019.

Kern, S.: A new method for medium-resolution sea ice analysis using weather-influence corrected Special Sensor Mi-
crowave/Imager $85 \mathrm{GHz}$ data, Int. J. Remote Sens., 25, 45554582, https://doi.org/10.1080/01431160410001698898, 2004.

Kern, S., Kaleschke, L., and Clausi, D. A.: A comparison of two 85-GHz SSM/I ice concentration algorithms with AVHRR and ERS-2 SAR imagery, IEEE T. Geosci. Remote, 41, 2294-2306, https://doi.org/10.1109/TGRS.2003.817181, 2003.

Kern, S., Kaleschke, L., and Spreen, G.: Climatology of the Nordic (Irminger, Greenland, Barents, Kara and White/Pechora) Seas ice cover based on $85 \mathrm{GHz}$ satellite microwave radiometry: 1992 2008, Tellus A, 62, 411-434, https://doi.org/10.1111/j.16000870.2010.00457.x, 2010.

Kuuliala, L., Kujala, P., Suominen, M., and Montewka, J.: Estimating operability of ships in ridged ice fields, Cold Reg. Sci. Technol., 135, 51-61, https://doi.org/10.1016/j.coldregions.2016.12.003, 2017.

Kwok, R.: Sea ice concentration estimates from satellite passive microwave radiometry and openings from SAR ice motion, Geophys. Res. Lett., 29, 1311, https://doi.org/10.1029/2002GL014787, 2002.

Lavergne, T., Sørensen, A. M., Kern, S., Tonboe, R., Notz, D., Aaboe, S., Bell, L., Dybkjær, G., Eastwood, S., Gabarro, C., Heygster, G., Killie, M. A., Brandt Kreiner, M., Lavelle, J., Saldo, R., Sandven, S., and Pedersen, L. T.: Version 2 of the EUMETSAT OSI SAF and ESA CCI sea-ice concentration climate data records, The Cryosphere, 13, 49-78, https://doi.org/10.5194/tc-13-49-2019, 2019.

Maass, N. and Kaleschke, L.: Improving passive microwave sea ice concentration algorithms for coastal areas: applications to the Baltic Sea, Tellus A, 62, 393-410, https://doi.org/10.1111/j.1600-0870.2010.00452.x, 2010.

Markus, T. and Burns, B. A.: A method to estimate subpixel-scale coastal polynyas with satellite passive microwave data, J. Geophys. Res., 100, 4473-4487, 1995.

Markus, T. and Cavalieri, D. J.: An enhancement of the NASA Team sea ice algorithm, IEEE T. Geosci. Remote, 38, 13871398, 2000.

Markus, T. and Dokken, S. T.: Evaluation of late summer passive microwave Arctic sea ice retrievals, IEEE T. Geosci. Remote, 40, 348-356, 2002.

Meier, W. N.: Comparison of passive microwave ice concentration algorithm retrievals with AVHRR imagery in Arctic peripheral seas, IEEE T. Geosci. Remote, 43, 1324-1337, https://doi.org/10.1109/TGRS.2005.846151, 2005.

Meier, W. N. and Steward, J. S.: Assessing uncertainties in sea ice extent climate indicators, Environ. Res. Lett., 14, 035005, https://doi.org/10.1088/1748-9326/aaf52c, 2019.

Meier, W. N. and Windnagel, A.: Sea ice concentration - climate algorithm theoretical basis document, NOAA Climate Data Record Program CDRP-ATBD-0107 Rev. 7 (03/06/2018), available at: https://www.ncdc.noaa.gov/cdr/oceanic/sea-ice-concentration (last access: 7 February 2019), 2018.

Meier, W. N., Hovelsrud, G. K., van Oort, B. E. H., Key, J. R., Kovacs, K. M., Michel, C., Haas, C., Granskog, M. A., Gerland, S., Perovich, D. K., Makshtas, A., and Reist, J. D.: Arctic sea ice in transformation: A review of recent observed changes and impacts on biology and human activity, Rev. Geophys., 51, 185217, https://doi.org/10.1002/2013RG000431, 2014.

Meier, W. N., Fetterer, F., Savoie, M., Mallory, S., Duerr, R., and Stroeve, J.: NOAA/NSIDC Climate Data Record of Pas- 
sive Microwave Sea Ice Concentration, Version 3, Boulder, Colorado USA. NSIDC: National Snow and Ice Data Center, https://doi.org/10.7265/N59P2ZTG, 2017.

Melia, N., Haines, K., Hawkins, E., and Day, J. J.: Towards seasonal Arctic shipping route predictons, Environ. Res. Lett., 12, 084005 , https://doi.org/10.1088/1748-9326/aa7a60, 2017.

Niederdrenk, A. L. and Notz, D.: Arctic sea ice in a $1.5^{\circ} \mathrm{C}$ warmer world, Geophys. Res. Lett., 45, 1963-1971, https://doi.org/10.1002/2017GL076159, 2018.

Njoku, E. G., Rague, B., and Fleming, K.: The Nimbus-7 SMMR Pathfinder Brightness Temperature Data Set, Jet Propulsion Laboratory Publication, Pasadena, USA, 98-4, 1998.

Notz, D.: Sea-ice extent and its trend provide limited metrics of model performance, The Cryosphere, 8, 229-243, https://doi.org/10.5194/tc-8-229-2014, 2014.

OSI SAF: Global Sea Ice Concentration Climate Data Record v2.0 - Multimission, EUMETSAT SAF on Ocean and Sea Ice, https://doi.org/10.15770/EUM_SAF_OSI_0008 (last access: 5 December 2019), 2017.

Ozsoy-Cicek, B., Xie, H., Ackley, S. F., and Ye, K.: Antarctic summer sea ice concentration and extent: comparison of ODEN 2006 ship observations, satellite passive microwave and NIC sea ice charts, The Cryosphere, 3, 1-9, https://doi.org/10.5194/tc-3-12009, 2009.

Pedersen, L. T., Dybkjær, G., Eastwood, S., Heygster, G., Ivanova, N., Kern, S., Lavergne, T., Saldo, R., Sandven, S., Sørensen, A., and Tonboe, R. T.: ESA Sea Ice Climate Change Initiative (Sea_Ice_cci): Sea Ice Concentration Climate Data Record from the AMSR-E and AMSR-2 instruments at $25 \mathrm{~km}$ grid spacing, version 2.1, Centre for Environmental Data Analysis, https://doi.org/10.5285/f17f146a31b14dfd960cde0874236ee5 (last access: 5 December 2019), 2017a.

Pedersen, L. T., Dybkjæ, G., Eastwood, S., Heygster, G., Ivanova, N., Kern, S., Lavergne, T., Saldo, R., Sandven, S., Sørensen, A., and Tonboe, R. T.: ESA Sea Ice Climate Change Initiative (Sea_Ice_cci): Sea Ice Concentration Climate Data Record from the AMSR-E and AMSR-2 instruments at $50 \mathrm{~km}$ grid spacing, version 2.1. Centre for Environmental Data Analysis, https://doi.org/10.5285/5f75fcb0c58740d99b07953797bc041e (last access: 5 December 2019), 2017 b.

Pedersen, L. T., Saldo, R., Ivanova, N., Kern, S., Heygster, G., Tonboe, R. T., Huntemann, M., Ozsoy, B., Girard-Ardhuin, F., and Kaleschke, L.: Reference dataset for sea ice concentration, https://doi.org/10.6084/m9.figshare.6626549.v6, 2019.

Peng, G., Meier, W. N., Scott, D. J., and Savoie, M. H.: A long-term and reproducible passive microwave sea ice concentration data record for climate studies and monitoring, Earth Syst. Sci. Data, 5, 311-318, https://doi.org/10.5194/essd-5-311-2013, 2013.

Petty, A. A., Stroeve, J. C., Holland, P. R., Boisvert, L. N., Bliss, A. C., Kimura, N., and Meier, W. N.: The Arctic sea ice cover of 2016: a year of record-low highs and higher-than-expected lows, The Cryosphere, 12, 433-452, https://doi.org/10.5194/tc12-433-2018, 2018.

Pizzolato, L., Howell, S. E. L., Dawson, J., Laliberte, F., and Copland, L.: The influence of declining sea ice on shipping activity in the Canasian Arctic, Geophys. Res. Lett., 43, 12146-12154, https://doi.org/10.1002/2016GL071489, 2016.

Reid, P., Stammerjohn, S., Massom, R., Scambos, T., and Lieser, J. L.: The record 2013 Southern Hemisphere sea-ice extent maximum, Ann. Glaciol., 56, 99-106, https://doi.org/10.3189/2015AoG69A892, 2015.

Schlosser, E., Haumann, F. A., and Raphael, M. N.: Atmospheric influences on the anomalous 2016 Antarctic sea ice decay, The Cryosphere, 12, 1103-1119, https://doi.org/10.5194/tc-12-11032018, 2018.

Smith, D. M.: Extraction of winter total sea ice concentration in the Greenland and Barents Seas from SSM/I data, Int. J. Remote Sens., 17, 2625-2646, 1996.

Smith D. M. and Barrett, E. C.: Satellite mapping and monitoring of sea ice, CB/RAE/9/2/4/2034/113/ARE, RSU, University of Bristol, Bristol, UK, 1994.

Spreen, G., Kaleschke, L., and Heygster, G.: Sea ice remote sensing using AMSR-E 89-GHz channels, J. Geophys. Res., 113, C02S03, https://doi.org/10.1029/2005JC003384, 2008.

Svendsen, E., Mätzler, C., and Grenfell, T. C.: A model for retrieving total sea ice concentration from a spaceborne dual-polarized passive microwave instrument operating near $90 \mathrm{GHz}$, Int. J. Remote Sens., 8, 1479-1487, 1987.

Stuecker, M. F., Bitz, C. M., and Armour, K. C.: Conditions leading to the unprecedented low Antarctic sea ice extent during the 2016 austral spring season, Geophys. Res. Lett., 44, 9008-9019, https://doi.org/10.1002/2017GL074691, 2017.

Tonboe, R. T., Eastwood, S., Lavergne, T., Sørensen, A. M., Rathmann, N., Dybkjær, G., Pedersen, L. T., Høyer, J. L., and Kern, S.: The EUMETSAT sea ice concentration climate data record, The Cryosphere, 10, 2275-2290, https://doi.org/10.5194/tc-102275-2016, 2016.

Turner, J., Hosking, J. S., Phillips, T., and Marshall, G. J.: Temporal and spatial evolution of the Antarctic sea ice prior to the September 2012 record maximum extent, Geophys. Res. Lett., 40, 5894-5898, https://doi.org/10.1002/2013GL058371, 2013.

Turner, J., Phillips, T., Marshall, G. J., Hosking, J. S., Pope, J. O., Bracegirdle, T. J., and Deb, P.: Unprecedented springtime retreat of Antarctic sea ice in 2016, Geophys. Res. Lett., 44, 6868-6875, https://doi.org/10.1002/2017GL073656, 2017.

Wayand, N. E., Bitz, C. M., and Blanchard-Wrigglesworth, E.: A year-round subseasonal-to-seasonal sea ice prediction portal, Geophys. Res. Lett., 46, 3298-3307, https://doi.org/10.1029/2018GL081565, 2019.

Wiebe, H., Heygster, G., and Markus, T.: Comparison of the ASI ice concentration algorithm with Landsat-7 ETM+ and SAR imagery, IEEE T. Geosci. Remote, 47, 3008-3015, https://doi.org/10.1109/TGRS.2009.2026367, 2009.

Worby, A. P. and Allison, I. A.: Ship-Based Technique for Observing Antarctic Sea Ice: Part I: Observational Techniques and Results, Research Report No. 14, Antarctic Cooperative Research Centre, Hobart, TAS, Australia, 1999.

Worby, A. P. and Comiso, J. C.: Studies of the Antarctic sea ice edge and ice extent from satellite and ship observations, Remote Sens. Environ., 92, 98-111, 2004.

Worby, A. P. and Dirita, V.: A technique for making ship-based observations of Antarctic sea-ice thickness and characteristics Part II: User Operating Manual, Research Report No. 14, Antarctic Cooperative Research Centre, Hobart, TAS, Australia, 1999.

Worby, A. P., Geiger, C. A., Paget, M. J., Van Woert, M. L., Ackley, S. F., and DeLiberty, T. L.: The thickness distribution of Antarctic sea ice, J. Geophys. Res., 113, C05S92, https://doi.org/10.1029/2007JC004254, 2008. 